\title{
FABRICATE AND TEST \\ AN ADVANCED NON-POLLUTING \\ TURBINE DRIVE GAS GENERATOR
}

\section{FINAL REPORT}

Reporting Period Start Date: 1 September 2000

Reporting period End Date: 1 June 2003

Authors:

Eugene Baxter, Project Manager

Roger E. Anderson, Principal Investigator

Stephen E. Doyle, President, CES

\section{JUNE 2003}

Cooperative Agreement No. DE-FC26-00NT 40804

Submitted by:

Clean Energy Systems, Inc. 11330 Sunco Drive, Suite A

Rancho Cordova CA 95742 


\section{DISCLAIMER}

This report was prepared as an account of the work sponsored by an agency of the United States Government. Neither the United States Government nor any agency thereof, nor any of their employees, makes any warranty, express or implied, or assumes any legal liability of responsibility for the accuracy, completeness, or usefulness of any information, apparatus, product, or process disclosed, or represents that its use would not infringe privately owned rights. Reference herein to any specific commercial product, process or service by trade name, trademark or manufacturer, or otherwise does not necessarily constitute or imply its endorsement, recommendation, or favoring by the United States Government or any agency thereof. The views and opinions of authors expressed herein do not necessarily state or reflect those of the United States Government or any agency thereof. 


\begin{abstract}
In September 2000 the Department of Energy's National Energy Technology Laboratory (DOE/ NETL) contracted with Clean Energy Systems, Inc. (CES) of Sacramento, California to design, fabricate, and test a $20 \mathrm{MW}_{\mathrm{t}}\left(10 \mathrm{MW}_{\mathrm{e}}\right)$ gas generator. Program goals were to demonstrate a nonpolluting gas generator at temperatures up to $3000^{\circ} \mathrm{F}$ at $1500 \mathrm{psi}$, and to demonstrate resulting drive gas composition, comprising steam and carbon dioxide substantially free of pollutants. Following hardware design and fabrication, testing, originally planned to begin in the summer of 2001, was delayed by unavailability of the contracted test facility.

CES designed, fabricated, and tested the proposed gas generator as originally agreed. The CES process for producing near-zero-emissions power from fossil fuels is based on the nearstoichiometric combustion of a clean gaseous fuel with oxygen in the presence of recycled water, to produce a high-temperature, high-pressure turbine drive fluid comprising steam and carbon dioxide.

Tests demonstrated igniter operation over the prescribed ranges of pressure and mixture ratios. Ignition was repeatable and reliable through more than 100 ignitions. Injector design "A" was operated successfully at both low power $\left(\sim 20 \%\right.$ of rated power) and at rated power $\left(\sim 20 \mathrm{MW}_{\mathrm{t}}\right)$ in more than 95 tests.

The uncooled gas generator configuration (no diluent injectors or cooldown chambers installed) produced drive gases at temperatures approaching $3000^{\circ} \mathrm{F}$ and at pressures greater than 1550 psia. The fully cooled gas generator configuration, with cooldown chambers and injector "A", operated consistently at pressures from 1100 to 1540 psia and produced high pressure, steam-rich turbine drive gases at temperatures ranging from $\sim 3000$ to as low as $600^{\circ} \mathrm{F}$.

This report includes description of the intended next steps in the gas generator technology demonstration and traces the anticipated pathway to commercialization for the gas generator technology developed in this program.
\end{abstract}




\section{TABLE OF CONTENTS}

$\underline{\text { Subject }}$

$\underline{\text { Page }}$

DISCLAIMER

ii

$\begin{array}{lll}\text { ABSTRACT } & \text { iii }\end{array}$

TABLE OF CONTENTS IV

LISTS OF GRAPHICAL MATERIALS vi

$\begin{array}{ll}\text { INTRODUCTION } & 1\end{array}$

$\begin{array}{ll}\text { EXECUTIVE SUMMARY } & 2\end{array}$

$\begin{array}{ll}\text { EXPERIMENTAL } & 3\end{array}$

Program Funding 4

Gas Generator Design 5

Gas Generator Fabrication and Assembly 13

Gas Generator Testing $\quad 18$

$\begin{array}{ll}\text { Test Durations and Hardware Durability } & 19\end{array}$

Planned versus Completed Testing 20

Test Results 21

RESULTS AND DISCUSSION 23

$\begin{array}{ll}\text { Igniter Test Data } & 25\end{array}$

Detailed Gas Generator Test Run Data $\quad 25$

Gas Sampling 30

RELATED PROGRAM ACTIVITIES $\quad 33$

Technical Papers Produced 33

Turbine Development Cooperative Agreement 33

Remaining Materials $\quad 34$

Reheater Development $\quad 35$

Safety, Health \& Environmental Impacts 35

Permits and Licenses $\quad 35$

Safety Record 36

Environmental Compliance $\quad 36$

Next Steps to Commercialization $\quad 36$

Status of Technology - Current Cost Structure 36

Bases of Cost Estimates $\quad 37$

Near-Term Cost Comparison $\quad 38$

$\begin{array}{ll}\text { Competitive Position } & 38\end{array}$

Status of Marketing Activities $\quad 41$ 


\section{TABLE OF CONTENTS (cont.)}

Premium Price Electricity Markets $\quad 41$

Enhanced Hydrocarbon Recovery Applications $\quad 41$

California Market $\quad 42$

Foreign Markets $\quad 42$

National Policy and Strategic Considerations $\quad 43$

Production Readiness/Commercialization $\quad 43$

Potential for Clean Coal Power $\quad 43$

Buy America Policy 44

Lobbying and Other Non-Allowable Expenses $\quad 44$

$\begin{array}{ll}\text { CONCLUSION } & 44\end{array}$

$\begin{array}{ll}\text { REFERENCES } & 45\end{array}$ 


\section{LISTS OF GRAPHICAL MATERIALS}

\section{Figures}

Figure 1. The CES Process $\quad 3$

Figure 2. $\quad$ Gas Generator Design Concept 6

Figure 3. $\quad$ Fully Assembled Gas Generator 6

Figure 4. $\quad$ Gas Generator Igniter Design 7

Figure 5. $\quad$ Injector Assembly with Fuel, Oxidizer, and Water Inlets 8

Figure 6. Injector Face Plate, Pattern "A" $\quad 8$

Figure 7. $\quad$ Exploded View - Gas Generator Combustion Chamber 9

Figure 8. $\quad$ Original Diluent Injector and Modified Injector Manifolds 10

Figure 9. Cooling Water Diverter Manifold $\quad 10$

Figure 10. $\quad$ Exploded View - Gas Generator Cooldown Section 11

Figure 11. In/Out Cooling Water Manifolds 12

Figure 12. Turbine Simulator Used for Testing 12

Figure 13. $\quad$ Fully Assembled Gas Generator Design 13

Figure 14. Gas Generator Igniter Mounted for Testing, One of Two Views 14

Figure 15. Gas Generator Igniter Mounted for Testing, One of Two Views 14

Figure 16. $\quad$ Fuel and Oxygen Inlet Lines and Injector Assembly 14

Figure 17. Injector Platelet Stack with the Faceplate, Pattern "A" 15

Figure 18. An Internal Platelet on the Platelet Stack $\quad 15$

Figure 19. Cooldown Chamber with Brazed Liner, Ready for Final Machining 15

Figure 20. Cooldown Chamber Liner, and Completed Chamber Assembly 16

Figure 21. Combustion Chamber Liner (left) and Completed Assembly (right) 16

Figure 22. For and Aft Views of the Uncooled Copper Chamber Used for Testing 17

Figure 23. A Cooldown Section and the Turbine Simulator, Closed for Pressure Testing 17

$\begin{array}{lll}\text { Figure 24. } & \text { Fully Assembled Gas Generator } & 18\end{array}$

$\begin{array}{lll}\text { Figure 25. Uncooled Chamber Mounted for Testing } & 20\end{array}$

Figure 26. Fully Assembled Gas Generator on the Test Stand 21

Figures 26 a \& b Uncooled and Cooled Chamber Firings 23

Figure 27. Operating Chamber Pressure During Uncooled Gas Generator Test \#56 27

Figure 28. Chamber Pressure and Gas Temperature Cooled Gas Generator Test \#179 27

Figure 29. Chamber Pressure and Gas Temperature Cooled Gas Generator Test \#183 28

Figure 30. Chamber Pressure and Gas Temperature Cooled Gas Generator Test \#185 28

Figure 31. Chamber Pressure and Gas Temperature Cooled Gas Generator Test \#190 $\quad 29$

Figure 32. Chamber Pressure and Gas Temperature Cooled Gas Generator Test \#193 $\quad 29$

Figure 33. Chamber Pressure and Gas Temperature Cooled Gas Generator Test \#194 30

Figure 34. NETL Developed Reheater at NASA Test Site near Sandusky OH 35

\section{Tables}

TABLE I. SUMMARY OF GAS GENERATOR COMPONENT AND ASSEMBLY TESTS 22

TABLE II. SUMMARY OF $10 \mathrm{MW}_{\mathrm{e}}$ GAS GENERATOR TESTS $\quad 24$

TABLE III. $\quad$ SUMMARY OF IGNITER TEST DATA 26

TABLE IV. $\quad$ SUMMARY OF GAS GENERATOR TEST DATA $\quad 31$

TABLE IV. $\quad$ SUMMARY OF GAS GENERATOR TEST DATA (continued) 32

TABLE V. COMPARATIVE COSTS OF ELECTRICITY, CES vs. COMBINED CYCLES 39

TABLE VI. COMPARATIVE COSTS OF ELECTRICITY (WITH CO $\mathrm{CO}_{2}$ REVENUE) 40 


\section{INTRODUCTION}

In September 2000 the Department of Energy's National Energy Technology Laboratory (DOE/ NETL) contracted with Clean Energy Systems, Inc. (CES) of Sacramento, California to design, fabricate, and test a $20 \mathrm{MW}_{\mathrm{t}}\left(10 \mathrm{MW}_{\mathrm{e}}\right)$ gas generator. Program goals were to demonstrate a nonpolluting gas generator at temperatures up to $3000^{\circ} \mathrm{F}$ at $1500 \mathrm{psi}$, and to demonstrate resulting drive gas composition, comprising steam and carbon dioxide substantially free of pollutants. A graphic representation showing the gas generator in the CES process is presented in Figure 1.

CES designed, fabricated, and tested the proposed gas generator. The CES process for producing near-zero-emissions power from fossil fuels is based on the near-stoichiometric combustion of a clean gaseous fuel with oxygen in the presence of recycled water, to produce a high-temperature, high-pressure turbine drive fluid comprising steam and carbon dioxide.

Tests demonstrated the gas generator igniter's operation over prescribed ranges of pressures and mixture ratios. Ignition was repeatable and reliable through more than 100 ignitions. The primary injector design was operated successfully at both low power ( $20 \%$ of rated power) and at rated power $\left(\sim 20 \mathrm{MW}_{\mathrm{t}}\right)$ in more than 95 tests.

The uncooled gas generator configuration (no diluent injectors or cooldown chambers installed) produced drive gases at temperatures approaching $3000^{\circ} \mathrm{F}$ and at pressures greater than 1550 psia. The fully cooled gas generator configuration, with cooldown chambers and using the primary injector, operated consistently at pressures from 1100 to 1540 psia and produced high pressure, steam-rich turbine drive gases at temperatures ranging from $\sim 3000$ to as low as $600^{\circ} \mathrm{F}$.

Figure 1 - The CES Process

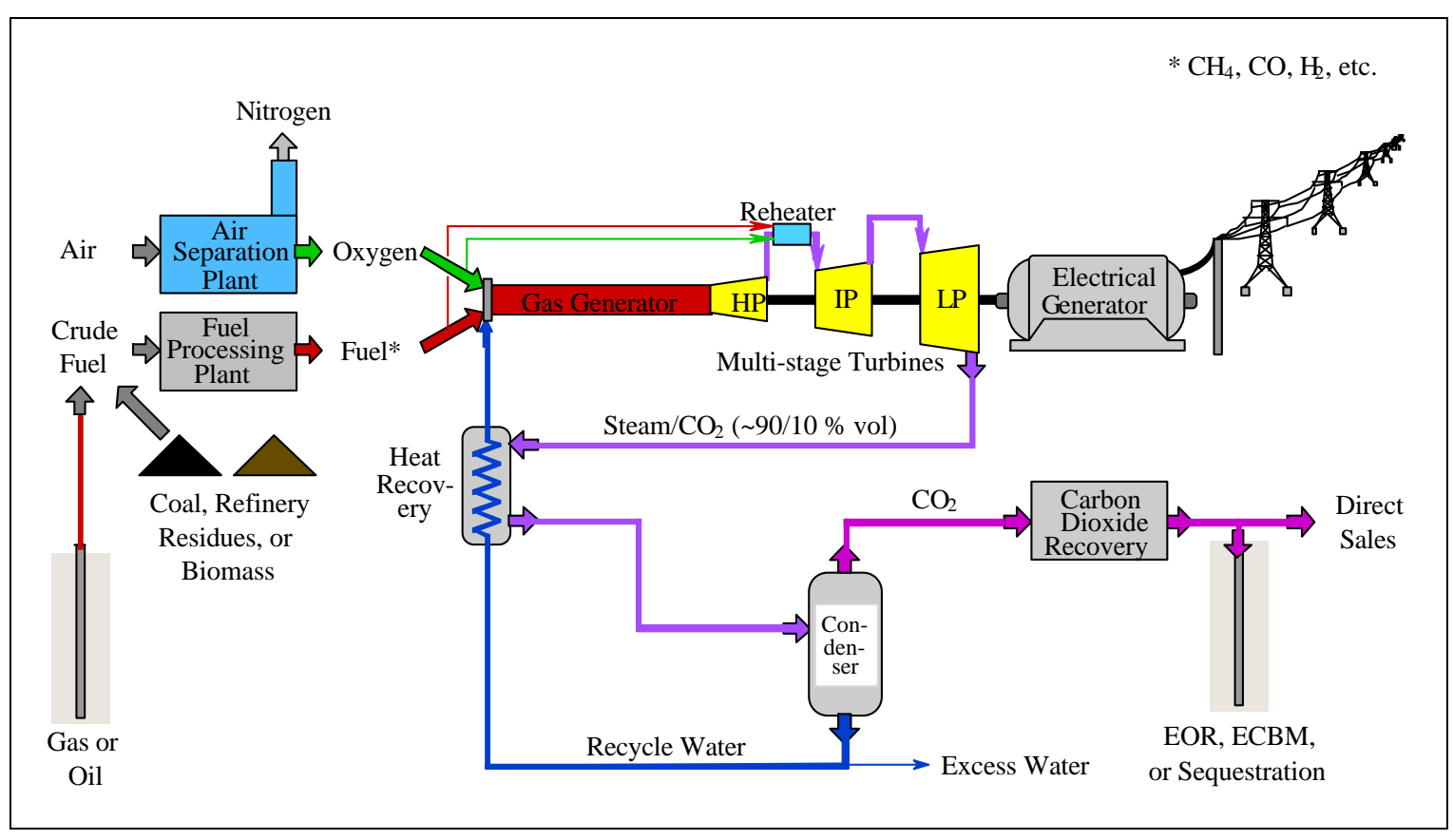


Although gas generator durability could not be experimentally demonstrated in the planned, relatively short tests, steady state operations were achieved in at least five tests and maintained for a total of more than 4 minutes. Measured wall temperatures in the most critical zone (the combustion chamber) were significantly lower than design values. This indicated that the predicted life limiting failure mode, low-cycle fatigue, will be less of a problem in terms of durability and reliability than estimated during design. The gas generator successfully sustained approximately 100 starts in the course of the testing effort and thereby provided some measure of durability in terms of cycle life.

Gas samples were obtained via a gas sample probe and sampling train during testing. A gas sample examined by a quadrupole mass spectrometer was analyzed despite the presence of some water. The mass spectrometer indicated that the gas contained $\sim 95.2 \% \mathrm{v} \mathrm{CO} 2$ and $\sim 4.8 \% \mathrm{v} \mathrm{O} 2$ (dry basis) versus a predicted $96 \% \mathrm{CO}_{2}$ and $4 \% \mathrm{O} 2$ based on the mass flow ratio of $\mathrm{O} 2$ to $\mathrm{CH} 4$. Further gas analyses are planned when the $10 \mathrm{MWe}$ gas generator is integrated with a complete, interactive, digital control system and retested later in 2003 in a separate program.

A need to modify cooling procedures was revealed in early November 2002, near the end of the planned testing. Relatively minor hardware modifications to accomplish the separation of watercooling and water-injection circuits and a rework of the diluent-water injectors were completed during November and December 2002. The final series of tests was restarted in January 2003 and completed in February 2003. These tests proved the hardware modifications to be acceptable and beneficial. Test durations of three minutes (test facility limits) were completed successfully.

\section{EXECUTIVE SUMMARY}

In September 2000 the DOE's National Energy Technology Laboratory (DOE/NETL) contracted with Clean Energy Systems, Inc. (CES) of Sacramento, California to design, fabricate, and test a $20 \mathrm{MW}_{\mathrm{t}}\left(10 \mathrm{MW}_{\mathrm{e}}\right)$ gas generator. In succession, the constructive, always helpful DOE Project Managers were Richard A. Dennis and Tom J. George. Program objectives were to demonstrate a non-polluting gas generator operating at temperatures up to $3000^{\circ} \mathrm{F}$ at $1500 \mathrm{psi}$, and to demonstrate resulting drive gas composition of steam and carbon dioxide, substantially free of pollutants.

The CES process for producing near-zero-emissions power from fossil fuels is based on the nearstoichiometric combustion of a clean gaseous fuel with oxygen in the presence of recycled water, to produce a high-temperature, high-pressure turbine drive fluid comprising steam and carbon dioxide.

A clean fuel, containing primarily the elements carbon, hydrogen, and oxygen, can come from virtually any organic source, including fossil fuels, biomass, refinery residues, or land-fill gases. The main requirements for the fuel are: (1) that it is in the gaseous state and (2) that it is largely cleansed of precursors of regulated pollutants (components containing sulfur, nitrogen, mercury, etc.) Raw liquid fuels are generally reformed and cleaned as necessary prior to combustion. Solid fuels are gasified, normally by reaction with oxygen and steam, and cleaned of particulates and pollutants prior to combustion. 
The oxygen for combustion is obtained by separating it from air using any of several techniques, such as cryogenic distillation, vapor pressure swing absorption, or ion transfer membranes. Combustion occurs under carefully controlled conditions with sufficient injection of water to moderate the combustion temperature and minimize the formation of carbon monoxide. Additional water is injected at stages to decrease the exiting turbine drive gas temperature to a value acceptable to the downstream high-pressure turbine.

After passing through the high-pressure turbine, the gases are reheated by direct firing with oxygen and fuel, and directed to an intermediate pressure turbine and then to a low pressure turbine. The discharge gases pass on to a heat exchanger where residual heat in the turbine exhaust is recovered by the recycled water going to the CES gas generator. The cool exhaust gases then enter a condenser where the water separates naturally from the carbon dioxide. Most of the water is recycled to the gas generator but the process is a net producer of high quality water. The carbon dioxide goes to a recovery system where it is dried and compressed to conditions necessary for use in enhanced oil recovery (EOR), enhanced coal-bed methane recovery (ECBM), sequestration, or for direct sales. A system graphic is at Figure 1, above.

CES' innovation has been to apply gas generators and high-temperature, high-pressure turbines from aerospace applications to power generation, much like the process by which aircraft jet engines were adapted for aero-derivative turbines in conventional power plants.

\section{EXPERIMENTAL}

The contracted scope of the NETL/CES Cooperative Agreement was to design, fabricate, test and evaluate a prototype gas generator. The gas generator was to be designed to demonstrate the non-polluting aspects of the CES concept. Operational performance was to be evaluated to verify the claimed operational characteristics. The prototype gas generator was to have nominal size of 10 Megawatts electric $(3096 \mathrm{lb} / \mathrm{hr}$ of methane). The prototype was to burn methane with oxygen; with water injected to produce additional drive gas and to control the gas temperature. From parametric data obtained by testing, CES was to characterize the operational performance of the gas generator. Sampling techniques were to be employed to determine exhaust gas composition. Post-test inspection and assessment were to determine any observable material degradation characteristics. In addition to these programmatic objectives there were standard reporting requirements and various deliverables required to be submitted to NETL on agreed dates. Specific tasks to be performed under this broad statement of objectives included:

1) Develop a project plan and submit the plan on a timely basis.

2) Develop a formal test plan and submit the test plan on a timely basis.

3) Design a prototype gas generator, including a formal design review.

4) Fabricate required components, and do component testing and assembly.

5) Prepare an appropriate test facility and calibrate required sensors and equipment.

6) Conduct gas generator tests and record all parametric data obtained.

7) Evaluate test data and prepare and submit a report containing test results.

8) Submit as deliverables:

a. an approved project plan,

b. an approved test plan, 
c. prototype design drawings (for review only),

d. periodic financial and technical progress reports (quarterly), and

e. an approved Final Report.

Briefings were required to be conducted, including:

- Project Kick-off meeting in Morgantown, West Virginia,

- mid-term reports as technical papers at appropriate conference forums, and

- final project briefing in Morgantown, West Virginia.

\section{Program Funding}

This project was conducted under Cooperative Agreement No. DE-FC26-00NT 40804, dated 1 September 2000, between DOE's National Energy Technology Laboratory (NETL) at Morgantown West Virginia, and Clean Energy Systems, Inc. of Sacramento, California. The original agreement provided for the following funding structure:

$\begin{array}{lrr}\text { Total Project Cost: } & \$ 2,716,685 & 100.0 \% \\ \text { Total Federal Share of Cost: } & 1,830,869 & 67.4 \% \\ \text { Total CES Share of Cost: } & 885,816 & 32.6 \%\end{array}$

The initial project budget provided the following cost breakout:

\begin{tabular}{lrr} 
& Federal & Non-federal \\
Engineering costs & $\$ 324,174$ & $\$ 250,521$ \\
Fabrication \& subcontract(s) & 695,750 & 0 \\
Testing \& subcontract(s) & 697,576 & 495,129 \\
Project direction & 113,369 & 140,166 \\
\hline Totals & $\$ 1,830,869$ & $\$ 885,816$
\end{tabular}

It was subsequently agreed between the parties that all expenditures in the program would be shared on a $67.4 \%$ federal $32.6 \%$ CES basis, regardless of expense category.

In the early summer of 2002, it became clear that, because of delays which occurred in the planned testing of the hardware, because of non-availability of the selected test site, the program would require more time and involve higher costs than originally planned. CES petitioned NETL to consider a contract modification. On 31 July 2002, NETL notified CES that the Cooperative Agreement was modified to extend the duration of work, and funding was adjusted as follows:

$\begin{array}{lrr}\text { Total Project Cost: } & \$ 3,700,081 & 100.0 \% \\ \text { Total Federal Share of Cost: } & 2,493,678 & 67.4 \% \\ \text { Total CES Share of Cost: } & 1,206,403 & 32.6 \%\end{array}$

The revised project budget was reapportioned, and provided for the following cost breakout:

\begin{tabular}{|c|c|c|c|}
\hline & $\begin{array}{l}\text { Original } \\
\text { Budget }\end{array}$ & $\begin{array}{l}\text { Revised } \\
\text { Budget }\end{array}$ & $\begin{array}{l}\text { Requested } \\
\text { Revision }\end{array}$ \\
\hline Personnel & $\$ \overline{846,833}$ & $\$ \overline{502,326}$ & $\$ \overline{(344,507)}$ \\
\hline Labor Overhead & 296,396 & 220,024 & $(76,372)$ \\
\hline Travel & 6,700 & 18,644 & 11,944 \\
\hline Contractual & $1,338,052$ & $1,411,936$ & 73,884 \\
\hline Consultants & not separated & 243,883 & 243,883 \\
\hline
\end{tabular}




$\begin{array}{lrrr} & \begin{array}{c}\text { Original } \\ \text { Budget }\end{array} & \begin{array}{c}\text { Revised } \\ \text { Budget }\end{array} & \begin{array}{c}\text { Requested } \\ \text { Revision }\end{array} \\ \text { Total Direct Charges } & 2,487,981 & 2,396,813 & (91,168) \\ \text { G\&A } & 228,704 & 1,303,268 & 1,074,564 \\ \text { Total Direct and Indirect } & 2,716,685 & 3,700,081 & 983,396 \\ \text { Recipients Share (@ 32.6\%) } & \$ 885,816 & 1,206,403 & 320,587 \\ \text { Federal Share (@ 67.4\%) } & 1,830,869 & 2,493,678 & 662,809 \\ \text { Totals } & 2,716,685 & 3,700,081 & 983,396\end{array}$

The substantial increase in the General and Administrative (G\&A) expense was caused partly by non-commencement of a parallel contract, which had been expected to bear a share of G\&A expenses, and contract stretch-out. With this increased budget, the original termination date of the period of performance was extended seven months, from 31 May 2002 to 31 December 2002.

In the final phase of gas generator testing, in early November 2002, CES discovered an anomaly in the gas generator behavior and convened a team of expert consultants to evaluate the anomaly, identify the causes, and recommend any appropriate solutions to the problem. The group completed its evaluation in two weeks, and before the end of November 2002, recommended modest redesigns of cooling circuits of the combustion chamber and diluent injectors. These recommendations resulted in redesigns of selected components in late November, and manufacture of recommended modified hardware in December 2002. In early January, testing was restarted and all testing of the gas generator concluded on 21 February 2003.

Meanwhile, realizing that the appearance of the anomaly would push the program into 2003, CES petitioned NETL for a no-cost contract extension of five months, from 31 December 2002, to 1 June 2003. This request was granted in December 2002, extending the date of project completion to 1 June 2003. Federal sharing of costs ended in December 2002, with the payout of all budgeted federal share dollars. Thereafter, all extended costs beyond planned budget were met $100 \%$ by CES. The additional costs, paid by CES, including overhead, were approximately $\$ 300,000$.

\section{Gas Generator Design}

The design of the gas generator is depicted schematically in Figure 2 and is based on the concept of near-stoichiometric combustion of a clean gaseous fuel with oxygen in the presence of water. It comprises an injector section, a combustion section, and a variable number of similar mixing/ cooldown sections. The injector section includes an igniter. The primary function of the injector section is to intimately mix the oxygen, fuel, and water in precise ratios to provide a very slight excess of oxygen and sufficient water to yield a combustion temperature that minimizes the formation of volatile organic compounds (VOC's). The injector is internally cooled by the incoming oxygen, fuel, and water. The combustion chamber provides containment of the highpressure, high-temperature reactive mixture and sufficient residence time for the reactions to approach chemical equilibrium. Generally, pressures are in the range of 1000 to 1500 psia, temperatures are in the range of 2800 to $3000^{\circ} \mathrm{F}$, and the residence time in the combustion section is on the order of milliseconds. The walls of the combustion chamber are cooled with water. Each cooldown section comprises a water injector (referred to as a diluent injector) and a flanged barrel. The diluent injector disperses highly atomized water into the forward end of the section in a quantity selected to cool the gases to a selected temperature. The amount of cooling that occurs in a given section is chosen to optimize the residence time/temperature conditions 
most favorable for elimination of undesired by-products of combustion. The number of cooldown sections in a given gas generator is dependent upon the temperature the high-pressure turbine can tolerate. The walls of every cooldown chamber are water cooled to provide long life.

Figure 2. Gas Generator Design Concept

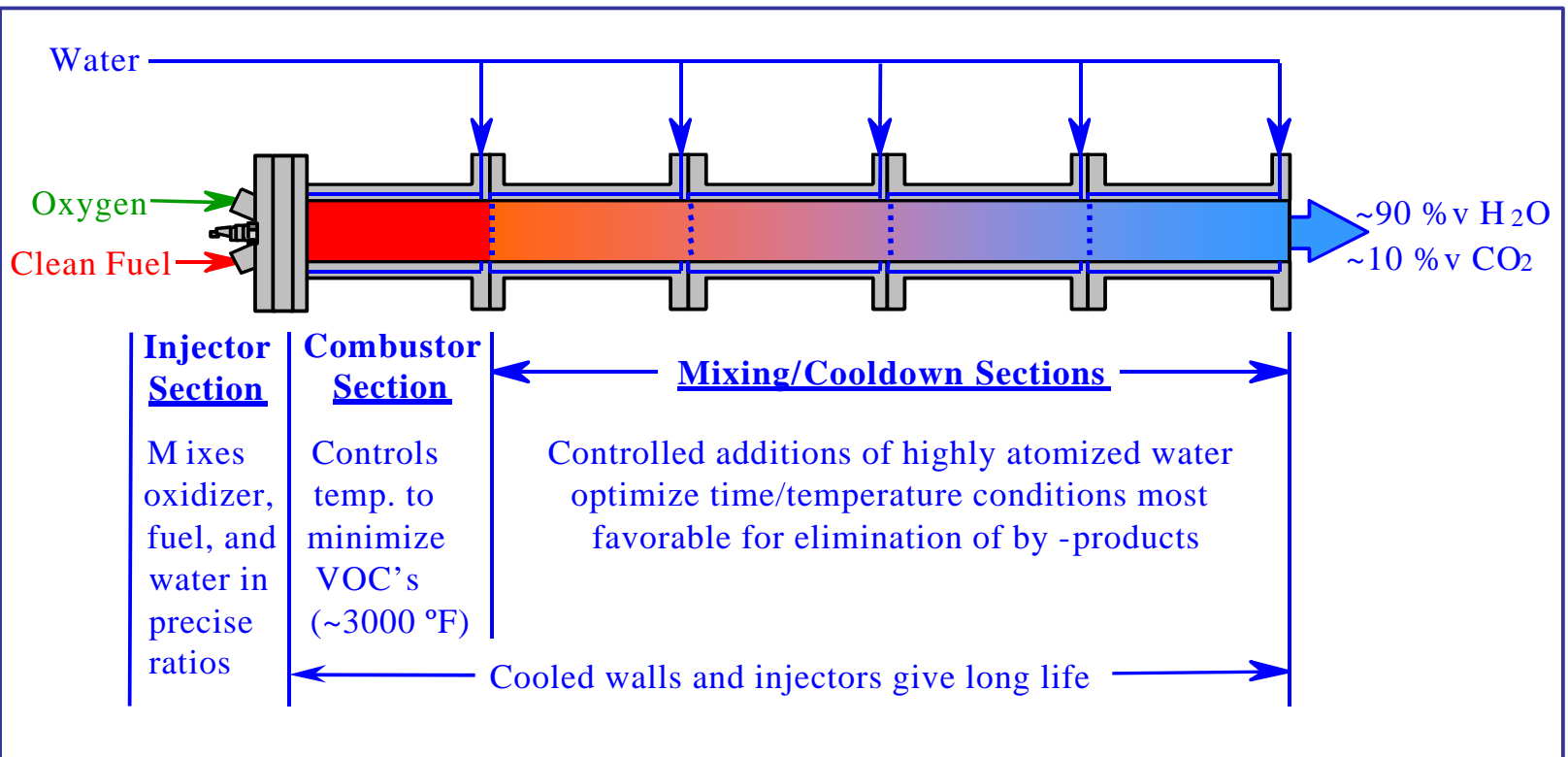

Figure 3. illustrates the general configuration of the overall gas generator. Broadly, it comprises inlet manifolds for oxygen and fuel (methane) and associated plumbing, an igniter, a main chamber injector, a combustion chamber and its cooling water inlet manifold, four cooldown chambers and their associated diluent injectors, and a turbine simulator (for experimental purposes only). The forward end of the first cooldown chamber and the aft end of the fourth cooldown chamber have associated water inlet and outlet manifolds for ducting cooling water along the walls of the cooldown chambers. The turbine simulator also features a water inlet manifold to provide injected cooling water to its convergent section. The overall weight of the gas generator is approximately $844 \mathrm{lbs}$. It has an inside diameter of 4 inches, an outside diameter at the flanges of 10 inches, and an overall length of 74 inches (excluding main injector and oxygen and fuel inlets).

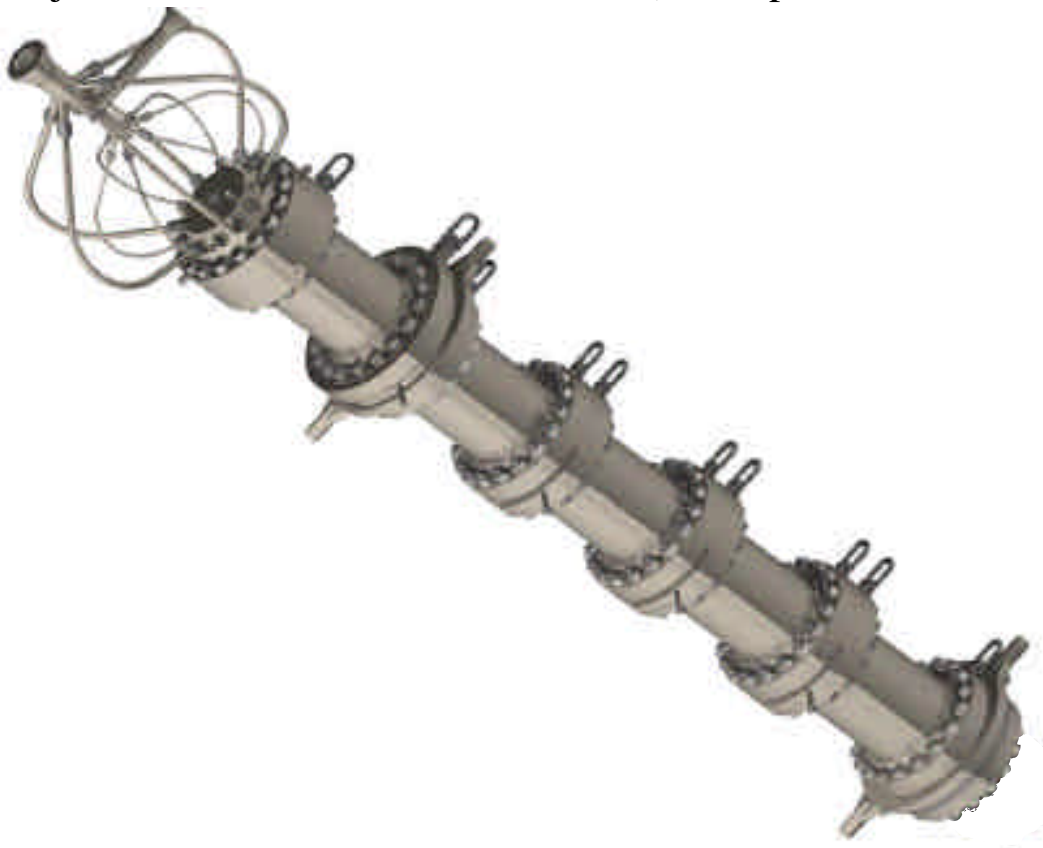

Figure 3. Fully Assembled Gas Generator 
Figure 4. Gas Generator Igniter Design

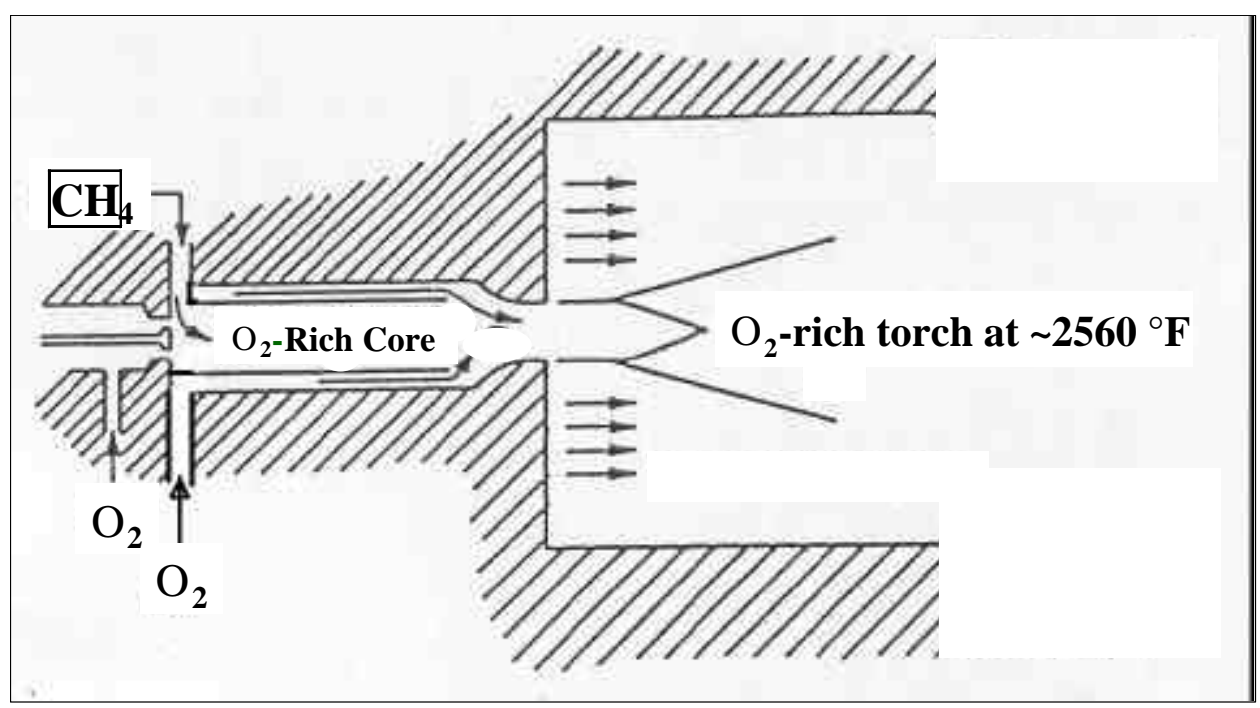

The igniter design, depicted in Figure 4., shows a spark initiated torch which burns methane with oxygen in a very oxygen-rich regime. Oxygen enters upstream of the spark gap zone and ionizes as it passes through the spark gap. The ionized oxygen then mixes with methane at an oxygen/fuel mass ratio of approximately 18 . This mixture ignites forming an $\mathrm{O}_{2}$-rich core flow at approximately $3700^{\circ} \mathrm{F}$. Additional oxygen flows through cooling passages surrounding the core and mixes with the core flow just upstream of the convergent section of a critical-flow nozzle. The $\mathrm{O}_{2}$-rich torch exiting the critical-flow nozzle provides the ignition source for the main chamber. This torch operates at an overall oxygen/fuel mass ratio of approximately 30 and produces a flame temperature of about $2560^{\circ} \mathrm{F}$. The composition of the torch flow is $\sim 81 \% \mathrm{v}$ $\mathrm{O}_{2}, \sim 13 \% \mathrm{v} \mathrm{H}_{2} \mathrm{O}$, and $\sim 6 \% \mathrm{v} \mathrm{CO}_{2}$.

The design of the feed inlets and the main injector is depicted in Figure 5. Oxygen feed enters a central axial manifold that separates radially into six equally spaced lines that feed an oxygen inlet manifold at the rear of the injector. Methane is fed transversely into a manifold that similarly separates radially into six equally spaced lines that feed a methane inlet manifold at the rear of the injector. The main chamber injector comprises a machined body of Monel 400 and a stack of Inconel 625 photo-etched platelets that are diffusion bonded into a monolithic structure, which is in turn diffusion bonded onto the injector body. In the original design, injection water for the main chamber entered the platelet stack from injector inlet passages, which mated with the cooling water channels of the combustion chamber.

Three different photo-etched platelet injector patterns were designed. Each of these designs used a common body with integral manifolds feeding oxygen, fuel, and water to the injector platelet stacks. Each design featured integral acoustic cavities (depicted in Figure 6 by the 36 quadrilaterals at the outer boundary). These cavities are designed to attenuate 1 st through 3 rd tangential combustion instability modes. The first design (referred to as injector "A") depicted in Figure 6, has 126 fuel $x$-doublets under 126 oxidizer doublets as the oxygen/methane mixing elements. All the injection water flowed immediately behind the face platelet to provide 
convective cooling. Ninety percent of the water exited the injector as face weep coolant via 2000 weep holes; ten percent exited the injector at the periphery serving as a barrier coolant to

Figure 5. Injector Assembly with Fuel, Oxidizer, and Water Inlets

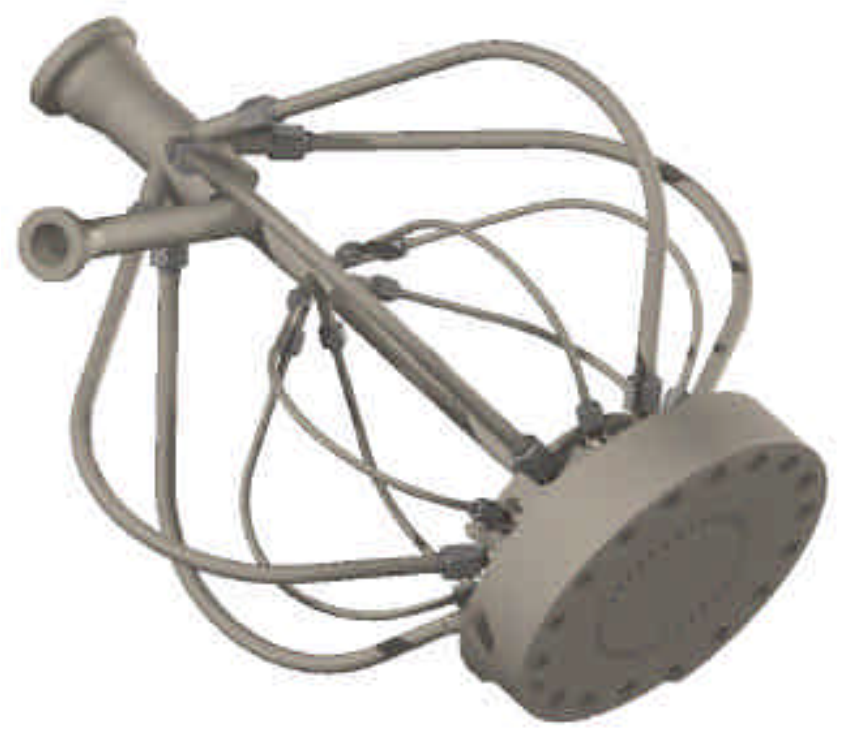

protect the combustion chamber walls in the very intense flame zone. The second injector (referred to as injector "B"), featured the same number of mixing elements but the elements were of a vortex type in which all the oxygen and fuel and $30 \%$ of the water were injected into the vortex elements. Sixty percent $(60 \%)$ of the water was injected through face swirl elements and $10 \%$ of the water was injected as barrier coolant near the chamber wall. Injector "C" was similar to injector " $B$ " except the mixing elements were of a double vortex type and the water distribution was $20 \%$ through the vortex elements, $70 \%$ via face swirl elements, and $10 \%$ was as barrier coolant near the chamber wall.

Figure 6. Injector Face Plate, Pattern A

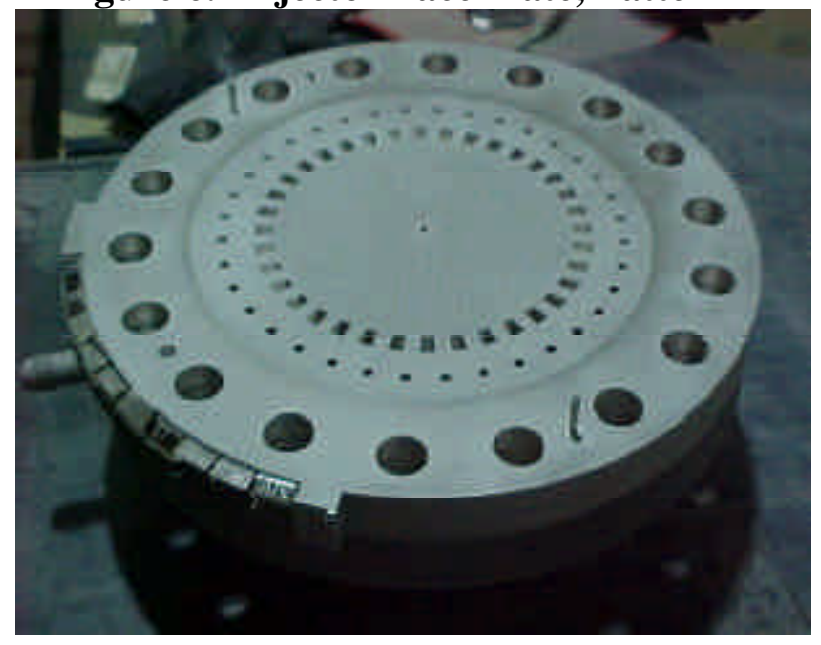

The design of the main combustion chamber is shown as an exploded view in Figure 7. The combustion chamber consists of a centrifugally cast Inconel 625 housing, an Inconel 625 liner, forward and aft flanges, a water inlet manifold, forward and aft closeout rings, lifting lugs, and instrumentation ports. The liner features 50 milled cooling water slots and is brazed into the 
housing. Cooling water enters via the water inlet manifold and flows radially inward through 18 passages located between bolt holes in the aft flange. The water collects in an aft annulus that feeds forward through the 50 cooling slots in the liner. It collects in a forward annulus and exits the forward flange through 50 holes that mate with 50 water inlet passages in the main chamber injector. After the combustion chamber diverter manifold was installed in January 2003, the water exited via mating passages in the diverter manifold rather than into the main injector. Inconel 625 closeout rings are brazed into the forward and aft flanges. Lifting lugs are provided to permit safe handling. Ports leading to the interior of the combustion chamber are provided for pressure and temperature measurements and for insertion of a gas sampling probe. Ten holes are drilled through the housing and partway through the lands of the liner to accept thermocouples and thereby permit monitoring of gas-side wall temperatures.

Figure 7. Exploded View - Gas Generator Combustion Chamber

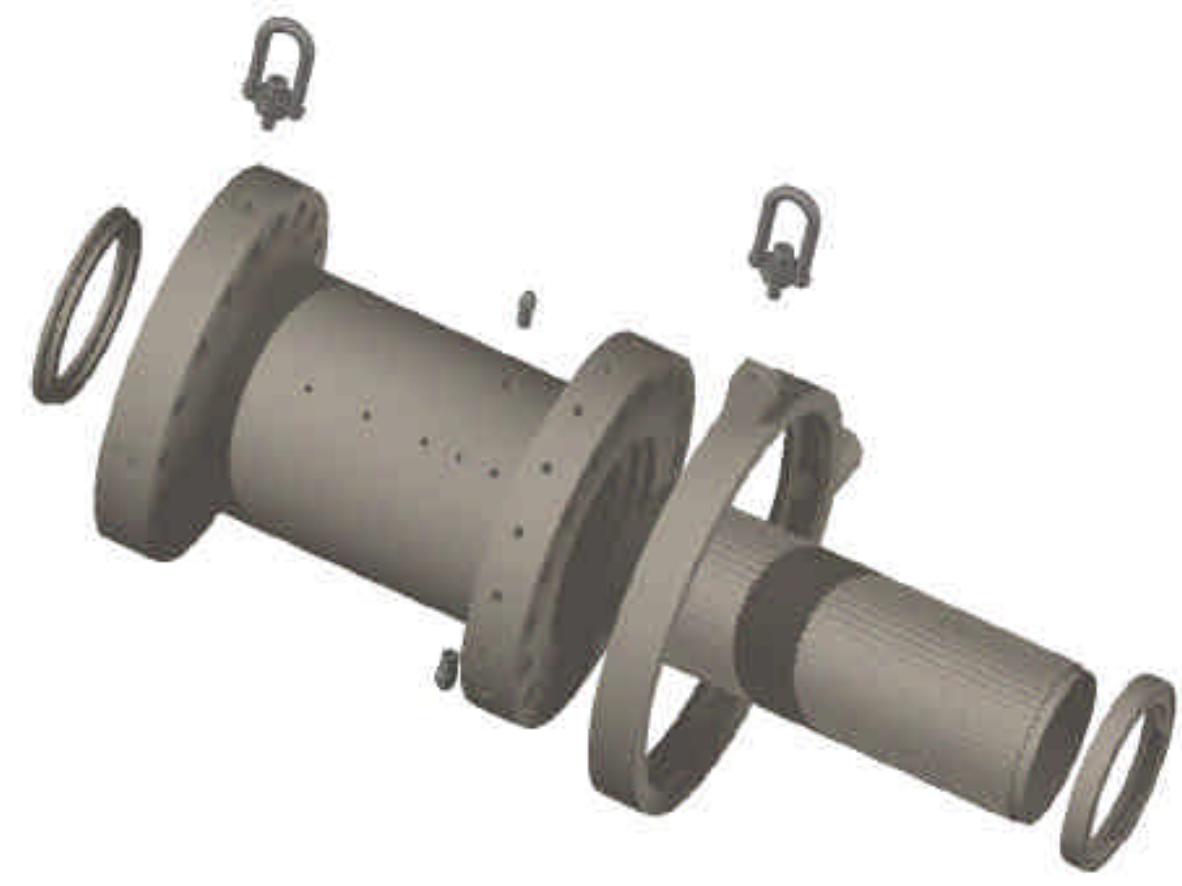

The original diluent water injectors, as shown in Figure 8 (left), featured spokes that protruded various distances toward the centerlines of the cooldown chambers. Three of the spokes protruded approximately $90 \%$ of the distance from the wall toward the centerline, three others protruded approximately $75 \%$ of the way, and six protruded approximately $50 \%$ of the way. Each spoke and a 0.2 inch wall rim contained numerous injection elements that projected fans of water droplets inward and forward against the gas flow field. The spokes and rim obstructed $\sim 40 \%$ of the superficial flow area. The injection elements were located to provide a nearly uniform mass distribution of water over the gas flow area. The design was based on photoetched platelet technology and diffusion bonding of the multiple platelets making up the platelet stack. The gas-side surfaces of the injectors were cooled by the incoming water prior to the water being redirected into the gas stream via the injection elements. Each injector was $0.5 \mathrm{in}$. thick and had two diametrically opposite water inlet ports.

Partway through the test program, the injector spokes were heat damaged because of operational problems that allowed them occasionally to operate dry for very short periods during the gas generator start transient. To permit an expedient return to testing, the damaged spokes were 
removed from each injector, and sleeves with small water injection orifices were welded into the injector bodies. This "fix", shown in Figure 8 (right), permitted the test program to be completed successfully with minimal delay.

Figure 8. Original Diluent Injector and Modified Injector Manifolds
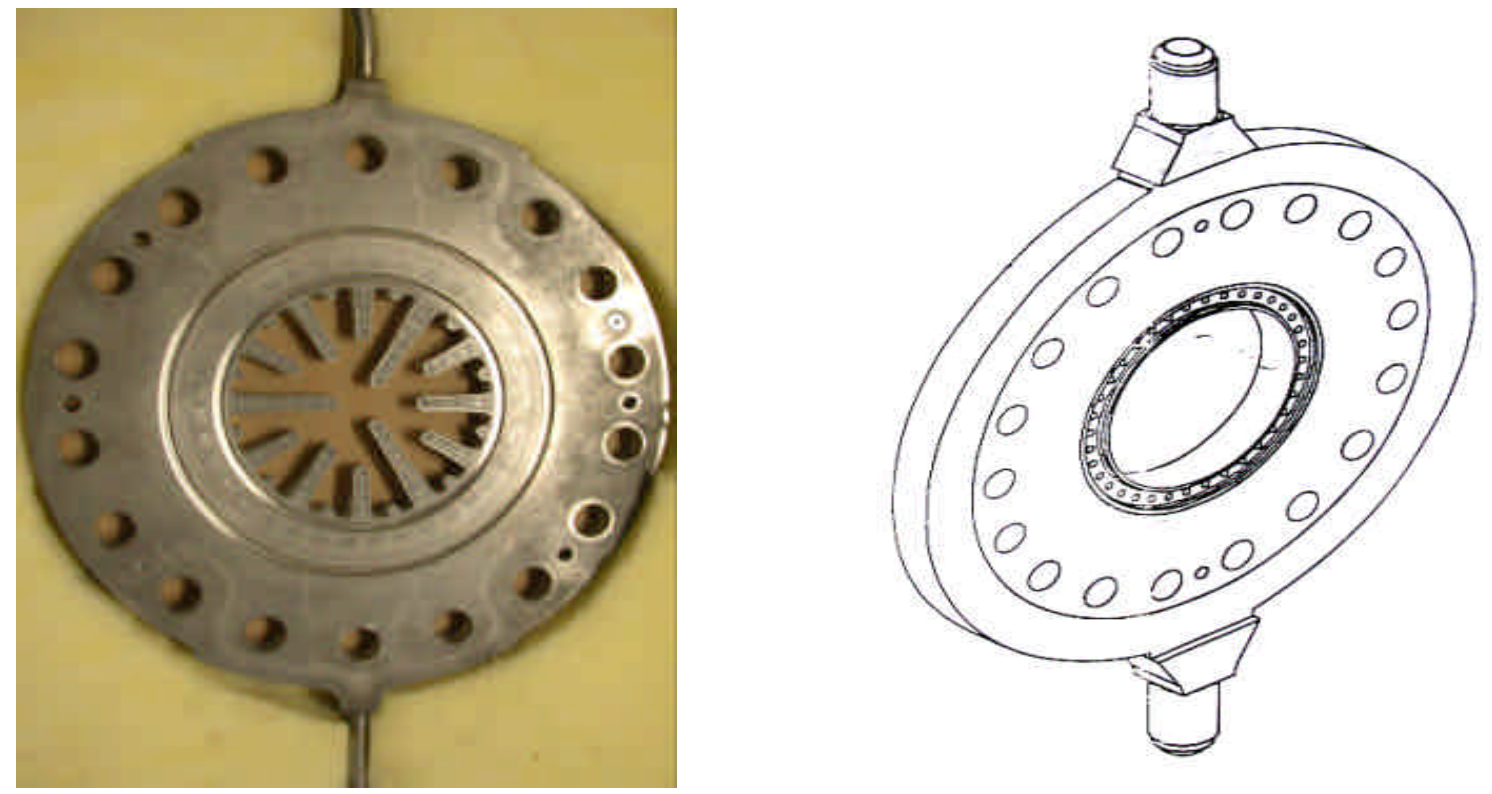

Figure 9. Cooling Water Diverter Manifold

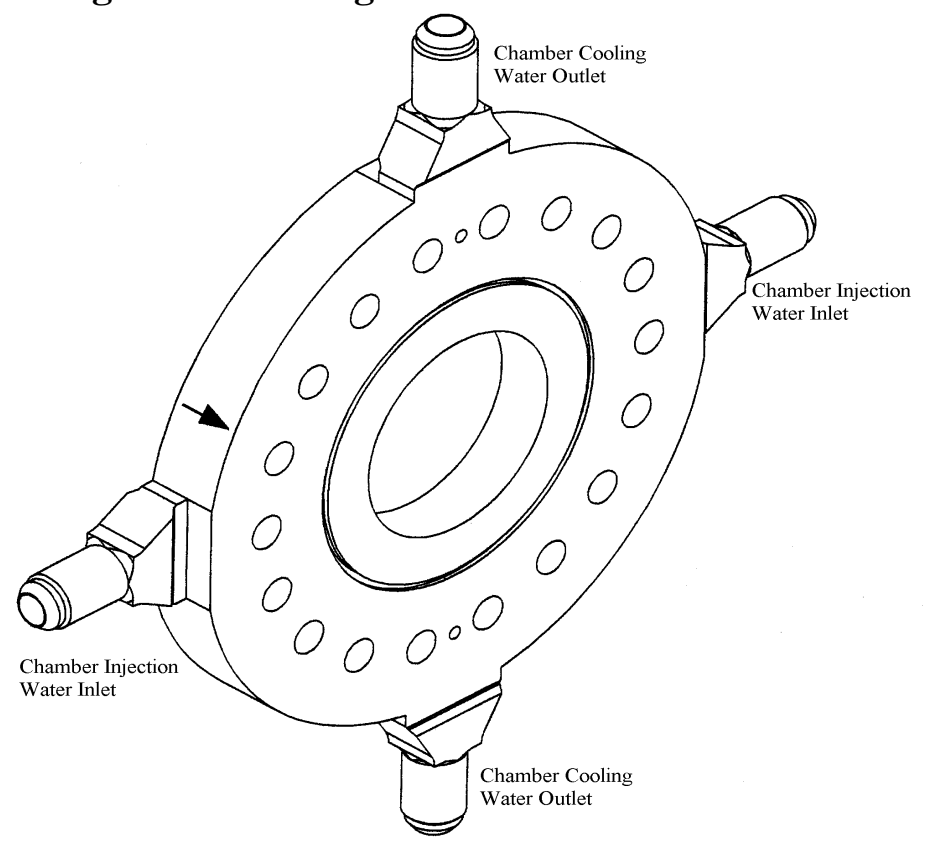

Also, partway through the test program, a diverter manifold was designed and built to fit between the combustion chamber and the main injector. The diverter manifold separated the combustion chamber cooling circuit from the injection water circuit. See Figure 9. After that modification, water was fed to the injector via the diverter manifold from a separate source while 
the chamber cooling water exited via the diverter manifold and subsequently served as a supply of injection water to the turbine simulator and as coolant for the gas sampling probe.

The design of the main cooldown chambers is shown as an exploded view in Figure 10. Each cooldown chamber consists of a centrifugally cast Inconel 625 housing, an Inconel 625 liner, forward and aft flanges, forward and aft closeout rings, lifting lugs, and instrumentation ports. The liner features 36 milled cooling water slots and is brazed into the housing. Cooling water enters via a separate water inlet manifold or from an adjacent cooldown chamber and flows longitudinally through the 36 cooling water channels. It exits through 36 holes that mate with 36 water inlet passages of an adjacent cooldown chamber or with a separate water outlet manifold. Inconel 625 closeout rings are brazed into the forward and aft flanges. Lifting lugs are provided to permit safe handling. Ports leading to the interior of the combustion chamber are provided for pressure and temperature measurements and for insertion of a gas-sampling probe.

\section{Figure 10. Exploded View - Gas Generator Cooldown Section}

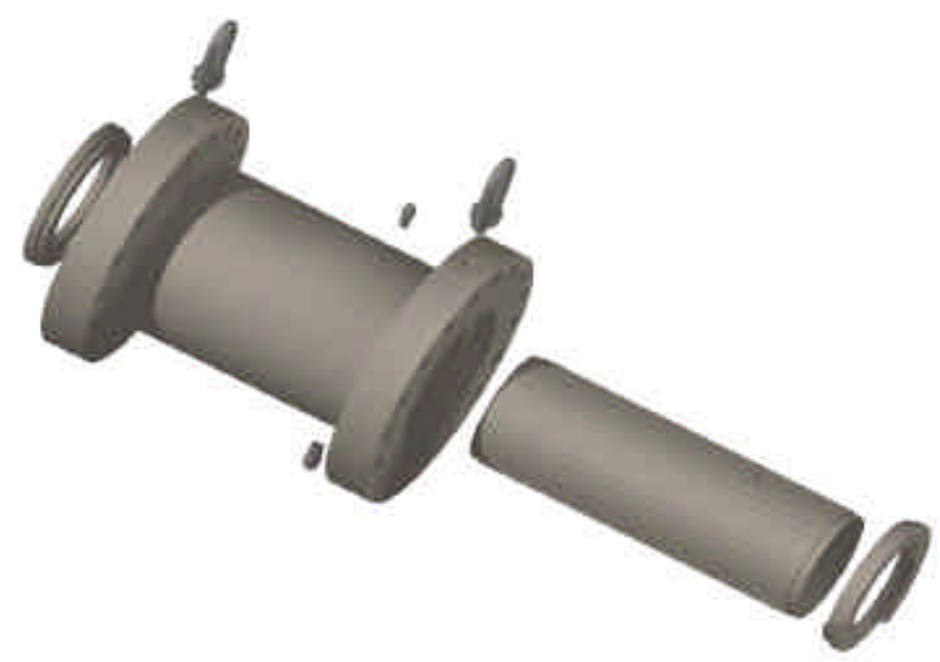

The design of the in/out cooling water manifolds, which supply cooling water to the jackets of the cooldown chambers, is depicted in an exploded view in Figure 11. Cooling water enters the forward end of the first cooldown chamber via a water inlet manifold and flows radially inward through 16 passages located between bolt holes in the body of the manifold. The water collects in an annulus and exits in the aft direction through 36 passages that mate with the 36 cooling channels in the liner. The cooling water continues to flow aft through crossovers in the diluent injectors and the channels in the successive cooldown chambers until it exits the last cooldown chamber. It then enters a water outlet manifold that is physically identical with the water inlet manifold. The water enters this manifold through 36 passages and collects in an annulus. The water flows radially outward through 16 passages located between bolt holes in the body of the manifold and collects in an outer annulus. Water exits the outer annulus through two diametrically opposite outlet ports.

The turbine simulator, depicted in Figure 12, provides the means for maintaining a back pressure on the gas generator similar to that encountered at the inlet of a high pressure turbine. It is used only for test purposes in the absence of a real turbine system. It consists of several parts as follows: (1) a water inlet manifold; (2) a distribution manifold with an associated inner closeout; (3) a convergent section; and (4) a series of replaceable orifice plates. Water enters the inlet manifold at two diametrically opposite inlet ports and collects in an annulus in the distribution 
manifold. The water then flows radially inward and collects in an inner annulus. The inner annulus feeds 60 swirl elements that provide film cooling to the copper convergent section and the orifice plate. The replaceable, Inconel 625 , orifice plates differ from one another only in the

\section{Figure 11. In/Out Cooling Water Manifolds}

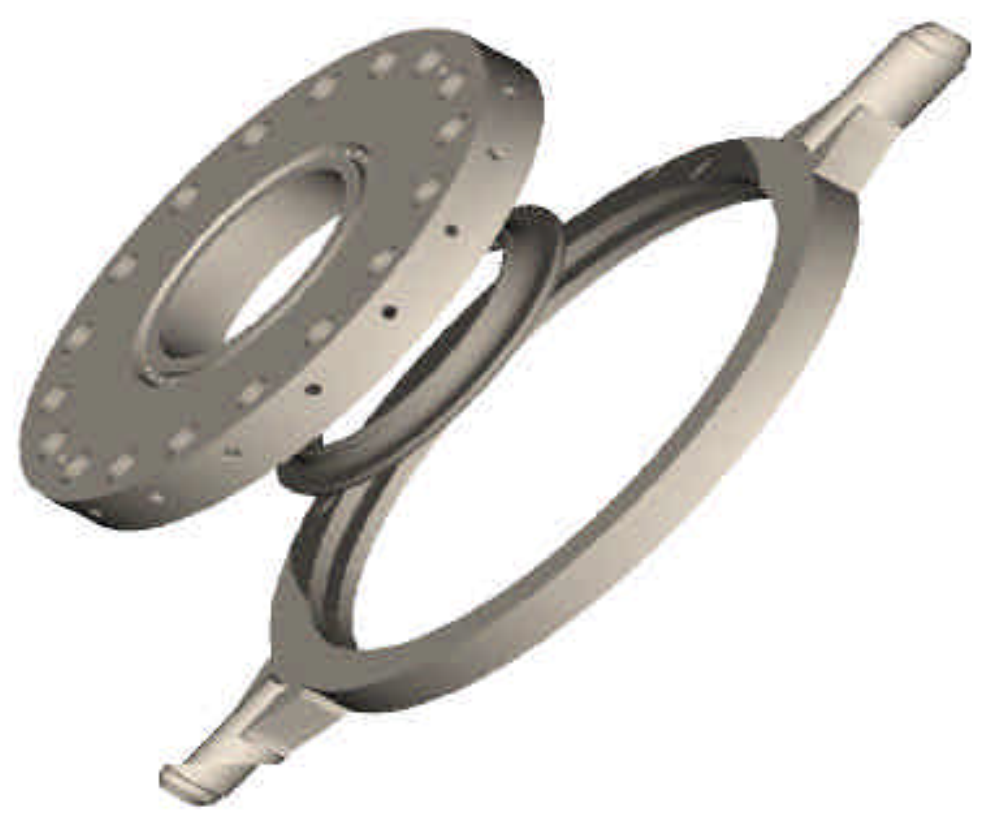

Figure 12. Turbine Simulator Used for Testing

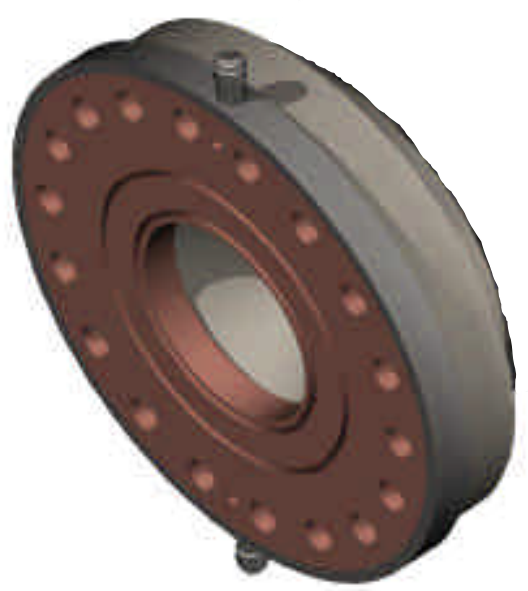

the diameters of their orifices. The orifice plates are attached to the convergent section by breakaway bolts that provide protection to the gas generator against possible over pressurization.

The fully assembled gas generator, comprising: oxygen and fuel inlet manifolds, an igniter, main injector, a combustion chamber, four cooldown sections with their associated diluent injectors and jacket cooling inlet and outlet manifolds, and the turbine simulator are assembled as shown 
in the design drawing at Figure 13. The overall gas generator assembly is supported and attached to the support stand by specially designed brackets. These brackets transfer the gas generator loads (mass and thrust) to the support stand. The support stand itself is bolted to brackets anchored into the concrete within the gas generator test cell.

The design phase of the project was originally expected to extend six months from the commencement of the project in September 2000. The externally imposed delays, which arose during the project because of test facility preemption by another federal program, permitted the design phase to be extended to the end of June 2001. During the additional time, modifications and refinements of design were accomplished. The process of fabrication of the gas generator, and the process and results of its testing, are described in the following sections of this report.

\section{Figure 13. Fully Assembled Gas Generator Design}

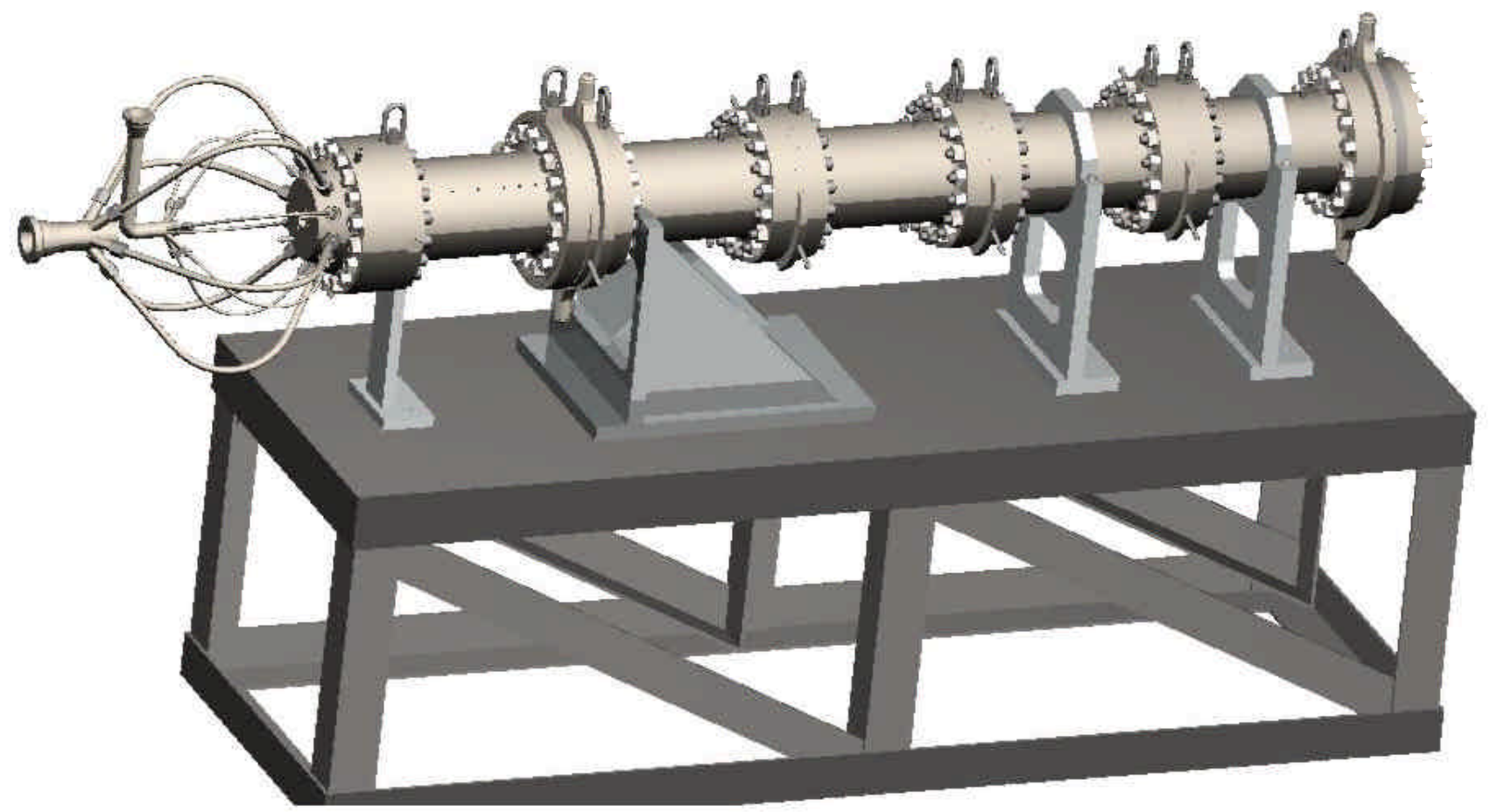

\section{Gas Generator Fabrication and Assembly}

The gas generator was designed to be built with replaceable components for ease of field maintenance. The components were individually tested and cold flowed, where appropriate, and proof and leak checked prior to the assembly of the entire unit. Graphics following show in several cases individual testing as well as manufactured component configuration.

The photographs shown below in Figures 14 and 15, show the igniter body mounted for igniteronly testing in a special test fixture that simulates a main injector body. A spark plug enters the body of the igniter from the rear at the centerline. Oxygen and methane feed lines and instrumentation lines enter the aft portion of the igniter along its periphery.

The photograph in Figure 16 shows the manufactured inlets and manifolds for the oxygen and fuel feeds into the main injector body. The igniter (not shown here) fits into the cavity in the back of 
the injector body. The injector, comprising a body and integral diffusion-bond stack of photoetched platelets, is at the bottom of the photograph. A cooldown chamber stands at the right.

Figures 14 and 15. Gas Generator Igniter Mounted for Testing, Two Views
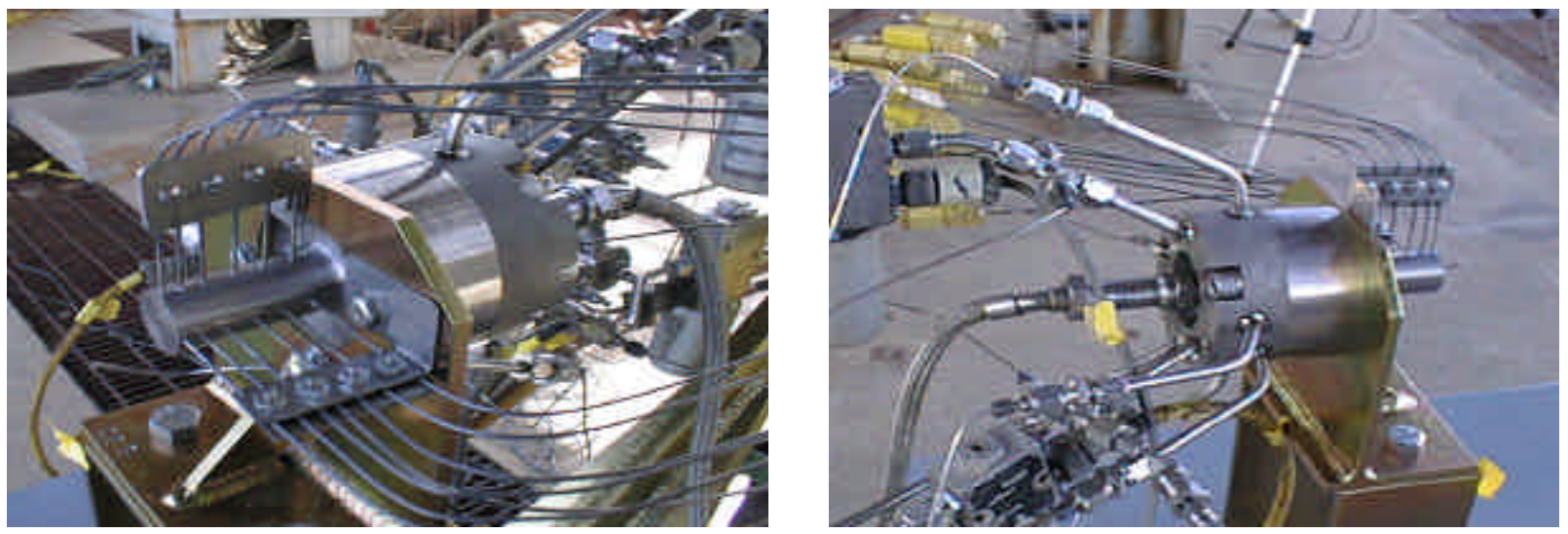

Figure 16. Fuel and Oxygen Inlet Lines and Injector Assembly

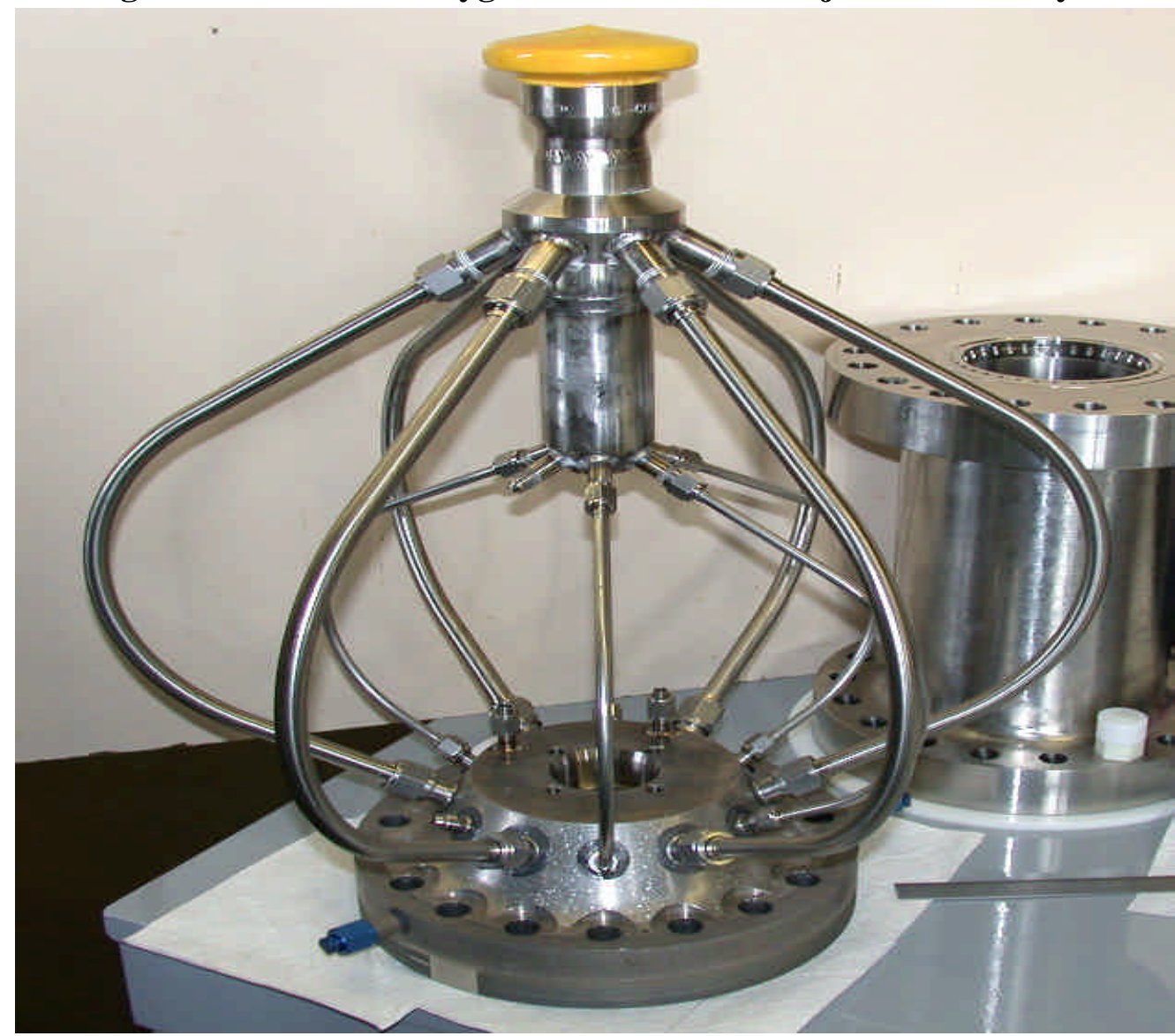

A face view of the diffusion-bonded stack of photo-etched platelets that make up the injector is shown in the photograph at Figure 17, prior to the bonding of the injector platelet stack to the injector body. One of the many different platelets that make up the platelet stack is shown in the photograph at Figure 18. The large openings to cavities in the lower-left corner of Figure 18, are built-in acoustic resonator cavities for mitigation of possible combustion instabilities. No instabilities were experienced. The small opening in the upper-right corner of the same photo- 
graph is at the center of the injector and is the passage that ducts the hot oxygen-rich gases from the igniter through the injector and into the combustion chamber.

Figure 17. Injector Platelet Stack with the Faceplate, Pattern "A"

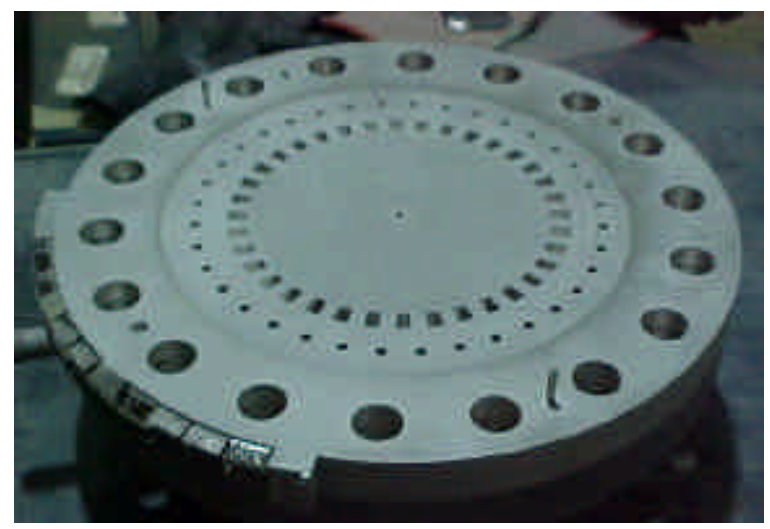

\section{Figure 18. An Internal Platelet on} the Platelet Stack

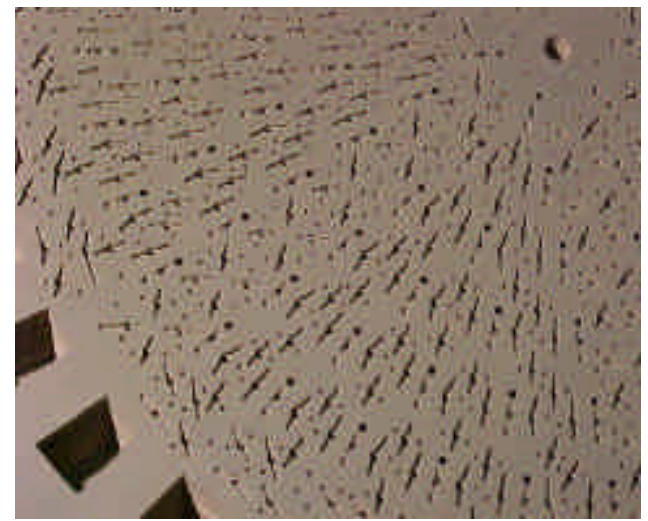

Figure 19 shows a cooldown chamber after the liner has been brazed into the housing, prior to final machining to remove excess liner and prepare for installation of closeout rings at each end.

Figure 19. Cooldown Chamber with Brazed Liner, Ready for Final Machining

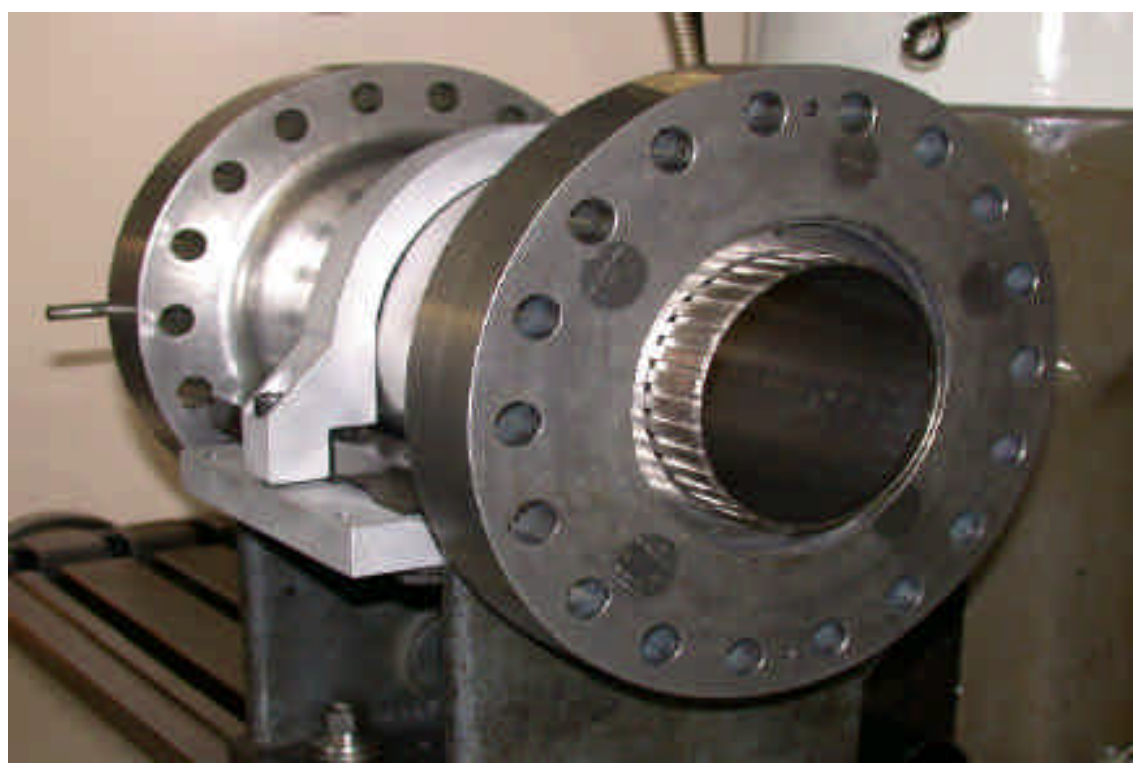

The photograph in Figure 20 shows a completed cooldown chamber housing next to a liner with its milled cooling channels.

The photograph on the left in Figure 21 shows the liner for the combustion chamber with its milled cooling passages. The "eye" provides land space for penetration of instrumentation or gas sampling access into the interior of the combustion chamber. The photograph on the right shows 
a completed combustion chamber after the liner, closeout rings, and the cooling water inlet manifold have been brazed into or onto the combustion chamber housing.

Figure 20. Cooldown Chamber Liner, and Completed Chamber Assembly
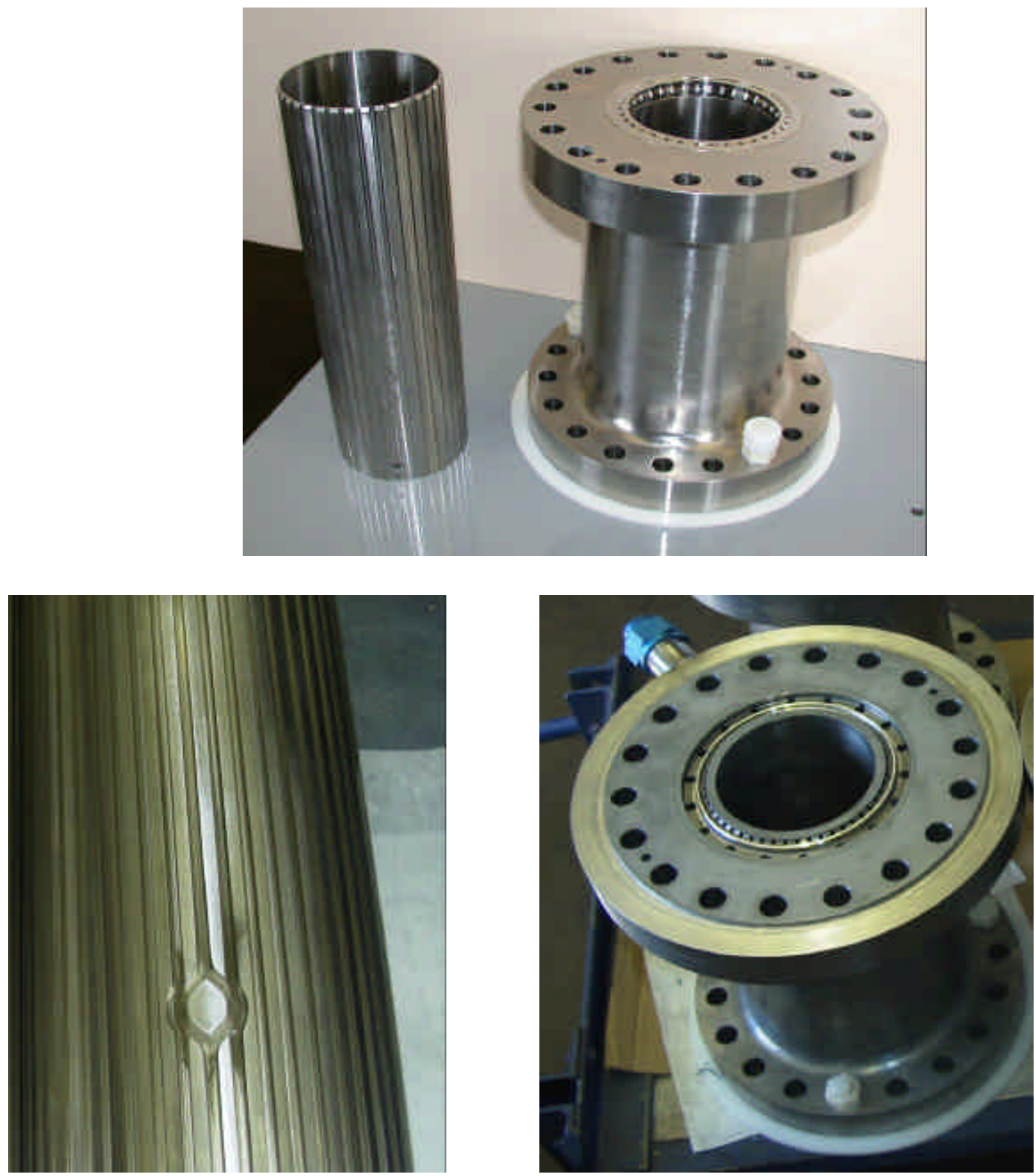

Figure 21. Combustion Chamber Liner (left) and Completed Assembly (right)

The uncooled copper chamber, shown in Figure 22, is a specialized item of test hardware used in early tests to evaluate the alternative injectors for the main combustion chamber, and to aide in defining appropriate start sequencing, system/test stand operating behavior, and "kill" parameters. This chamber permits testing of a gas generator system for short durations without 
the complexity of the all-up system with its multiple cooldown chambers, diluent injectors, and cooling circuits, which involve substantial plumbing and valve operations. The photograph on the left provides a view from the forward or main injector end. The photograph on the right is the same chamber viewed from the aft or discharge (turbine simulator) end. A turbine simulator is attached to simulate the system back pressures, which would be presented by a turbine on line with the gas generator.

\section{Figure 22. Fore and Aft Views of the Uncooled Copper Chamber Used for Testing}
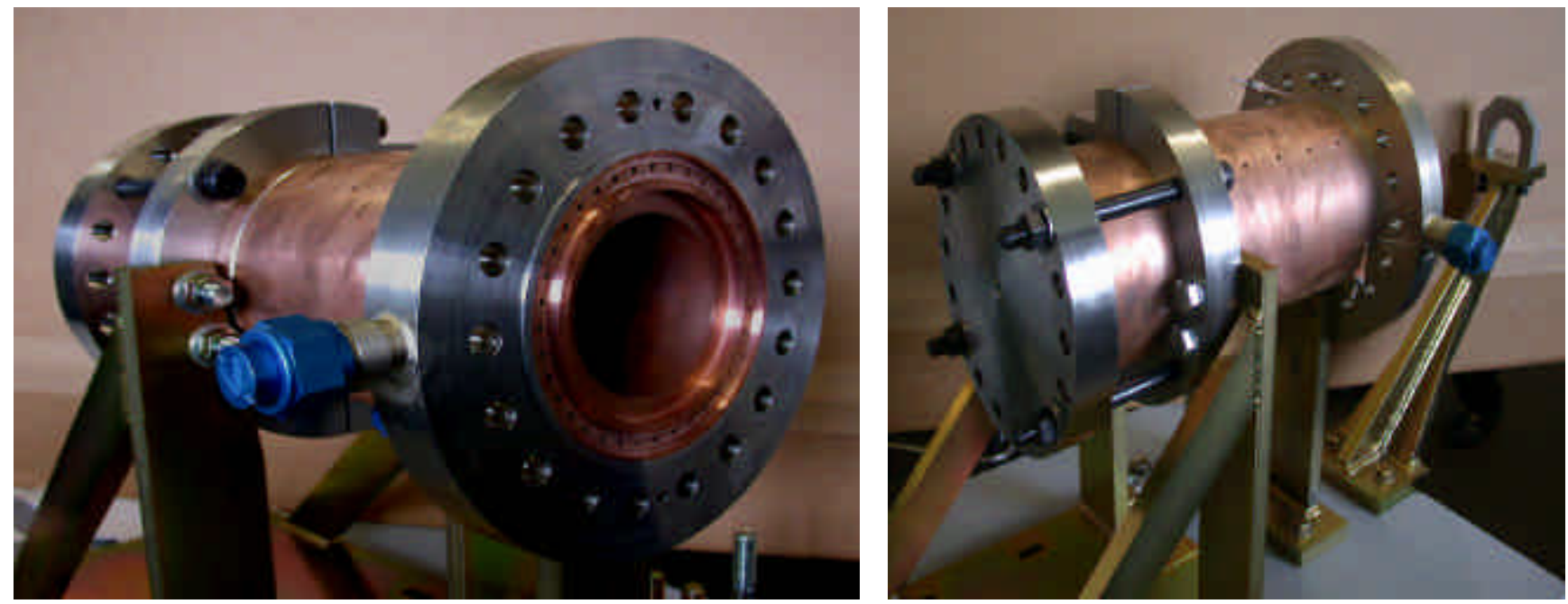

Figure 23. A Cooldown Section and the Turbine Simulator, Closed for Pressure Testing
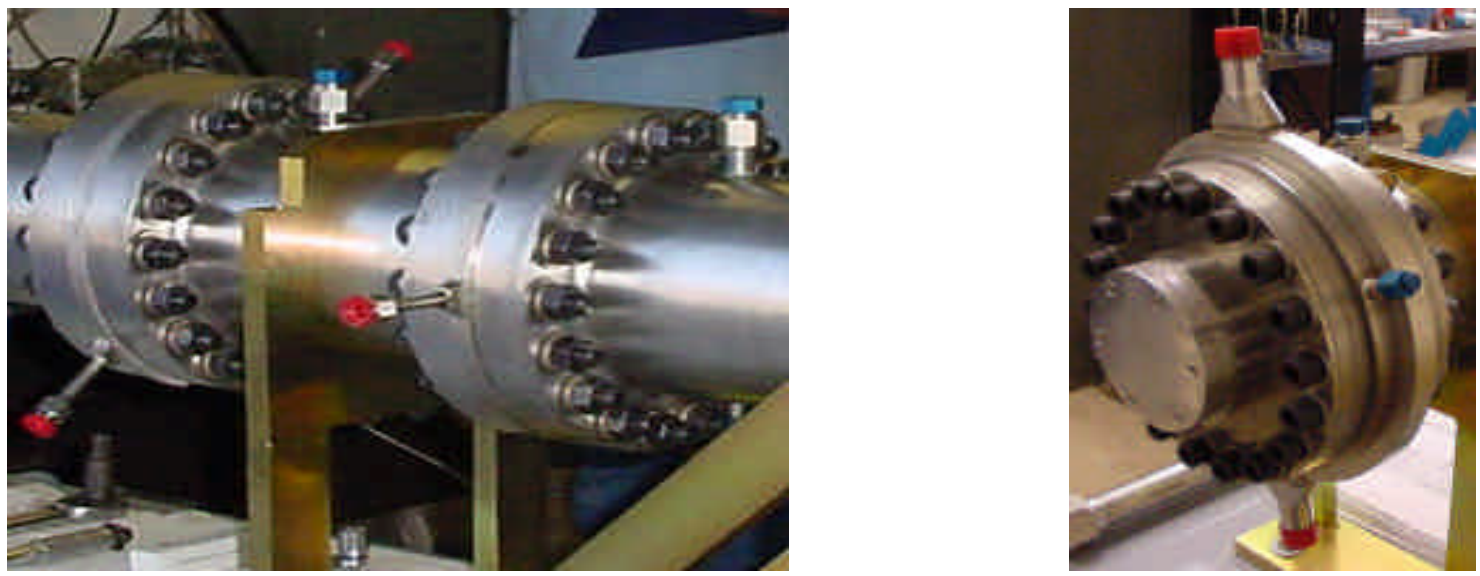

The photograph on the left in Figure 23 shows a typical cooldown chamber as installed in the fully cooled gas generator with gas flow proceeding from right to left. Diluent injectors are shown sandwiched between successive cooldown chambers. The capped tubes protruding from the diluent injectors are cooling water inlet ports. The capped ports along the upper surface of the cooldown chambers are ports for inserting gas sampling probes. Similar ports (out of view) along the lower surface provide access for pressure transducers and thermocouples into the interior of the gas generator.

The turbine simulator is shown in the photograph on the right in Figure 23. The actual outlet (discharge orifice) of the simulator is covered by a leak-test closure. The port with the cap is the inlet for the injection water that provides film cooling to the convergent section of the simulator. 
A similar inlet is present diametrically opposite but is out of view. Top and bottom capped ports in this view are not part of the turbine simulator, but are water outlets for cooling water to the jackets of the cooldown chambers.

\section{Figure 24. Fully Assembled Gas Generator}

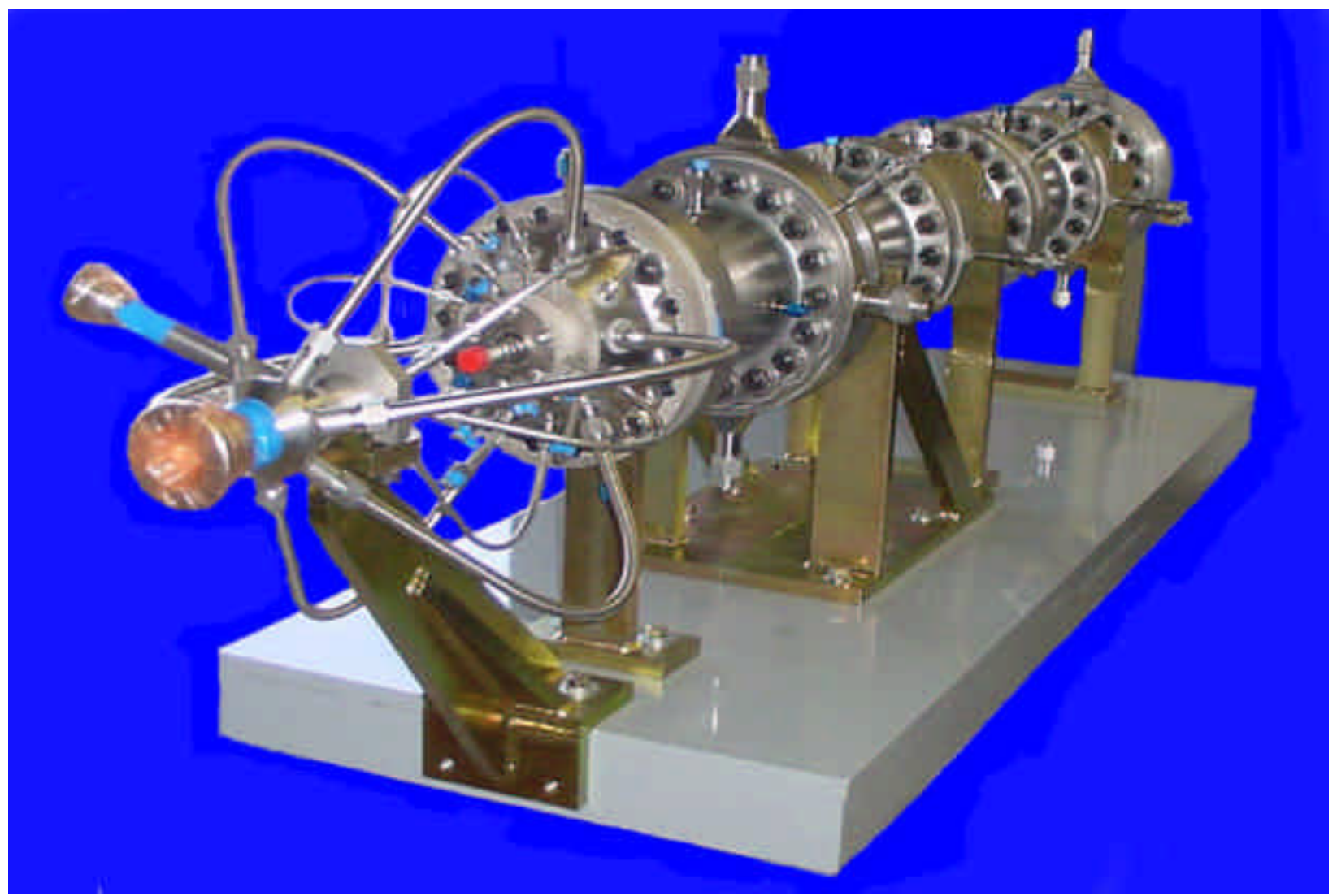

Figure 24 is a photograph of the fully assembled gas generator, which was tested successfully at the facilities of National Technical Systems, in Santa Clarita, California, during September, October and November 2002, and January and February 2003.

\section{$\underline{\text { Gas Generator Testing }}$}

Having completed design and fabrication of the $20 \mathrm{MW}_{\mathrm{t}}\left(10 \mathrm{MW}_{\mathrm{e}}\right)$ gas generator in 2001, CES planned originally to begin testing in the spring of 2001. The original testing was delayed. The igniter for the gas generator was successfully tested in September-October 2001. Testing of the complete gas generator was then planned to begin at the same test site in January 2002, and that date was slipped to early April 2002. In March 2002, the test facility operator informed CES that the test site would not be available before August 2002, and that later date could not be assured. CES withdrew the work from that site and put the remaining test work out for competitive rebidding. National Technical Systems, Inc. (NTS) of Santa Clarita, California was selected to perform the remaining testing. A contract was let in May 2002 with testing planned to begin not later than 1 August. In spite of NTS' best efforts, and a contract incentive for testing earlier, the test facility buildup proved to be more time-consuming than anticipated. Actual testing began in September 2002. Hot-fire testing of the gas generator ensued at the NTS test facility from early October until 6 November 2002 when, just prior to starting the final series of tests, a hardware 
anomaly was discovered. The anomaly was thoroughly evaluated by a team of expert consultants and a course of action to correct it was implemented. The action involved relatively minor hardware modifications to separate the water-cooling and water-injection circuits to the combustion chamber and modification of the diluent-water injectors as explained at pages 9-10 above. Testing was restarted in January 2003 and concluded successfully on 21 February 2003.

Despite the anomaly, during testing in November, state points were reached and held for up to a minute. Though not held nearly as long as planned, achieving these brief state points convinced CES engineers that the tests to that time demonstrated the feasibility of the technology at $10 \mathrm{MW}$ scale and larger. After the gas generator was modified to separate the water-cooling and waterinjection circuits to the combustion chamber, and thereby better assure positive water-cooling of all components exposed to the combustion gases during the critical start transient, in final testing, the gas generator achieved all of its design objectives.

Test Durations and Hardware Durability

Previous rocket experience with combustion devices similar to the gas generator suggested that pressures, flow rates, and gas temperatures would stabilize within a very few seconds of operation and that cooling water and wall temperatures would stabilize (reach steady state) within a few tens of seconds. It was also known that gas sampling and gas analysis instruments presented data lag times on the order of one minute because of sample line fill times and instrument response times. Thus, the original test plan and RFP's for testing services called for test times of equal to or greater than 120 seconds ( 2 minutes). This test duration was judged to be sufficient to achieve steady-state operation and thereby demonstrate concept feasibility, permit acquisition of limited gas analysis data, and to be economically realistic. Long-term durability and reliability were not goals of this project but, rather, were considered to be goals for subsequent projects wherein useful products (e.g., electricity and $\mathrm{CO}_{2}$ ) could be produced as part of the testing to help defray costs, and other power plant components could also be evaluated.

In this program, $95 \%$ of steady-state operating pressure and essentially steady state flows of oxygen, methane, and injection water were achieved in less than 2 seconds after main fuel valve opening. The gas temperature in the last $\left(4^{\text {th }}\right)$ cooldown chamber approached its steady-state value within $20^{\circ} \mathrm{F}$ in less than 4 seconds. The cooling water and gas generator inner wall temperatures reached steady state values approximately 40 seconds after main fuel valve opened.

The test facility safely permitted a full-power test of 3-minutes duration, more than $41 / 2$ times the duration needed to achieve steady state conditions. In the final series of tests (i.e., after the modification of the cooling and injection water circuits), three of those tests were nominally 1minute tests, one test was a 11/2-minute test, and one test was a 3-minute test.

Although durability could not be experimentally demonstrated in these relatively short tests, steady-state operations were achieved in at least five tests and maintained for a total of more than 4 minutes. It is also important to note that measured wall temperatures in the most critical zone (the combustion chamber) were significantly lower than design values. This indicates the predicted life limiting failure mode, low-cycle fatigue, will be less of a problem in terms of durability and reliability than estimated during design. The gas generator successfully sustained approximately 100 starts in the course of the testing effort and thereby provided some measure of durability in terms of cycle life. 


\section{Planned versus Completed Testing}

After preliminary cold flow tests were run, tests were performed using the uncooled combustion chamber to verify injector performance (see Figures 22 and 25, with associated texts), and tests were done with the fully cooled gas generator (shown at Figure 26). Components and assemblies tested include: (1) the igniter, (2) igniter/main injector assemblies, (3) cooldown chamber/diluent injector assemblies, and (4) combustion chamber assemblies.

The types of tests conducted on most of these components or assemblies included: (1) static proof tests to pressures near 3000 psia, (2) leak tests using gaseous nitrogen, (3) flow calibration of contained flow circuits to define flow rates versus differential pressures using the fluids $\mathrm{O}_{2}$, $\mathrm{CH}_{4}$, or $\mathrm{H}_{2} \mathrm{O}$ as appropriate, (4) valve timing tests to establish the times from actuation signals to the achievement of prescribed pressure or flow responses at downstream points, (5) pattern checks of the various injectors to assure they produce the desired distributions of the fluids, and (6) hot-fire testing of the stand-alone igniter.

All planned tests of components and subassemblies were completed. The results of these tests were judged satisfactory and the hardware was deemed acceptable for hot-fire testing.

The gas generator configurations to be tested included: (1) the uncooled copper chamber with injector pattern "A", (2) the uncooled copper chamber with injector pattern "B", (3) fully cooled gas generator with injector "A", and (4) fully cooled gas generator with injector "B".

The types of hot-fire tests to be conducted on these configurations of the gas generator included: (1) tests of the igniter only installed within the combustion chamber, (2) low-fire (nominal $20 \%$ of rated full power) gas generator tests, (3) high-fire, full power $\left(\sim 20 \mathrm{MW}_{\mathrm{t}}\right)$ gas generator tests of various durations: a) short duration (up to $\sim 10 \mathrm{sec}$ ), b) extended durations (up to $\sim 1 \mathrm{~min}$.), and c) extended duration with gas sampling (up to $\sim 4$ min.).

\section{Figure 25. Uncooled Chamber Mounted for Testing}

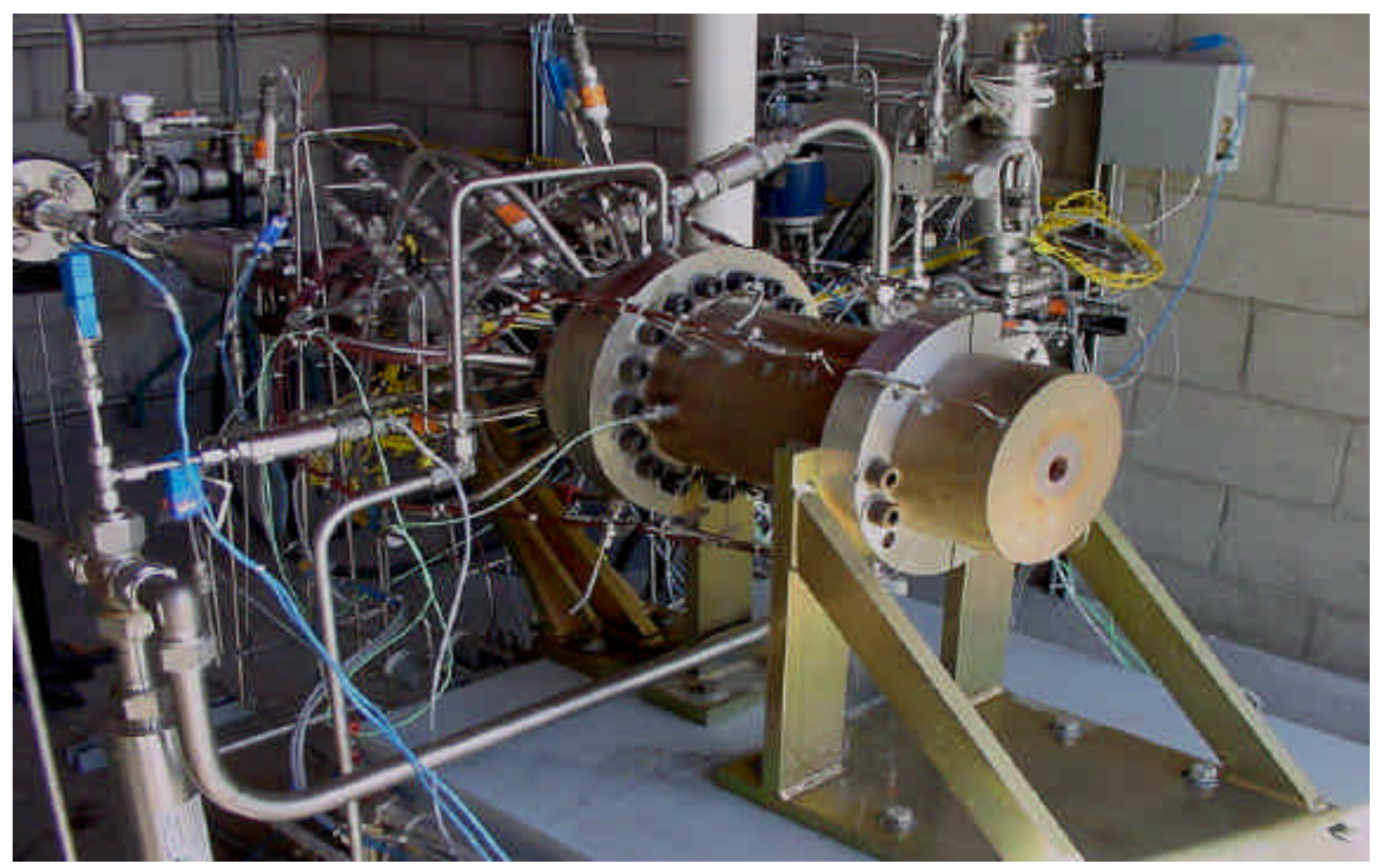




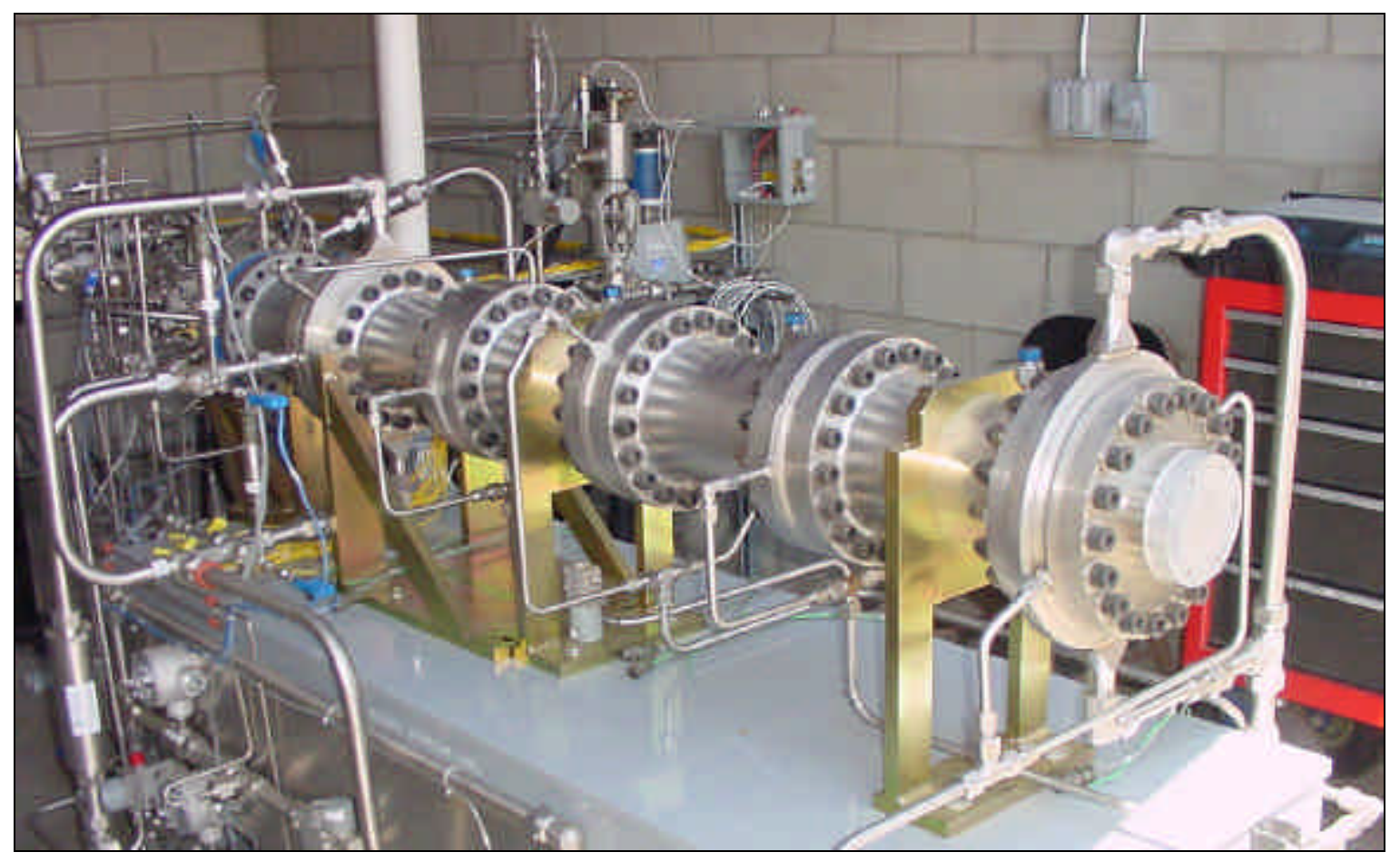

Figure 26. Fully Assembled Gas Generator on the Test Stand

The limited test durations were a consequence of the limited cooling and fuel capacities of the test facility and the high demands for fuel, oxygen and water at the $20 \mathrm{MW}$ power level. All but two of the originally planned sets of hot-fire tests described above were completed. The extended duration tests of the fully cooled chamber with injector "B" were not conducted because injector " $B$ " failed. Thus, the only extended duration hot-fire tests were done with limited gas sampling on the fully cooled gas generator with injector " $\mathrm{A}$ ". The uncooled chamber mounted for testing is at Figure 25, the fully cooled gas generator is shown at Figure 26.

\section{Test Results}

A summary of the planned versus completed testing is shown in matrix form in Table I. The upper portion of the table is relevant to component and assemblies and non-firing tests only, except for the igniter, whereas the lower portion of Table I is relevant to the various gas generator configurations and the various types of hot-fire tests planned and completed. Table I shows that all planned tests of components and subassemblies were completed. The results of these tests were judged satisfactory and the hardware was deemed acceptable for hot-fire testing.

The lower portion of Table I shows that all except three of the originally planned sets of hot-fire test have been completed (shown in bold type NA's). Those tests relate to the fully cooled chamber with injector "B" and were deemed "Not Applicable" because of the injector "B" failure. All the applicable tests of the gas generator were successfully completed. 
TABLE I.

SUMMARY OF GAS GENERATOR COMPONENT AND ASSEMBLY TESTS

\begin{tabular}{|c|c|c|c|c|c|c|c|c|c|c|c|c|}
\hline \multirow[b]{2}{*}{ Component or Assembly } & \multicolumn{2}{|c|}{$\begin{array}{l}\text { Proof } \\
\text { Tests }\end{array}$} & \multicolumn{2}{|c|}{$\begin{array}{l}\text { Leak } \\
\text { Tests }\end{array}$} & \multicolumn{2}{|c|}{$\begin{array}{c}\text { Flow } \\
\text { Calibration }\end{array}$} & \multicolumn{2}{|c|}{$\begin{array}{c}\text { Valve } \\
\text { Timing }\end{array}$} & \multicolumn{2}{|c|}{$\begin{array}{l}\text { Pattern } \\
\text { Checks }\end{array}$} & \multicolumn{2}{|c|}{$\begin{array}{c}\text { Hot Fire } \\
\text { Tests }\end{array}$} \\
\hline & Plan'd & Cmplt'd & Plan'd & Cmplt'd & Plan'd & Cmplt'd & Plan'd & Cmplt'd & Plan'd & Cmplt'd & Plan'd & Cmplt'd \\
\hline Igniter & Yes & Yes & Yes & Yes & Yes & Yes & Yes & Yes & No & NA & Yes & Yes \\
\hline Igniter/Main Injector Assemblies & Yes & Yes & Yes & Yes & Yes & Yes & Yes & Yes & Yes & Yes & No & NA \\
\hline Cooldown Cham./Diluent Inj. Assemblies & Yes & Yes & Yes & Yes & Yes & Yes & Yes & Yes & Yes & Yes & No & NA \\
\hline Main Inj./Comb. Chamber Assemblies & Yes & Yes & Yes & Yes & Yes & Yes & Yes & Yes & No & NA & No & NA \\
\hline
\end{tabular}

$\underline{\text { Gas Generator Hot-Fire Tests }}$

\begin{tabular}{|c|c|c|c|c|c|c|c|c|c|c|}
\hline \multirow[b]{3}{*}{ Gas Generator Configuration } & \multirow{2}{*}{\multicolumn{2}{|c|}{$\begin{array}{l}\text { Igniter } \\
\text { Only }\end{array}$}} & \multirow{2}{*}{\multicolumn{2}{|c|}{$\begin{array}{c}\text { Low-Fire } \\
\text { Tests }^{[1]}\end{array}$}} & \multicolumn{6}{|c|}{ High-Fire Tests $^{[2]}$} \\
\hline & & & & & \multicolumn{2}{|c|}{$\begin{array}{c}\text { Short } \\
\text { Duration }\end{array}$} & \multicolumn{2}{|c|}{$\begin{array}{l}\text { Extended } \\
\text { Duration } \\
\end{array}$} & \multicolumn{2}{|c|}{$\begin{array}{l}\text { With Gas } \\
\text { Sampling } \\
\end{array}$} \\
\hline & Plan'd & Cmplt'd & Plan'd & Cmplt'd & Plan'd & Cmplt'd & Plan'd & Cmplt'd & Plan'd & Cmplt'd \\
\hline Uncooled Copper Chamber with Injector "A" & Yes & Yes & Yes & Yes & Yes & Yes & Yes & Yes & No & NA \\
\hline Uncooled Copper Chamber with Injector "B" & Yes & Yes & Yes & Yes & Yes & Yes & Yes & Yes & No & NA \\
\hline Fully Cooled Gas Generator with Injector "A" & No & NA & Yes & Yes & Yes & Yes & Yes & Yes & Yes & Yes \\
\hline Fully Cooled Gas Generator with Injector "B" & No & NA & Yes & & Yes & & Yes & & No & NA \\
\hline
\end{tabular}

[1] Operation at a nominal $20 \%$ of rated, full power $\left(\sim 4 \mathrm{MW}_{\mathrm{t}}\right)$ on $\mathrm{O}_{2}, \mathrm{CH}_{4}$, and water.

[2] Operation at rated, full power $\left(\sim 20 \mathrm{MW}_{\mathrm{t}}\right)$ on $\mathrm{O}_{2}, \mathrm{CH}_{4}$, and water. 


\section{RESULTS AND DISCUSSION}

A summary of all $10 \mathrm{MW}_{\mathrm{e}}$ gas generator testing is presented in Table II. That summary describes the types of tests conducted, the number of valid tests in each category, the cumulative test time and maximum test duration (where applicable), and the corresponding significant results and/or findings derived from those tests.

These tests have demonstrated the igniter for the gas generator operates successfully over the prescribed ranges of pressure and mixture ratios, is repeatable, and reliable through more than 100 ignitions. The key component of the gas generator is an injector, which precisely mixes the oxygen, fuel, and water. Injector " $A$ " has been operated successfully at both low power ( 20\% of rated power) and at rated power $\left(\sim 20 \mathrm{MW}_{\mathrm{t}}\right)$ in more than 60 valid tests and 700 seconds of cumulative operation.

The uncooled gas generator (i.e., without diluent injectors or cooldown chambers installed) is shown on the right undergoing testing. It has produced drive gases at temperatures in excess of $3000^{\circ} \mathrm{F}$ and pressures up to 1550 psia. Such high-energy gases can drive the future steam turbines in highly efficient, near-zero emissions power plants.

The fully cooled gas generator configuration with cooldown chambers and injector " $A$ " is shown on the lower right. It has operated continuously to the duration limits of the test facility (more than three minutes) at pressures in the range from 1100 to 1650 psia and produced drive gases with temperatures in the range of 600 to $1800^{\circ} \mathrm{F}$. Such drive gases can re-power existing power plants and convert them to near-zero emissions facilities, or be used to power advanced turbines in efficient, near-zero emission power plants.

These test have demonstrated CES's gas generator to be capable of producing steam-rich turbine drive gases at very high pressures and at temperatures ranging from $>3000$ to as low as $600^{\circ} \mathrm{F}$.

Figures 26 a \& 26 b

\section{Uncooled and Cooled Chambers Firings}
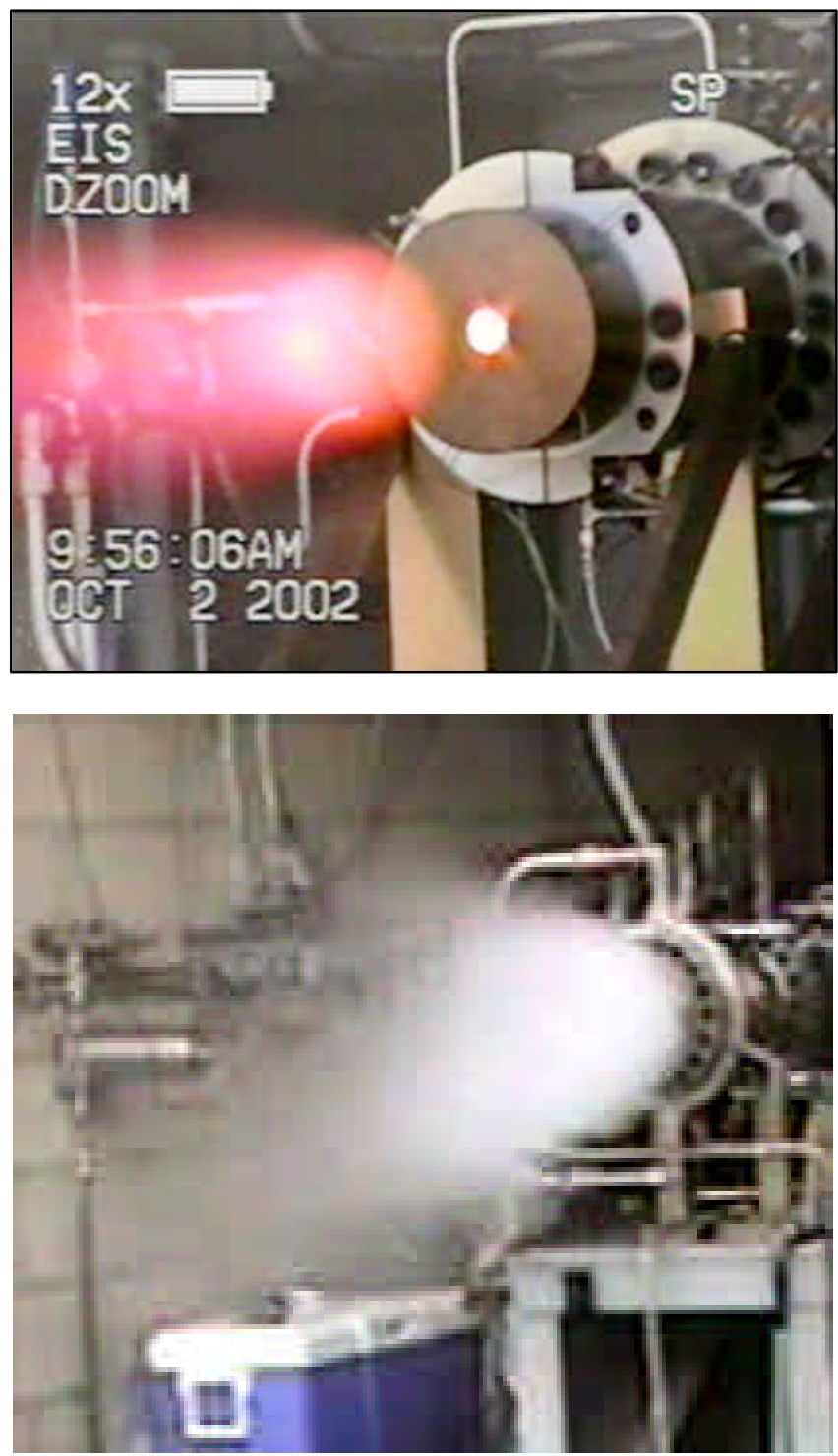


\section{TABLE II. \\ SUMMARY OF 10 MW GAS GENERATOR TESTS}

\begin{tabular}{|c|c|c|c|c|}
\hline $\begin{array}{l}\text { Type } \\
\text { of Test }\end{array}$ & $\begin{array}{l}\text { Valid } \\
\text { Tests }\end{array}$ & $\begin{array}{c}\text { Accumulated } \\
\text { Time, sec. }\end{array}$ & $\begin{array}{l}\text { Max. } \\
\text { Dur.,sec. }\end{array}$ & Significant Results/Findings \\
\hline \multicolumn{5}{|c|}{ Tests Conducted at Aerojet } \\
\hline Igniter only & 17 & 130 & 25 & Demonstrated satisfactory operation over prescribed ranges of pressures and mixture ratios \\
\hline \multicolumn{5}{|c|}{ Tests Conducted at NTS } \\
\hline Leak tests & 2 & NA & NA & Assembled complete gas generator (two configurations) and passed leak tests \\
\hline Water flow tests & 7 & NA & NA & Measured flow rates versus $\Delta \mathrm{P}^{\prime}$ s to define orifice sizes to properly balance flow circuits \\
\hline $\mathrm{CH}_{4}$ flow tests & 4 & NA & NA & Measured flow rates versus $\Delta \mathrm{P}^{\prime} \mathrm{s}$ to define restrictors to properly balance flow circuits \\
\hline $\mathrm{O}_{2}$ flow tests & 2 & NA & NA & Measured flow rates versus $\Delta \mathrm{P}^{\prime} \mathrm{s}$ to define restrictors to properly balance flow circuits \\
\hline Valve timing & 7 & NA & NA & Measured valve actuation and line fill times to define appropriate valve sequencing \\
\hline Igniter in GG & $8^{[1]}$ & 69 & 25 & Demonstrated repeatable operation in assembled gas generator at NTS test facility \\
\hline \multicolumn{5}{|c|}{ Uncooled Chamber with Injector "A" } \\
\hline Low-fire tests & 5 & 8 & 3.4 & Demonstrated successful main chamber ignition and combustion at $20 \%$ of full power \\
\hline Full power tests & 8 & 22 & 7.4 & Demonstrated full power gas generator operation at rated pressure ( $\geq 1550$ psia) \\
\hline \multicolumn{5}{|c|}{ Uncooled Chamber with Injector "B" } \\
\hline Low-fire tests & 2 & 8.2 & 4.1 & Demonstrated successful main chamber ignition and combustion at $20 \%$ of full power \\
\hline Full power tests & 1 & 1.8 & 1.8 & Successful operation at full power and pressure but injector suffered excessive damage \\
\hline \multicolumn{5}{|c|}{ Cooled Chamber with Injector "A" } \\
\hline Low-fire tests & $24^{[2]}$ & 13.1 & 1.1 & Demonstrated successful main chamber ignition and combustion at $20 \%$ of full power \\
\hline Full power tests & 37 & $664^{[3]}$ & 181 & $\begin{array}{l}\text { Demonstrated full power gas generator operation at pressures of } 1100 \text { to } 1650 \text { psia. } \\
\text { Incorporated beneficial hardware modifications. Performed 3-minute test. Sampled gases. }\end{array}$ \\
\hline
\end{tabular}

[1] 21 additional prior tests (10 ignitions and 11 non-ignitions) were required to detect, find, and resolve a facility problem, a failed diaphragm in a fuel pressure regulator.

[2] An additional 37 "low-fire" test operations accompanied the 37 full-power tests.

[3] An additional $37 \mathrm{sec}$ of "low-fire" operation was coincident with the 37 full-power tests. 
As explained above, at page 18, a need to modify the gas generator was revealed in early November 2002, near the end of the planned testing. Relatively minor hardware modifications to accomplish the separation of water-cooling and water-injection circuits and rework of the diluent-water injectors were completed during November and December 2002. The final series of tests, involving longer duration tests and gas sampling, was restarted in January 2003 and was completed in February 2003. These latter tests proved the hardware modifications to be acceptable and beneficial. Test durations up to the limit of the test facilities (approximately three minutes) and gas sampling were accomplished.

\section{Igniter Test Data}

Detailed data on the igniter derived from tests conducted at both the Aerojet and NTS test sites are summarized in Table III. The data from the testing at Aerojet clearly show the capability of the igniter to operate over a range of pressures and mixture ratios and the data from the testing at NTS show the excellent repeatability of the igniter at nominally constant $\mathrm{O}_{2}$ and $\mathrm{CH}_{4}$ inlet conditions. The igniter functioned reliably through more than 100 ignitions of the gas generator.

\section{Detailed Gas Generator Test Run Data}

More detailed results of a typical extended-duration test of the gas generator in the uncooled configuration follow. Operating pressure data from a typical extended-duration firing of the gas generator (Run \# 56, 10/2/02) with an uncooled copper chamber and injector "A" (but no diluent injectors) is shown in Figure 27. In this test, the gas generator operated in a low-fire condition (approximately $20 \%$ of rated full power) for approximately 1 second then ramped rapidly and smoothly to full power and a very stable operating pressure of $\sim 1564$ psia. The exit temperature could not be measured because the installed thermocouple had failed previously, but the calculated temperature is $\sim 2900^{\circ} \mathrm{F}$. The test was conducted essentially at stoichiometric ratio to form $\mathrm{H}_{2} \mathrm{O}$ and $\mathrm{CO}_{2}\left(\mathrm{O}_{2}\right.$ to $\mathrm{CH}_{4}$ equivalence ratio of 1.003). The gas generation rate was $\sim 33,000$ $\mathrm{lb} / \mathrm{hr}$ at $\sim 1564 \mathrm{psia}$ and $\sim 2900^{\circ} \mathrm{F}$. This corresponds to a firing rate of $\sim 18.6 \mathrm{MW}_{\mathrm{t}} \mathrm{LHV}$.

Operating pressures and gas temperatures are shown in Figures 28 to 33 for the final series of six long-duration firings (27 to 180 seconds) of the gas generator. In each test, the gas generator comprised a cooled chamber with injector " $A$ ", four cooldown chambers with modified diluent injectors, and the diverter manifold that separated the combustion chamber cooling-water and injection-water circuits. In each test, the gas generator operated in the low-fire condition (approximately $20 \%$ of rated full power) for approximately 1 second, then ramped rapidly and smoothly to full power. The steady-state operating pressures ranged from approximately 1450 to 1580 psia and mean gas temperatures near the exit of the last (fourth) cooldown chamber ranged from approximately 950 to $1800^{\circ} \mathrm{F}$. All these tests were conducted at oxygen/methane ratios very near the stoichiometric ratio to form $\mathrm{H}_{2} \mathrm{O}$ and $\mathrm{CO}_{2}$. The steady-state $\mathrm{O}_{2}$ to $\mathrm{CH}_{4}$ equivalence ratios ranged from approximately 0.98 to 1.08 . The gas generation rates ranged from about 45,000 to $53,000 \mathrm{lb} / \mathrm{hr}$ and the heating rates (LHV) ranged from about 60 to $64 \mathrm{MMBtu} / \mathrm{hr}$ (17.7 to $18.7 \mathrm{MW}_{\mathrm{t}}$ ). Detailed test data for these six tests at various times during the tests are summarized in Table IV. 


\section{TABLE III. \\ SUMMARY OF IGNITER TEST DATA}

\begin{tabular}{|c|c|c|c|c|c|c|c|c|c|c|}
\hline \multicolumn{11}{|c|}{ Data from Aerojet Test Site } \\
\hline \multirow{3}{*}{$\begin{array}{c}\text { CES Test } \\
\text { Matrix } \\
\text { No. }\end{array}$} & \multirow{3}{*}{$\begin{array}{c}\text { Aerojet } \\
\text { Test } \\
\text { No. }\end{array}$} & \multirow{3}{*}{$\begin{array}{c}\text { Igniter } \\
\text { Pressure, } \\
\text { psia }\end{array}$} & \multicolumn{4}{|c|}{ Flow Rates, lb/sec } & \multirow{2}{*}{\multicolumn{2}{|c|}{ Mixture Ratio }} & \multirow{3}{*}{$\begin{array}{c}\text { Exhaust } \\
\text { Temp., } \\
{ }^{\circ} \mathrm{F}\end{array}$} & \multirow{3}{*}{$\begin{array}{r}\text { Test } \\
\text { Dur, } \\
\text { sec }\end{array}$} \\
\hline & & & \multicolumn{2}{|c|}{ Oxygen $\left(\mathrm{O}_{2}\right)$} & \multirow{2}{*}{$\begin{array}{l}\mathrm{CH}_{4} \\
\text { Core }\end{array}$} & \multirow[b]{2}{*}{ Total } & & & & \\
\hline & & & Core & Coolant & & & Core & Overall & & \\
\hline 4 & 109 & 138.5 & 0.00880 & 0.00582 & 0.000447 & 0.01506 & 19.7 & 32.7 & NA & $\sim 1$ \\
\hline 5 & 110 & 138.9 & 0.00878 & 0.00577 & 0.000441 & 0.01498 & 19.9 & 33.0 & NA & $\sim 1$ \\
\hline 7 & 115 & 140.4 & 0.00808 & 0.00558 & 0.000514 & 0.01418 & 15.7 & 26.6 & 1742 & $\sim 2$ \\
\hline 6 & 111 & 1411 & 0.00890 & 0.0 & 0.00 & 0.01 & 19.4 & 32.1 & 1546 & $\sim 2$ \\
\hline 17 & & & & & & 0.01404 & 15.6 & 26.3 & 1779 & $\sim 25$ \\
\hline 8 & 116 & 142.7 & 0.00925 & 0.00 & 0.000438 & 0.01593 & 21.1 & 35.4 & 1440 & $\sim 2$ \\
\hline 9 & 117 & 144.0 & 0.00877 & 0.00588 & 0.000485 & 0.01513 & 18.1 & 30.2 & 1733 & $\sim 3.8$ \\
\hline 9 & & & & & & & 18.2 & & & $\sim 5$ \\
\hline 16 & 127 & 147.9 & 0.00891 & 0.00636 & 0.000489 & 0.01575 & 18.2 & 31.2 & 1657 & $\sim 25$ \\
\hline 10 & 120 & 324.2 & 0.02027 & 0.01357 & 0.001104 & 0.03494 & 18.4 & 30.7 & NA & $\sim 1$ \\
\hline 13 & 123 & & & & & & 15.3 & 26.1 & 2036 & $\sim 2$ \\
\hline 19 & 131 & 325.8 & 0.01842 & 0.01215 & 0.001184 & 0.03175 & 15.6 & 25.8 & 2268 & $\sim 25$ \\
\hline 20 & 132 & 342.7 & 0.02065 & 0.01407 & 0.001075 & 0.03580 & 19.2 & 32.3 & 1759 & $\sim 2$ \\
\hline 11 & & 343.7 & 0.02023 & & & 0.03486 & 18.0 & 30.1 & 1837 & $\sim 2$ \\
\hline 15 & 126 & 344.8 & 0.02030 & 0.01373 & 0.001115 & 0.03515 & 18.2 & 30.5 & 2022 & $\sim 5$ \\
\hline 12 & 121 & 345.4 & 0.02088 & 0.01355 & 0.001128 & 0.03556 & 18.5 & 30.5 & 1838 & $\sim 2$ \\
\hline 18 & 129 & 348.6 & 0.02064 & 0.01367 & 0.001125 & 0.03543 & 18.3 & 30.5 & 1975 & $\sim 25$ \\
\hline
\end{tabular}

\begin{tabular}{|c|c|c|c|c|c|c|c|c|c|c|}
\hline \multicolumn{11}{|c|}{ Data from the NTS Test Site } \\
\hline \multirow{3}{*}{$\begin{array}{l}\text { NTS } \\
\text { Test } \\
\text { No. }\end{array}$} & \multirow{3}{*}{$\begin{array}{l}\text { Data } \\
\text { File } \\
\text { No. }\end{array}$} & \multirow{3}{*}{$\begin{array}{c}\text { Igniter } \\
\text { Pressure, } \\
\text { psia }\end{array}$} & \multicolumn{4}{|c|}{ Flow Rates, lb/sec } & \multirow{2}{*}{\multicolumn{2}{|c|}{ Mixture Ratio }} & \multirow{3}{*}{$\begin{array}{c}\text { Exhaust } \\
\text { Temp., } \\
{ }^{\circ} \mathrm{F}\end{array}$} & \multirow{3}{*}{$\begin{array}{l}\text { Test } \\
\text { Dur, } \\
\text { sec }\end{array}$} \\
\hline & & & \multicolumn{2}{|c|}{ Oxygen $\left(\mathrm{O}_{2}\right)$} & \multirow{2}{*}{$\begin{array}{l}\mathrm{CH}_{4} \\
\text { Core }\end{array}$} & \multirow[b]{2}{*}{ Total } & & & & \\
\hline & & & Core & Coolant & & & Core & Overall & & \\
\hline 23 & A154 & 328.9 & 0.01970 & 0.01234 & 0.0009693 & 0.03301 & 20.3 & 33.1 & NA & $\sim 7$ \\
\hline 24 & A155 & 328.9 & 0.01971 & 0.01234 & 0.0009703 & 0.03302 & 20.3 & 33.0 & NA & $\sim 7$ \\
\hline 25 & A157 & 328.7 & 0.01970 & 0.01234 & 0.0009704 & 0.03301 & 20.3 & 33.0 & NA & $\sim 7$ \\
\hline 26 & A158 & 328.3 & 0.01969 & 0.01233 & 0.0009704 & 0.03299 & 20.3 & 33.0 & NA & $\sim 7$ \\
\hline 27 & A159 & 329.1 & 0.01969 & 0.01233 & 0.0009703 & 0.03299 & 20.3 & 33.0 & NA & $\sim 7$ \\
\hline & Avg. & 329.0 & 0.01970 & 0.01233 & 0.0009698 & 0.03300 & 20.3 & 33.0 & & \\
\hline & Std Dev. & 0.25 & 0.00001 & 0.00001 & 0.0000004 & 0.00001 & 0.01 & 0.02 & & \\
\hline
\end{tabular}


Figure 27. Operating Chamber Pressure During Uncooled Gas Generator Test \# 56

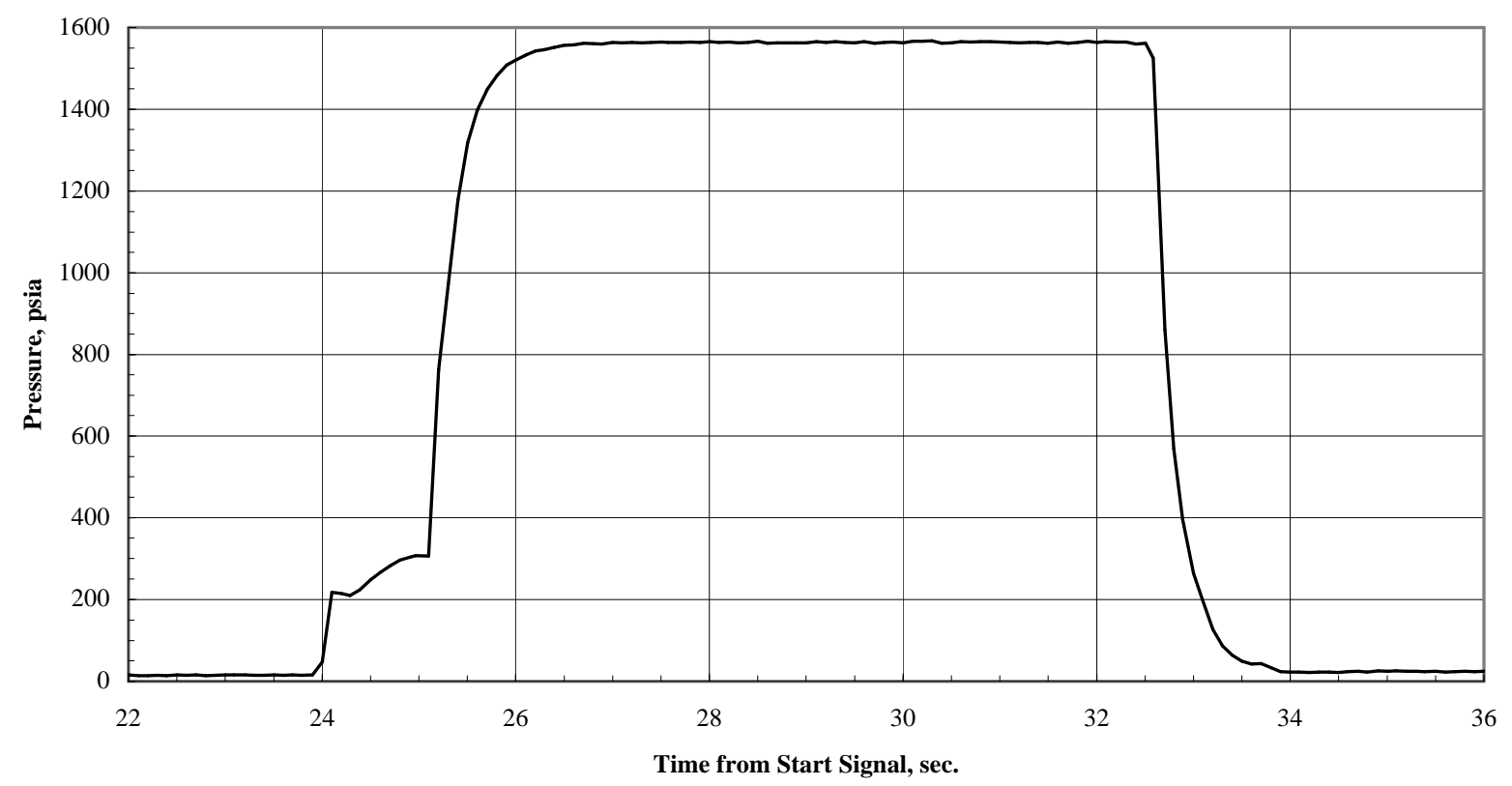

Figure 28. Chamber Pressure and Gas Temperature Cooled Gas Generator Test \# 179

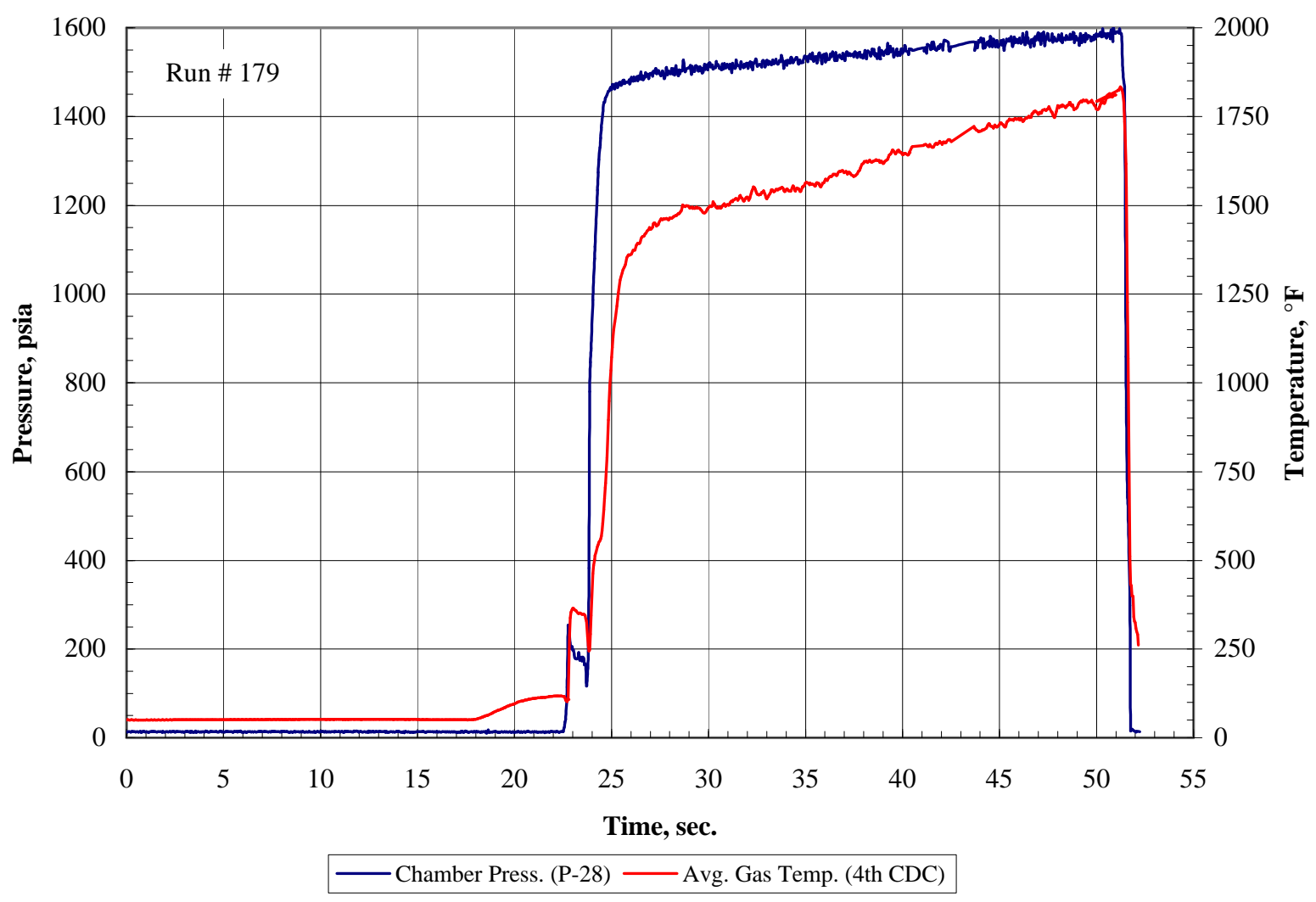


Figure 29. Chamber Pressure and Gas Temperature Cooled Gas Generator Test \#183

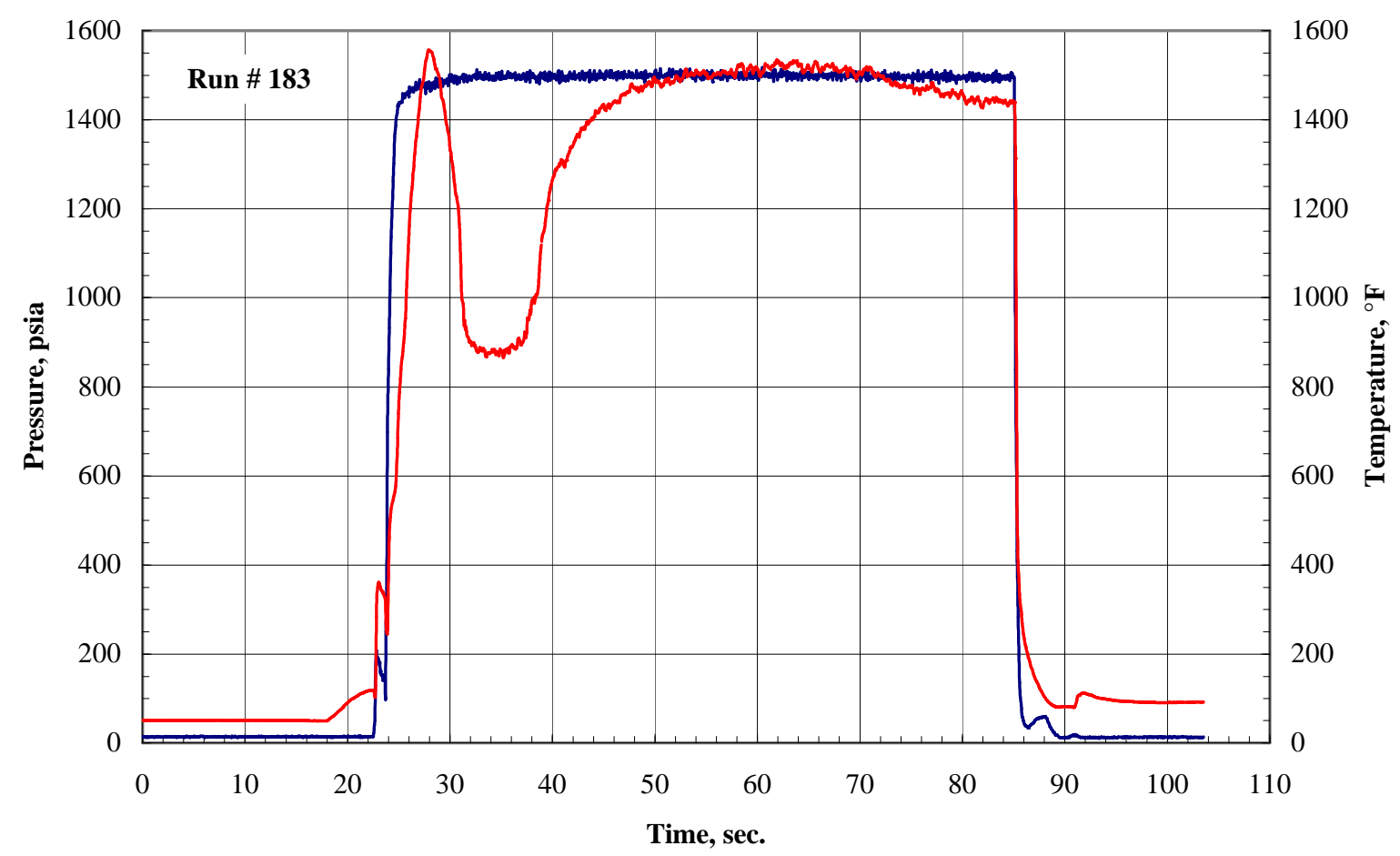

- Chamber Press. (P-28) — Avg. Gas Temp. (4th CDC)

Figure 30. Chamber Pressure and Gas Temperature Cooled Gas Generator Test \# 185

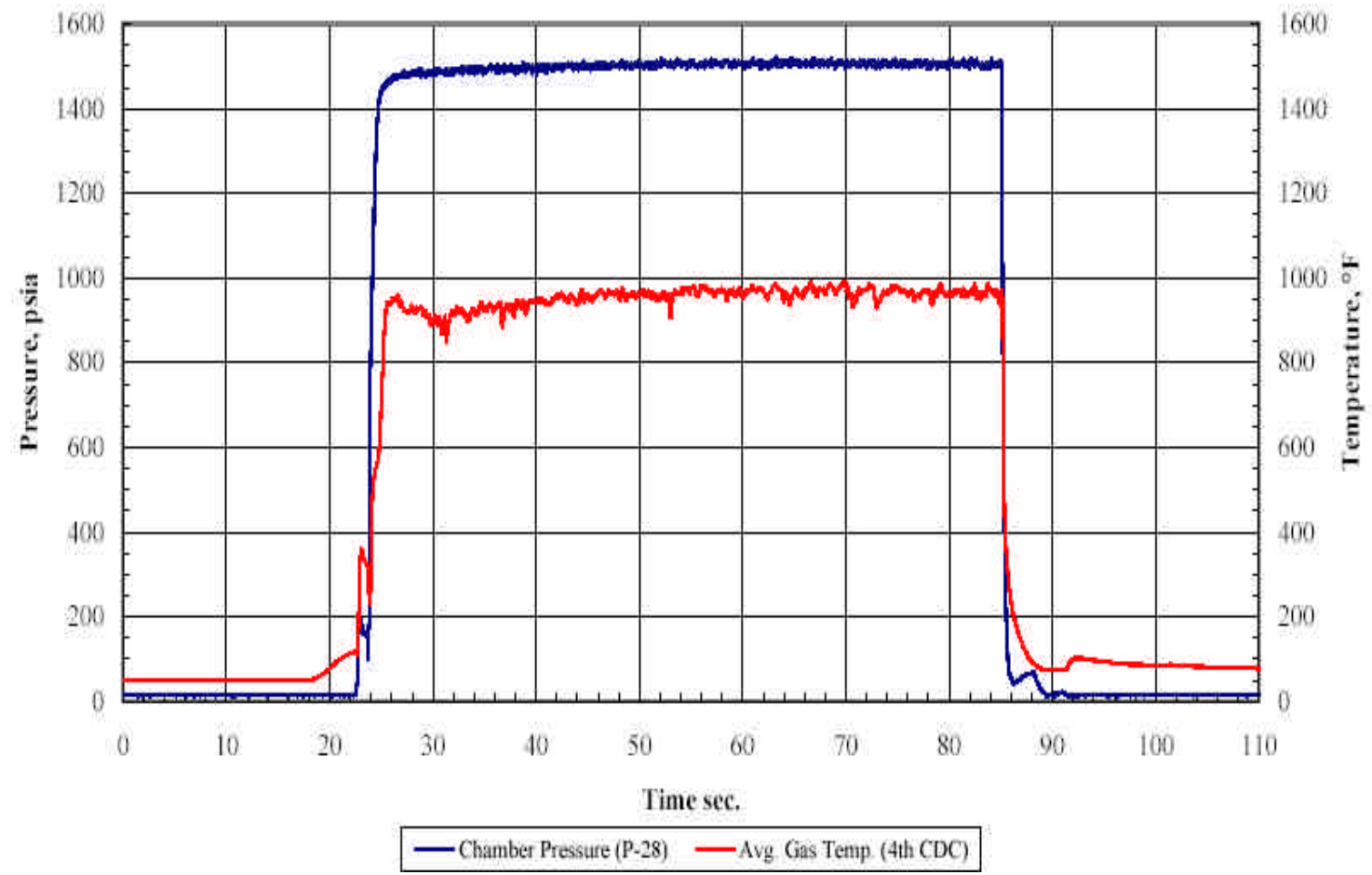


Figure 31. Chamber Pressure and Gas Temperature Cooled Gas Generator Test \#190

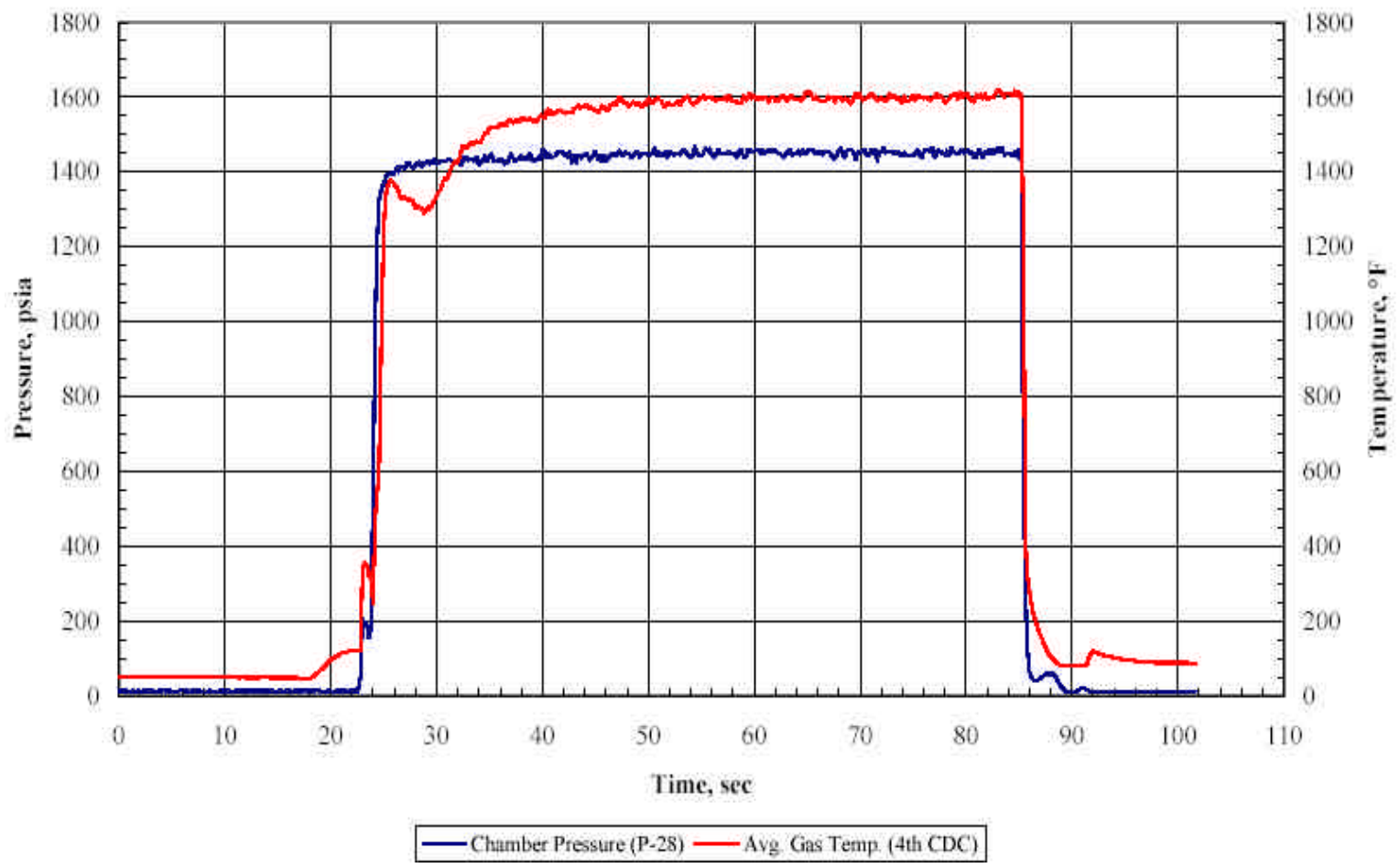

Figure 32. Chamber Pressure and Gas Temperature Cooled Gas Generator Test \# 193

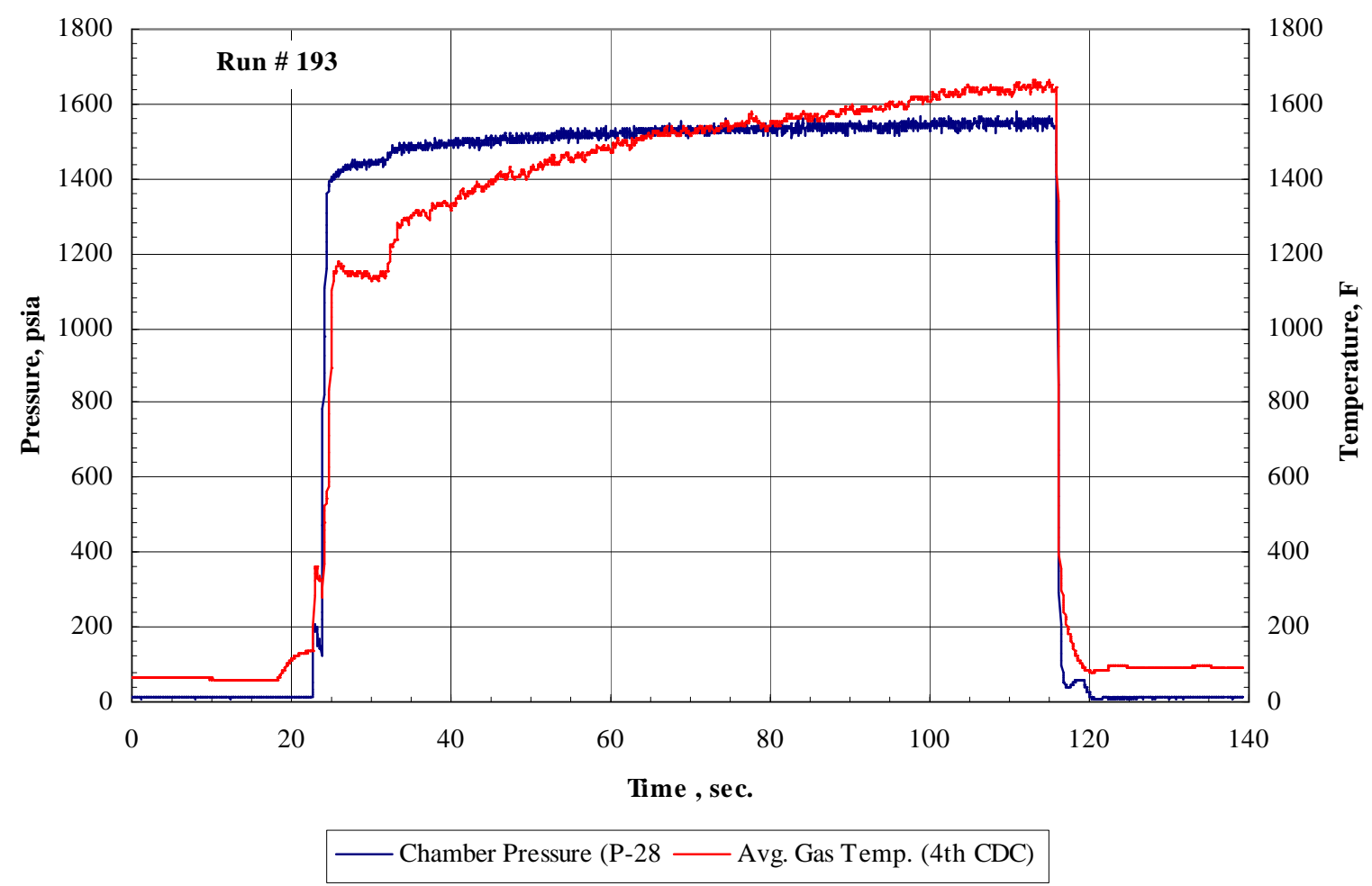


Figure 33. Chamber Pressure and Gas Temperature Cooled Gas Generator Test \# 194

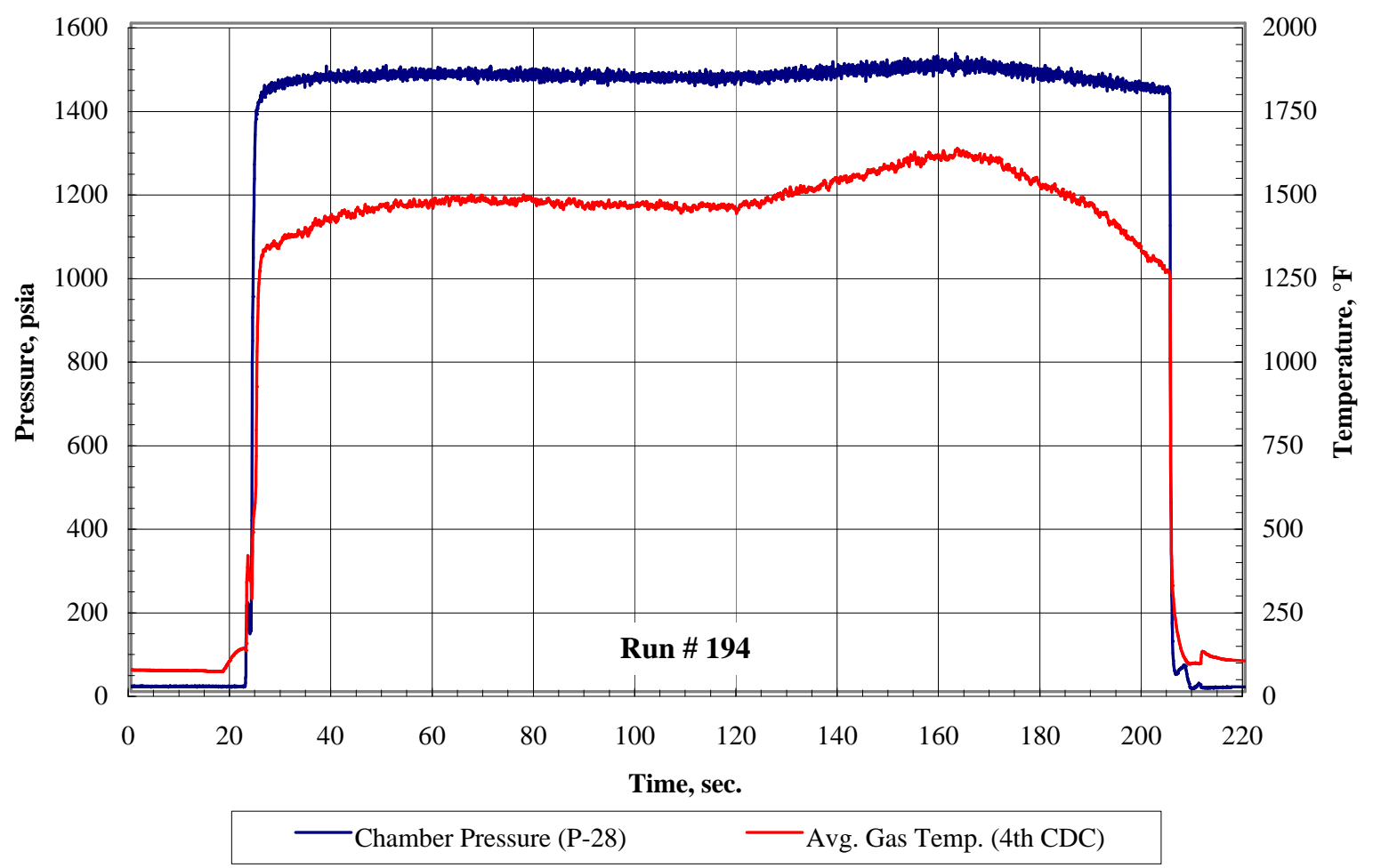

\section{Gas Sampling}

Gas samples were obtained from the 2 nd cooldown chamber via the gas sample probe and sampling train during Run \#193 ( 90-second test) and sent to O2, CO, and NOx analyzers, and to a quadrupole mass spectrometer. At the conclusion of the test, water contamination at the entrance to the analyzers was observed. This water carryover was attributed to incomplete separation of liquid water from the depressurized, cooled residual gases in the sampling train. The wet residual gas sample appeared to interfere with the proper operation of the $\mathrm{O} 2, \mathrm{CO}$, and $\mathrm{NO}_{\mathrm{x}}$ analyzers and thus yielded unreliable data. The gas sample reaching the quadrupole mass spectrometer, on the other hand, was analyzed despite the presence of some water. The mass spectrometer indicated that the gas contained $\sim 95.2 \% \mathrm{v} \mathrm{CO} 2$ and $\sim 4.8 \% \mathrm{v} \mathrm{O} 2$ (dry basis) versus a predicted $96 \% \mathrm{CO}_{2}$ and $4 \% \mathrm{O} 2$ based on the mass flow ratio of $\mathrm{O} 2$ to $\mathrm{CH} 4$. More comprehensive analyses will require improvement of the gas/water separation in the gas sampling system, longer run times, and more positive control of gas generator operating conditions. Such analyses are planned when the $10 \mathrm{MWe}$ gas generator is integrated with a complete, interactive control system and retested later in 2003. 
TABLE IV.

SUMMARY OF GAS GENERATOR TEST DATA

\begin{tabular}{|c|c|c|c|c|c|c|c|c|c|c|c|c|c|}
\hline Run \# & 179 & \multicolumn{4}{|c|}{183} & \multicolumn{4}{|c|}{185} & \multicolumn{4}{|c|}{190} \\
\hline Time from Test Start Signal, sec & 50 & 50 & 60 & 70 & 80 & 50 & 60 & 70 & 80 & 50 & 60 & 70 & 80 \\
\hline Operating Pressure, psia & 1581 & 1500 & 1502 & 1499 & 1496 & 1503 & 1505 & 1506 & 1504 & 1451 & 1455 & 1454 & 1453 \\
\hline Gas Temp. (avg. at 4th CDC dischg), ${ }^{\circ} \mathrm{F}$ & 1793 & 1482 & 1513 & 1508 & 1452 & 962 & 966 & 968 & 967 & 1587 & 1599 & 1598 & 1602 \\
\hline $\mathrm{O}_{2}$ Inj. Rate, $\mathrm{lb} / \mathrm{sec}$ & 3.463 & 3.229 & 3.231 & 3.231 & 3.224 & 3.213 & 3.219 & 3.220 & 3.217 & 3.122 & 3.144 & 3.146 & 3.147 \\
\hline $\mathrm{CH}_{4}$ Inj. Rate, $\mathrm{lb} / \mathrm{sec}$ & 0.8024 & 0.7899 & 0.7924 & 0.7953 & 0.7984 & 0.7793 & 0.7845 & 0.7899 & 0.7959 & 0.8085 & 0.8161 & 0.8209 & 0.8247 \\
\hline Mixture Ratio, O/F, lb/lb & 4.315 & 4.088 & 4.077 & 4.063 & 4.038 & 4.123 & 4.103 & 4.077 & 4.042 & 3.862 & 3.853 & 3.833 & 3.816 \\
\hline Equivalence Ratio, $\mathrm{O} / \mathrm{F}$ & 1.082 & 1.025 & 1.022 & 1.018 & 1.012 & 1.033 & 1.029 & 1.022 & 1.013 & 0.968 & 0.966 & 0.961 & 0.957 \\
\hline Comb. Chamb. $\mathrm{H}_{2} \mathrm{O}$ Inj. Rate, lb/sec & 4.543 & 4.994 & 4.962 & 4.975 & 5.041 & 5.813 & 5.785 & 5.765 & 5.753 & 4.680 & 4.655 & 4.635 & 4.639 \\
\hline Comb. Cham. Water/Fuel Ratio, lb/lb & 5.661 & 6.323 & 6.262 & 6.255 & 6.314 & 7.459 & 7.374 & 7.298 & 7.229 & 5.788 & 5.705 & 5.646 & 5.625 \\
\hline Total CDC $\mathrm{H}_{2} \mathrm{O}$ Inj. Rate, lb/s & 3.903 & 4.299 & 4.270 & 4.287 & 4.347 & 4.955 & 4.933 & 4.914 & 4.908 & 4.047 & 4.024 & 4.017 & 4.019 \\
\hline Total Inj. Water/Fuel Ratio, lb/lb & 10.52 & 11.77 & 11.65 & 11.65 & 11.76 & 13.82 & 13.66 & 13.52 & 13.39 & 10.79 & 10.64 & 10.54 & 10.50 \\
\hline Gas Gen. Rate, lb/hr & 45759 & 47927 & 47719 & 47836 & 48276 & 53134 & 52998 & 52879 & 52827 & 45567 & 45503 & 45429 & 45468 \\
\hline Heating Rate (HHV), MM Btu/hr & 68.93 & 67.85 & 68.07 & 68.31 & 68.58 & 66.94 & 67.39 & 67.85 & 68.37 & 69.45 & 70.10 & 70.51 & 70.84 \\
\hline Heating Rate $(\mathrm{HHV}), \mathrm{MW}_{\mathrm{t}}$ & 20.19 & 19.87 & 19.94 & 20.01 & 20.09 & 19.61 & 19.74 & 19.87 & 20.02 & 20.34 & 20.53 & 20.65 & 20.75 \\
\hline Heating Rate (LHV), MM Btu/hr & 62.12 & 61.14 & 61.34 & 61.56 & 61.80 & 60.32 & 60.73 & 61.14 & 61.61 & 62.58 & 63.17 & 63.54 & 63.84 \\
\hline Heating Rate (LHV), $\mathrm{MW}_{\mathrm{t}}$ & 18.19 & 17.91 & 17.97 & 18.03 & 18.10 & 17.67 & 17.79 & 17.91 & 18.04 & 18.33 & 18.50 & 18.61 & 18.70 \\
\hline Heat Transfer to CC Walls, Btu/sec & 249.1 & 216.1 & 220.4 & 220.3 & 219.8 & 210.5 & 213.0 & 212.6 & 215.4 & 224.7 & 219.8 & 221.1 & 222.3 \\
\hline Heat Flux to CC Walls, Btu/in ${ }^{2}$-sec & 1.510 & 1.310 & 1.336 & 1.335 & 1.332 & 1.276 & 1.291 & 1.289 & 1.305 & 1.362 & 1.332 & 1.340 & 1.347 \\
\hline Appx. Max. CC Wall Temp., $\cdot{ }^{\circ} \mathrm{F}$ & 734 & 596 & 598 & 593 & 584 & 565 & 568 & 568 & 573 & 595 & 590 & 586 & 586 \\
\hline Heat Transfer to CDC Walls, Btu/sec & 759.1 & 676.8 & 689.7 & 695.7 & 695.1 & 668.4 & 674.4 & 676.3 & 677.3 & 658.6 & 664.6 & 669.1 & 673.1 \\
\hline Heat Flux to CDC Walls, Btu/in ${ }^{2} \cdot \mathrm{sec}$ & 1.206 & 1.075 & 1.095 & 1.105 & 1.104 & 1.062 & 1.071 & 1.074 & 1.076 & 1.046 & 1.056 & 1.063 & 1.069 \\
\hline
\end{tabular}

Note: CDC is acronym for cooldown chamber and CC is acronym for combustion chamber 
TABLE IV.

SUMMARY OF GAS GENERATOR TEST DATA (continued)

\begin{tabular}{|c|c|c|c|c|c|c|c|c|c|c|c|c|c|c|}
\hline Run \# & \multicolumn{6}{|c|}{193} & \multicolumn{8}{|c|}{194} \\
\hline Time from Test Start Signal, sec & 50 & 60 & 70 & 80 & 90 & 100 & 60 & 80 & 100 & 120 & 140 & 160 & 180 & 200 \\
\hline Operating Pressure, psia & 1512 & 1523 & 1531 & 1536 & 1541 & 1547 & 1481 & 1480 & 1473 & 1473 & 1489 & 1503 & 1482 & 1450 \\
\hline Gas Temp. (avg. at 4th CDC dischg), ${ }^{\circ} \mathrm{F}$ & 1421 & 1484 & 1526 & 1544 & 1585 & 1615 & 1465 & 1467 & 1456 & 1448 & 1533 & 1602 & 1514 & 1313 \\
\hline $\mathrm{O}_{2}$ Inj. Rate, $\mathrm{lb} / \mathrm{sec}$ & 3.234 & 3.262 & 3.280 & 3.285 & 3.299 & 3.310 & 3.176 & 3.172 & 3.170 & 3.165 & 3.199 & 3.226 & 3.177 & 3.121 \\
\hline $\mathrm{CH}_{4}$ Inj. Rate, lb/sec & 7942 & .8005 & 0.8059 & 0.8104 & 0.8131 & 0.8146 & 0.7904 & 0.7999 & 0.8071 & 0.8095 & 0.8118 & 0.8145 & 0.8167 & 0.8189 \\
\hline Mixture Ratio, O/F, lb/lb & 4.072 & 4.075 & 4.070 & 4.054 & 4.057 & 4.063 & 4.018 & 3.965 & 3.927 & 3.910 & 3.940 & 3.961 & 3.891 & 3.812 \\
\hline Equivalence Ratio, O/F & 1.021 & 1.022 & 1.020 & 1.017 & 1.017 & 1.019 & 1.007 & 0.994 & 0.984 & 0.980 & 0.988 & 0.993 & 0.975 & 0.956 \\
\hline Comb. Chamb. $\mathrm{H}_{2} \mathrm{O}$ Inj. Rate, lb/sec & 4.930 & 4.876 & 4.845 & 4.817 & 4.798 & 4.763 & 4.961 & 4.952 & 4.945 & 4.916 & 4.847 & 4.779 & 4.830 & 5.006 \\
\hline Comb. Cham. Water/Fuel Ratio, lb/lb & 6.207 & 6.092 & 6.012 & 5.944 & 5.901 & 5.847 & 6.277 & 6.191 & 6.127 & 6.073 & 5.971 & 5.867 & 5.914 & 6.113 \\
\hline Total CDC $\mathrm{H}_{2} \mathrm{O}$ Inj. Rate, lb/s & 4.240 & 4.215 & 4.180 & 4.159 & 4.135 & 4.111 & 4.254 & 4.241 & 4.249 & 4.242 & 4.179 & 4.127 & 4.164 & 4.319 \\
\hline Total Inj. Water/Fuel Ratio, lb/lb & 13.15 & 12.87 & 12.65 & 12.47 & 12.34 & 12.22 & 13.32 & 13.04 & 12.86 & 12.74 & 12.50 & 12.27 & 12.34 & 12.74 \\
\hline Gas Gen. Rate, lb/hr & 47514 & 47351 & 47197 & 47060 & 46959 & 46795 & 47454 & 47393 & 47416 & 47276 & 46933 & 46606 & 46757 & 47755 \\
\hline Heating Rate (HHV), MM Btu/hr & 68.22 & 68.76 & 69.23 & 69.61 & 69.84 & 69.97 & 67.90 & 68.71 & 69.33 & 69.54 & 69.73 & 69.97 & 70.15 & 70.34 \\
\hline Heating Rate $(\mathrm{HHV}), \mathrm{MW}_{\mathrm{t}}$ & 19.98 & 20.14 & 20.27 & 20.39 & 20.46 & 20.49 & 19.88 & 20.12 & 20.30 & 20.37 & 20.42 & 20.49 & 20.55 & 20.60 \\
\hline Heating Rate (LHV), MM Btu/hr & 61.48 & 61.96 & 62.38 & 62.73 & 62.94 & 63.06 & 61.18 & 61.92 & 62.48 & 62.66 & 62.84 & 63.05 & 63.22 & 63.39 \\
\hline Heating Rate (LHV), $\mathrm{MW}_{\mathrm{t}}$ & 18.01 & 18.15 & 18.27 & 18.37 & 18.43 & 18.47 & 17.92 & 18.13 & 18.30 & 18.35 & 18.40 & 18.47 & 18.52 & 18.56 \\
\hline Heat Transfer to CC Walls, Btu/sec & 219.4 & 225.3 & 227.9 & 230.2 & 232.9 & 235.1 & 210.1 & 211.4 & 212.1 & 210.6 & 215.3 & 218.8 & 215.4 & 207.5 \\
\hline Heat Flux to CC Walls, Btu/in ${ }^{2}$-sec & 1.330 & 1.365 & 1.381 & 1.395 & 1.411 & 1.425 & 1.273 & 1.281 & 1.285 & 1.276 & 1.305 & 1.326 & 1.305 & 1.257 \\
\hline Appx. Max. CC Wall Temp., $\cdot{ }^{\circ} \mathrm{F}$ & 616 & 633 & 645 & 647 & 668 & 673 & 634 & 628 & 617 & 608 & 613 & 621 & 612 & 570 \\
\hline Heat Transfer to CDC Walls, Btu/sec & 677.6 & 696.7 & 706.8 & 712.9 & 716.6 & 723.5 & 655.4 & 660.1 & 661.1 & 659.4 & 668.7 & 680.8 & 672.2 & 652.5 \\
\hline Heat Flux to CDC Walls, Btu/in ${ }^{2} \cdot \mathrm{sec}$ & 1.076 & 1.107 & 1.123 & 1.132 & 1.138 & 1.149 & 1.041 & 1.048 & 1.050 & 1.047 & 1.062 & 1.081 & 1.068 & 1.036 \\
\hline
\end{tabular}

Note: CDC is acronym for cooldown chamber and CC is acronym for combustion chamber 


\section{RELATED PROGRAM ACTIVITIES}

Technical Papers Produced

During the course of this project, CES was encouraged by staff at DOE/NETL to present papers describing the work being done at appropriate conferences and symposiums. Opportunities were presented to present papers at various stages in our work. The following papers, among others, dealing with the CES technology have been presented and published:

Anderson R., Brandt H., Doyle S., Viteri F., “A Demonstrated $20 \mathrm{MW}_{\mathrm{t}}$ Gas Generator for a Clean Steam Power Plant," a paper presented at the $28^{\text {th }}$ International Technical Conference on Coal Utilization and Fuel Systems, March 2003, Clearwater, Forida.

Anderson R., Brandt H., Pronske K., Viteri F., "Near-Term Potential for Power Generation from Coal with Zero Atmospheric Emissions," in Proceedings of the $27^{\text {th }}$ International Technical Conference on Coal Utilization and Fuel Systems, March 4-7, 2002, Clearwater, Florida, at page 51.

Martinez-Frias J., Aceves S., Smith J. R., Lawrence Livermore National Laboratory, "Thermodynamic Analysis of a Zero Atmospheric Emissions Power Plant," a paper presented at the ASME International Conference in New Orleans in November 2002. The paper was accepted for publication in the Journal of Engineering for Gas Turbines and Power.

Smith J. R., and Terry Surles, Lawrence Livermore National Laboratory; Brian Marais, Bechtel National, Inc.; Harry Brandt, and F. (Vic) Viteri, Clean Energy Systems, Inc., "Power Production with Zero Atmospheric Emissions for the21st Century," a paper presented to the 5th International Conference on Greenhouse Gas Control Technologies, August 13-16, 2000, Cairns, Queensland, Australia.

Anderson R., Brandt H., Doyle S., Mueggenburg H., Taylor J., Viteri F., "A Unique Process for Production of Environmentally Clean Electric Power Using Fossil Fuels," a paper presented to the 8th International Symposium on Transport Phenomena and Dynamics of Rotating Machinery (ISROMAC-8), 28 March 2000, Honolulu, HI.

Turbine Development Cooperative Agreement

On 20 August 2001 Elliott Turbomachinery, of Jeannette PA, and CES signed a non-binding Letter of Intent. This document identified different collaborative opportunities for CES and Elliott, with the expectation of identifying new, mutually beneficial opportunities for each company. The original letter was updated and re-signed in February 2003. The current letter contains mutual undertakings, among the most significant of which are:

(1) The companies will exchange information and analyses concerning different plant cycles and configurations. 
(2) Using CES provided basic design criteria for "near term" turbines (i.e., within 5 years), Elliott will undertake design of a high pressure, high temperature turbine of a nominal 16 MW size with inlet conditions of approximately $1200 \mathrm{psig}$ and $1200^{\circ} \mathrm{F}$. An associated nominal $35 \mathrm{MW}$ intermediate turbine will have inlet conditions (after reheat) of $365 \mathrm{psig}$ and $2200^{\circ} \mathrm{F}$. An expected nominal $17 \mathrm{MW}$ low pressure turbine in this series will have inlet conditions of $17 \mathrm{psig}$ and $1200^{\circ} \mathrm{F}$.

For each turbine, Elliott undertakes to prepare a detailed development schedule, indicating the critical path to commercialization, the inputs required from CES, and the estimated program costs. In April 2002, CES personnel visited the Elliott plant in Jeannette, and received a progress report on the work to date. Preliminary design work and preliminary materials selection have been accomplished. 3-D ProE modeling and evaluation of the turbine's steam end were being reviewed for influence on selection of casing materials. Candidate materials for the turbine rotating and stationary bucketing had been investigated, but no definitive design had been established. Elliott has two full-time engineers committed to this project and is seeking additional internal funding to advance the program. Preliminary, proprietary configuration drawings have been produced and have been seen by CES.

The availability of higher pressure, higher temperature steam turbines will be a significant contributor to early realization of higher efficiencies in plants using CES technology. This will be an important part of CES' pathway to market rationale.

\section{$\underline{\text { Remaining Materials }}$}

Following the negotiation of the contract, CES considered alternative sources for various supplies. Throughout the duration of the project, materials were sought from reliable, lowest bidding sources by CES and its subcontractors. At project conclusion, there is a body of manufactured materials, test equipment, with spare parts and material, which are stored for possible future use in follow-on programs for further development and demonstration of the CES technology. All the Remaining Materials are identified in a separate report to DOE/NETL.

During the conduct of this project, CES has been developing a separate project in conjunction with the California Energy Commission, and industrial partners American Air Liquide and Mirant Corporation of California, to build a demonstration power plant in California to obtain durability data on the gas generator developed in this DOE/NETL co-funded project. It is our current expectation that the $10 \mathrm{MW}$ gas generator, built for and tested in this project, may be subjected to further testing under the State co-funded program, and eventually approved to be used in the California demonstration plant. Therefore, CES has catalogued and is storing the remaining materials and spare parts generated by this project, with the expectation that they may support the next phase of the demonstration of the gas generator, in an operational power plant.

A summary of material costs and an analysis of the full production costs will be submitted as part of the final report to the assigned property administrator. 


\section{$\underline{\text { Reheater Development }}$}

In parallel with the work of CES, DOE's National Energy Technology Laboratory (NETL) undertook, in 2002, to design, fabricate, and test a drive gas reheater to be used for turbine exhaust reheat in plants employing CES technology. The reheater is a combustion device that heats the steam/carbon dioxide stream exiting the high-pressure turbine by mixing and burning oxygen and a clean fuel in stoichiometric proportions with the steam/carbon dioxide mixture. This reheating operation increases the temperature of the gases entering the inter-mediatepressure turbine and thereby increases the thermodynamic efficiency of the power cycle.

The design of the reheater was headed by Dr. George Richards, of the NETL, Morgantown, West Virginia laboratory, who also spearheaded its fabrication and testing. The testing was performed at NASA's Plum Brook facilities near Sandusky, Ohio under the direction of Mr. Mark Woike. The reheater was installed within a pressurized test enclosure that featured quartz windows, permitting video observation of the combustion zone. A photograph of the reheater test setup is shown in Figure 34.

\section{Figure 34. NETL Developed Reheater at NASA Test Site near Sandusky OH.}

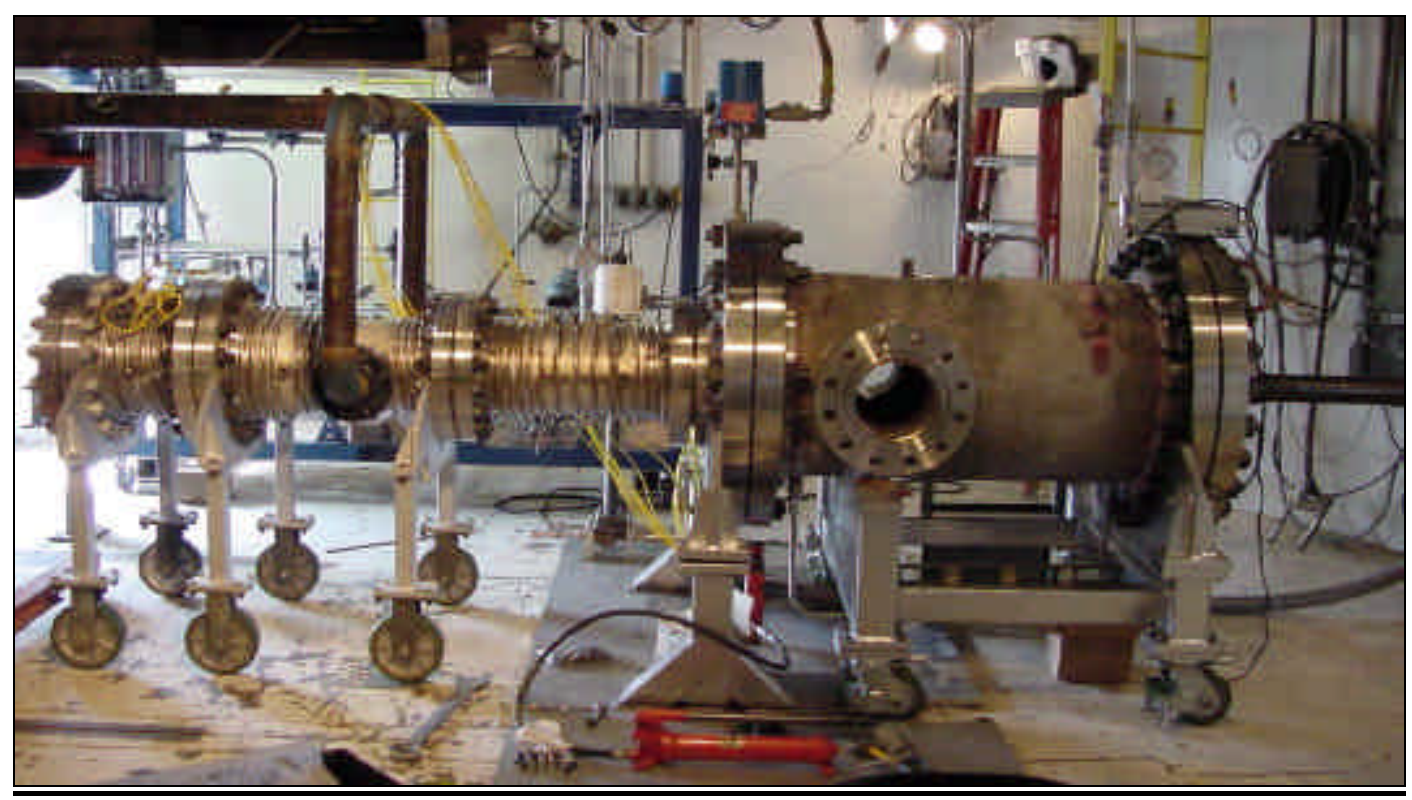

\section{$\underline{\text { Safety, Health and Environmental Impacts }}$}

\section{Permits and Licenses}

The conduct of this project by CES did not require permits. To the extent permits were required by subcontractors, the subcontracts were contractually required to obtain any federal, state, or local permits or licenses. To the extent that any permits or licenses were required with reference to this program, they were prior existing and in place at subcontractor locations at the time work under this program was undertaken. 


\section{Safety Record}

During the conduct of this project there were no lost time accidents, injuries to employees, or illnesses reported at CES. To the best of CES' knowledge this is also true of the CES subcontractors who performed work on this project.

\section{Environmental Compliance}

At the outset of the project CES filed EPA evaluation forms describing all the work areas expected to be involved in this project and there were no indicated environmental impact issues identified. There were no unauthorized emissions, no known uses or spills of any hazardous or regulated substances. Consequently, we believe the project was completed without any adverse environmental impacts.

CES has consistently conducted its work, and has ensured that its subcontractors' work was conducted in accordance with all applicable federal, state, and local laws, including codes, ordinances, and regulations covering safety, health, and environmental protection. To the best of CES' knowledge all activities were conducted in compliance with applicable law. There were no injuries occurring during the conduct of the CES program, no hazardous materials spills or other incidents, and there were no environmental violations known to CES at federal, state or local levels.

\section{$\underline{\text { Next Steps to Commercialization }}$}

A business plan has been developed and continues to evolve in sophistication as the markets, suppliers, strategic partners, sources of venture capital, and customers become increasingly defined. Suppliers of components and/or subsystems other than the gas generator, A\&E's, hosts for small scale demonstration plants have been identified and letters of intent to support demonstration efforts have been signed by several potential strategic partners/licensees. The technology has been positively received by both the public and private sectors, as evidenced by state and federal grants of co-funding received, by articles appearing in daily papers and trade journals, and by industrial support given to and industrial participation in proposed early phase demonstration projects.

\section{Status of Technology - Current Cost Structure}

In the fourth quarter of 2000, CES successfully completed "proof of concept" testing of its application of the gas generator technology with a $110 \mathrm{~kW}$ prototype. CES has now progressed through the design, fabrication, and testing of the $10 \mathrm{MW}$ gas generator.

CES will not itself work on the adaptation of high-temperature, high-pressure steam turbine technology to conventional power generation. CES expects, however, that steam turbine upgrading is technically achievable in a reasonable time frame and at a commercially acceptable cost, when supplemented by government co-funding. This perception has been confirmed by numerous industry sources, including turbine manufacturers with whom CES has had early discussions. In any case, until such time as advanced turbines are commercially available, CES' 
technology can work with today's turbine technology to produce power without pollution, but at costs comparable to renewable energy sources such as wind turbines, solar and fuel cells. Table $\mathrm{V}$. provides a cost comparison of CES technology, using current turbine technology and current oxygen production technology, to combined cycle plants in the sizes 10MW, 50MW, 100MW and 400MW. This cost structure is shown as a function of plant size, capital cost, fuel costs, and operating costs, with indications of net plant thermal efficiency. What can also be discovered from Table V. is that increased plant size has the largest effect on final electricity costs, due to economies of scale.

Table V. indicates that when using conventional steam turbine technology in the CES process, the cost structure is significantly higher than electricity production from combined cycle plants. What the table also shows, however, is full cost competitiveness with other forms of clean or "green" energy production, with costs comparable to wind power and significantly below solar power generation. When additional revenue streams from the beneficial use of carbon dioxide are included, CES technology is the lowest cost source of clean energy currently available.

\section{Bases of Cost Estimates}

The comparative costs of electricity of CES versus combined cycle plants shown in Table V. and Table VI. are based on the following references and information sources:

1. Performance: Power plant efficiencies are based on a computer program using Engineering Equations Solver (EES), developed jointly by CES and the Lawrence Livermore National Laboratory (LLNL). This program has been checked by NETL and Air Liquide using Aspen Plus and excellent agreement was demonstrated.

2. Air Separation plant costs were supplied by Air Products, Inc., in a proposal titled: "Cryogenic Air Separation Unit Budgetary Estimate for Clean Energy Systems, Inc.," 4/21/99; and by A. R. Smith, et. al., ASME paper 98 Gas Turbines 63.

3. Gas turbine and steam turbine costs were obtained from Gas Turbine World 2000 - 2001 Handbook, Volume 21, A Pequot Publication.

4. Gas generator and reheater costs were generated by CES, based on experience.

5. Heat exchangers, condenser, compressor, and pump costs were generated from vendor inquiries.

6. Cost studies performed by Bechtel National Inc. for a 5 MW CES power plant presented at the Zero Emission Steam Technology (ZEST) Workshop, August 28 \& 29, 2001, San Francisco, California.

\section{General References:}

"Evaluation of Innovative Fossil Fuel Power Plants with $\mathrm{CO}_{2}$ Removal: Interim Report" dated December 2000, EPRI \& Cosponsors, US Department of Energy/NETL. 
Chiesa, P. and Lozza, P., " $\mathrm{CO}_{2}$ Emission and Abatement in IGCC Power Plants by

Semi-closed Cycles: Part B.- With Air Blown Combustion and $\mathrm{CO}_{2}$ Physical

Adsorption," Journal of Engineering for Gas Turbines and Power, Oct. 1999, Vol. 121.

Simbeck, D. (1998) “A Portfolio Selection Approach for Power Plant $\mathrm{CO}_{2}$ Capture, Separation and R\&D Options," $4^{\text {th }}$ International Conference Greenhouse Gas Control Technology, Interlaken, Switzerland.

Gambini, M., Velleni, M. “ $\mathrm{CO}_{2}$ Emission Abatement from Fossil Fuel Power Plants by Exhaust Gas Treatment,” ASME Journal for Gas Turbines and Power, January 2003, Vol.125.

Ruether, J, et.al. DOE, "Prospects for Early Deployment of Power Plants Employing Carbon Capture," Electric Utilities Environment Conference, Tucson Arizona, January 22-25, 2002.

\section{Near-Term Cost Comparison}

Table VI. provides a comparison of the cost structure of CES plants, including all costs associated with obtaining oxygen, to the costs of combined cycle plants when $\mathrm{CO}_{2}$ revenue is taken into account. Four plant sizes are compared, showing net efficiencies ranging from $31 \%$ to $60 \%$, depending upon timing. Over the next five years (near-term) the capital cost of CES plants and combined cycle plants is expected to be comparable, but combined cycle plants will have higher efficiencies in the larger plant sizes. By-product sales of carbon dioxide of around \$10/ton, however, can make CES technology cost-competitive, even when comparing larger plants in the $400 \mathrm{MW}$ size.

\section{Competitive Position}

In addition to CES, a select few companies from the aerospace industry are probably capable of manufacturing gas generators. However, CES is unique in having worked since the early 1990s, using proprietary manufacturing methods, to adapt this technology for zero-emission power generation use. CES has protected its innovations through a strong patent strategy.

Since the CES process will be less efficient than conventional gas-fired power plants until the commercial availability of high-temperature, high-pressure steam turbines, CES will initially need to target specific markets with certain characteristics. With the introduction of the advanced turbines, however, CES expects that its technology can operate at thermal efficiencies in excess of those achievable with combined cycle plants using gas turbines. Therefore, CES believes that on a long-term basis (greater than ten years) power plants based on CES technology, including all costs associated with obtaining oxygen, will be cost-competitive with conventional gas turbine or combined cycle technology, even in an environment where there are no further requirements to reduce emissions levels. 
Unit Capital Cost - $\$ / \mathrm{kW}$

Net Thermal Efficiency - \%

Cost of Electricity - $\$ / \mathrm{kWh}$

$\mathrm{CO}_{2}$ Conditioning ${ }^{(2)}-\$ /$ ton

Unit Capital Cost - $\$ / \mathrm{kW}$

Net Thermal Efficiency - \%

Cost of Electricity - $\$ / \mathrm{kWh}$

$\mathrm{CO}_{2}$ Conditioning ${ }^{(2)}$ - \$/ton

Unit Capital Cost - $\$ / \mathrm{kW}$

Net Thermal Efficiency - \%

Cost of Electricity - $\$ / \mathrm{kWh}$

$\mathrm{CO}_{2}$ Conditioning ${ }^{(2)}-\$ /$ ton

Unit Capital Cost - \$/kW

Net Thermal Efficiency - \%

Cost of Electricity - $\$ / \mathrm{kWh}$

$\mathrm{CO}_{2}$ Conditioning ${ }^{(2)}-\$ /$ ton

TABLE V.

COMPARATIVE COSTS OF ELECTRICITY ${ }^{(1)}$

CES vS COMBINED CYCLE PLANTS

\begin{tabular}{|c|c|c|c|c|c|}
\hline \multicolumn{4}{|c|}{$\begin{array}{l}\text { Steam Turbine Technology } \\
100 \% \mathrm{CO}_{2} \text { Sequestered }\end{array}$} & \multirow[t]{2}{*}{ No $\mathrm{CO}_{2}$ Seques. } & \multirow{2}{*}{$85 \% \mathrm{CO}_{2}$ Seque } \\
\hline \multirow{2}{*}{\multicolumn{6}{|c|}{$\begin{array}{l}400 \text { MW Plant Size } \\
\text { Advanced Long-Term }\end{array}$}} \\
\hline & & & & & \\
\hline 1162 & 848 & 797 & 750 & 712 & 892 \\
\hline 34 & 50 & 55 & 60 & 58 & 48 \\
\hline 0.058 & 0.041 & 0.037 & 0.035 & 0.035 & 0.042 \\
\hline 5.4 & 3.8 & 3.4 & 3.3 & ------ & 19.0 \\
\hline \multicolumn{6}{|c|}{100 MW Plant Size } \\
\hline 1715 & 1367 & 1282 & 1209 & 1120 & 1423 \\
\hline 33 & 49 & 54 & 59 & 53 & 43 \\
\hline 0.070 & 0.052 & 0.048 & 0.044 & 0.045 & 0.056 \\
\hline 6.5 & 4.8 & 4.5 & 4.1 & ------ & 25.3 \\
\hline \multicolumn{6}{|c|}{50 MW Plant Size } \\
\hline 2204 & 1755 & 1645 & 1550 & 1379 & 1757 \\
\hline 32 & 48 & 53 & 58 & 52 & 42 \\
\hline 0.081 & 0.060 & 0.055 & 0.051 & 0.050 & 0.063 \\
\hline 7.5 & 5.6 & 5.1 & 4.7 & ------- & 28.5 \\
\hline \multicolumn{6}{|c|}{10 MW Plant Size } \\
\hline 4083 & 3119 & 2922 & 2754 & 2567 & 3431 \\
\hline 31 & 47 & 52 & 57 & 41 & 31 \\
\hline 0.120 & 0.088 & 0.081 & 0.076 & 0.080 & 0.107 \\
\hline 11.2 & 8.2 & 7.5 & 7.1 & ------- & 48.4 \\
\hline
\end{tabular}

(1) Assumptions: cost of fuel $=\$ 3.00$ per million Btu; interest @ $11 \%$ per year; plant utilization $85 \%$ per year; 20 year plant life; and operating and maintenance unit cost $=! 5 \%$ (capital unit cost + fuel unit cost)

(2) Energy for $\mathrm{CO}_{2}$ separation and pumping to $2100 \mathrm{psia}$; $\mathrm{CES}=93 \mathrm{kWh} / \mathrm{ton}$; Combined Cycle $=452 \mathrm{kWh} / \mathrm{ton}$ 


\section{TABLE VI. \\ COMPARATIVE COSTS OF ELECTRICITY \\ CES vS COMBINED CYCLE PLANTS}

(With $\mathrm{CO}_{2}$ Revenue)

\section{CES}

Combined Cycles

Steam Turbine Technology $100 \% \mathrm{CO}_{2}$ Sequestered

No $\mathrm{CO}_{2}$ Seques. $\quad 85 \% \mathrm{CO}_{2}$ Sequest

400 MW Plant Size

Unit Capital Cost - $\$ / \mathrm{kW}$

Net Thermal Efficiency - \%

Cost of Electricity - $\$ / \mathrm{kWh}$

$\mathrm{CO}_{2}$ Revenue - $\$ / \mathrm{kWh}$

Cost of Electricity - $\$ / \mathrm{kWh}$

$\%$

$\begin{array}{ll}\text { Current } & \text { Near-Term } \\ 1162 & 848\end{array}$

Advanced Long-Term

$\begin{array}{lllll}162 & 848 & 797 & 750 & 712\end{array}$

$\begin{array}{lllr}34 & 50 & 55 & 60 \\ 0.058 & 0.041 & 0.037 & 0.03\end{array}$

$\begin{array}{llll}0.058 & 0.041 & 0.037 & 0.035\end{array}$

$\begin{array}{llll}0.005 & 0.005 & 0.005 & 0.005\end{array}$

$0.032 \quad 0.030$

$\begin{array}{cc}58 & 48 \\ 0.035 & 0.042 \\ --- & 0.005 \\ 0.035 & 0.037\end{array}$

100 MW Plant Size

Unit Capital Cost - $\$ / \mathrm{kW}$

Net Thermal Efficiency - \%

Cost of Electricity - $\$ / \mathrm{kWh}$

$\mathrm{CO}_{2}$ Revenue - $\$ / \mathrm{kWh}$

Cost of Electricity - $\$ / \mathrm{kWh}$

h

$\begin{array}{cc}1282 & 1209 \\ 54 & 59 \\ 0.048 & 0.044 \\ 0.005 & 0.005 \\ 0.043 & 0.039\end{array}$

$\begin{array}{cc}1120 & 1423 \\ 53 & 43 \\ 0.045 & 0.056 \\ --- & 0.005 \\ 0.045 & 0.051\end{array}$

50 MW Plant Size

Unit Capital Cost - \$/kW

Net Thermal Efficiency - \%

Cost of Electricity - $\$ / \mathrm{kWh}$

$\mathrm{CO}_{2}$ Revenue - $\$ / \mathrm{kWh}$

Cost of Electricity - $\$ / \mathrm{kWh}$

$\begin{array}{cc}1715 & 1367 \\ 33 & 49 \\ 0.070 & 0.052 \\ 0.005 & 0.005 \\ 0.065 & 0.047\end{array}$

\begin{tabular}{cccc}
2204 & 1755 & 1645 & 1550 \\
32 & 48 & 53 & 58 \\
0.081 & 0.060 & 0.055 & 0.051 \\
0.005 & 0.005 & 0.005 & 0.005 \\
0.076 & 0.055 & 0.050 & 0.046 \\
\multicolumn{3}{c}{ 10 MW Plant Size } \\
& \multicolumn{3}{c}{}
\end{tabular}

$\begin{array}{cc}1379 & 1757 \\ 52 & 42 \\ 0.050 & 0.063 \\ ---0.050 & 0.005 \\ & 0.058\end{array}$

10 MW Plant Size

\begin{tabular}{|c|c|c|c|c|c|c|}
\hline \multirow[b]{2}{*}{ Unit Capital Cost - \$/kW } & \multicolumn{5}{|c|}{10 MW Plant Size } & \multirow[b]{2}{*}{3431} \\
\hline & 4083 & 3119 & 2922 & 2754 & 2567 & \\
\hline Net Thermal Efficiency - \% & 31 & 47 & 52 & 57 & 41 & 31 \\
\hline Cost of Electricity $-\$ / \mathrm{kWh}$ & 0.120 & 0.088 & 0.081 & 0.076 & 0.080 & 0.107 \\
\hline $\mathrm{CO}_{2}$ Revenue - $\$ / \mathrm{kWh}$ & 0.005 & 0.005 & 0.005 & 0.005 & ------- & 0.00 \\
\hline Cost of Electricity - $\$ / \mathrm{kWh}$ & 0.115 & 0.083 & 0.076 & 0.071 & 0.080 & 0.102 \\
\hline
\end{tabular}


Status of Marketing Activities

During 2003 and 2004, CES will actively market its technology based on current turbine technology. CES technology will have the most immediate interest in areas of the world where environmental pressures have a higher priority (and therefore a clean energy source will command a premium), and where the $\mathrm{CO}_{2}$ can be sold for use in enhanced hydrocarbon recovery or other commercial purposes.

Initial target markets are primarily those areas where power purchasers are capable of paying the electricity prices shown in Table V. for a $10 \mathrm{MW}$ to $50 \mathrm{MW}$ plant, because of desires to have zero emissions, high localized energy prices, and/or revenues available from the sale of $\mathrm{CO}_{2}$. To move CES technology beyond this niche market, requires advances in turbine technology, discussed elsewhere in this report, which in turn will be greatly facilitated by the availability of a National Research Facility.

\section{Premium Price Electricity Markets}

Thirty-one regions in the US are considered "non-attainment," where levels of pollution exceed federal health and safety standards. Typically, a developer of a power plant in an area that does not meet federal or state air quality standards must reach an agreement with another company such that, after introducing a new plant, the net effect will be no increase in regional emissions for several pollutants. The costs associated with these agreements continue to rise, and at times these emissions credits or offsets are simply unavailable.

Other clean sources of generation, such as wind or solar, require unique natural resources (wind) or large spaces (solar) which typically are not found in urban areas. When combined with bottlenecks in transmission capacity, insufficient capacity additions could lead to increasing risks of shortages and high, localized energy prices. The only viable options appear to be conservation efforts or new generation capacity in these constrained regions. The zero emission aspect of the CES process provides a competitive advantage because such plants will be easier to permit and can be sited near the load centers, with reduced transmission costs and losses, and in locations where energy prices are higher than national averages.

\section{Enhanced Hydrocarbon Recovery Applications}

There is a substantial market for the productive use of carbon dioxide -- beyond commercial applications such as food refrigeration and beverage carbonation -- by injecting it into exhausted oil wells to increase oil production. This Enhanced Oil Recovery (EOR) "flooding" process is in use at more than 40 oil fields domestically, and approximately four percent of the US crude oil supply is produced from $\mathrm{CO}_{2}$ flooded fields. The benefits from this flooding in the US are estimated at 150,000 barrels per day, and oil field operators pay between $\$ 10$ and $\$ 20$ per ton of $\mathrm{CO}_{2}$ for these purposes. The technique is also currently in use in other countries around the world. The $\mathrm{CO}_{2}$ market, however, is constrained by required physical proximity to naturally occurring underground $\mathrm{CO}_{2}$ reservoirs, and the associated pipeline system for its distribution, which greatly restricts its use in other parts of the country.

A similar application is the use of carbon dioxide for enhanced coal bed methane recovery. In this case, $\mathrm{CO}_{2}$ is injected into mineable or economically unmineable coal bed seams, where it 
adsorbs on the face of the coal and displaces methane gas. While there is less experience with enhanced coal bed methane recovery, the potential market is much larger than for EOR.

\section{California Market}

Southern California, in particular, offers the combination of premium pricing for electricity and a sizeable market for the sale of carbon dioxide for enhanced oil recovery (EOR). There are more than 43,000 producing oil wells in the state, producing nearly 900,000 barrels of oil per day. Of the state total, 33,000 of the wells are located in Kern County, north of Los Angeles. The Los Angeles basin also has many oil fields in the Long Beach area, and even in the cities of Venice Beach and Beverly Hills. Roughly $55 \%$ of all oil produced in California comes from injecting steam, water, or gas into oil reservoirs, and the availability of carbon dioxide in large quantities would increase production from many of these fields.

When applied to total state oil reserves of 3.75 billion barrels, an additional $15 \%$ could possibly be recovered from $\mathrm{CO}_{2}$ flooding practices. The carbon dioxide required for this could be produced from approximately 4,000 MW of CES technology-based power plants.

To date, marketing effort for EOR applications of CES technology has focused primarily on selected operators and oil fields in Southern California. A project involving several potentially cooperating companies is being developed where an oil extractor would buy the $\mathrm{CO}_{2}$, and some of the electricity provided. A Project Briefing Book was prepared and approved by the extractor, and was distributed to several potentially cooperating companies for consideration. Several of these companies have signed confidentiality agreements. Because of the $10 \mathrm{MW}$ gas generator project delays described above, these contacts were not actively pushed during 2002, although this work is commencing again. Restructuring of the CEC project, described under Remaining Materials, at page 34, to focus on additional testing of the gas generator and controls systems, also means that the first demonstration project will not be on line until early 2004, so it is unlikely that a commercial plant can be contracted until later in 2004.

Contacts were made with an independent power producer regarding idle or mothballed power plants in California. Initial discussions focused on one power plant near Los Angeles, California, but this plant is now back in service under a multi-year power sales agreement. However, another of their plants, a small biomass plant in the south end of the California central valley, is being discussed as a possible demonstration project. CES is currently exploring activation of this mothballed plant.

\section{Foreign Markets}

Two proposals were made for feasibility studies related to CES technology in Norway, through a carbon management firm in Norway. The first proposal was made to investigate a zero emission power plant in that region. Another proposal was made to the Norwegian Research Council to do a four-year development program for zero emission power plants. In both cases, CES would be a subcontractor to $\mathrm{CO}_{2}$ Norway for these studies. A response was expected in January 2003, but a Norwegian Government budget freeze has put all projects not already funded on hold. A meeting was held in Norway in March 2003, with attendance by several interested parties. 
Development of CES technology in Norway is essentially dependent upon emergence of governmental funding there.

Contacts have also been made with a British steam turbine manufacturer interested in CES technology. The mid-sized company, similar in some respects to Elliott Turbomachinery, is studying small plants in the $10 \mathrm{MW}$ to $20 \mathrm{MW}$ size for possible offshore oilfield installations. It is possible that CES technology could play a role in such plants.

With the development of advanced steam turbines, CES' design is expected to be fully cost competitive with other generation technologies and, therefore, CES eventually will expand its marketing to cover the global energy market. The primary market for CES will be power plants in the range of $10 \mathrm{MW}$ to $200 \mathrm{MW}$. Plants below $10 \mathrm{MW}$ will be less competitive because of the higher capital cost per unit output, whereas plants above $200 \mathrm{MW}$ will be initially limited in size by the maximum available oxygen separation plant size. Plants above $200 \mathrm{MW}$, however, can be constructed by using several $200 \mathrm{MW}$ trains, with separate oxygen supplies.

National Policy and Strategic Considerations

CES technology responds to many, if not most, of the major state and federal policy objectives. The gas generator can readily be incorporated into fuel cell hybrid processes. The synergies between the two systems could result in very high power cycle efficiencies. Two power plant concepts that integrate the CES process with solid oxide fuel cells have been developed. In the first process, the SOFC effluent is combined with the discharge stream from the high-pressure steam turbine, heated in a CES reheater, and fed to the intermediate turbine. This process recovers waste heat from the SOFC, and can attain an overall cycle efficiency of $64 \%$, including $\mathrm{CO}_{2}$ sequestration. In the second process, the gas generator is operated under fuel-rich conditions, producing a hydrogen-rich reformate for the SOFC anode. The SOFC discharge stream is directed to a reheater and brought up to the operating temperature of the intermediate pressure turbine. In this scheme, cycle efficiencies of $65 \%$ are possible.

Production Readiness/Commercialization

As mentioned above, extensive industry contacts have been established, and potential licensees of CES technology have been identified. Commitments to license agreements are expected within the next 12 to 18 months.

CES is fully capable of manufacturing the enabling technology component - the gas generator. All other components are readily available from the existing equipment suppliers.

\section{$\underline{\text { Potential for Clean Coal Power }}$}

Clean Energy Systems, Inc., (CES) has developed a coal-fueled, zero emission power plant concept that can use gasified coal to produce power without pollution. The goal of such a project would be initially to construct a small $\left(20 \mathrm{MW}_{\mathrm{e}}\right)$ power plant to demonstrate the CES technology for zero-emission power plants using a coal syngas, either alone or co-fired with renewable fuels. 
Long-term reliability and durability testing could be conducted over a multi-year operating period.

This plant would also demonstrate several critical enabling technologies that will help ensure a long-term clean, reliable and affordable electricity supply. In addition to the CES zero-emission power generation technology, the plant could use advanced steam turbines, currently under development, that are expected to operate at steam conditions of $1200^{\circ} \mathrm{F}$ and $1200 \mathrm{psig}$ (high pressure turbine) and $2200^{\circ} \mathrm{F}$ and $170 \mathrm{psig}$ (intermediate pressure turbine, with a reheater). Further, this plant could demonstrate a modern, efficient gasification technology. Using such technology advancements should facilitate new commercial opportunities for smaller scale zeroemission coal plants, ranging in size from $50 \mathrm{MW}$ to $400 \mathrm{MW}$.

\section{Buy America Policy}

All procurement undertaken in this program was obtained from United States industrial sources and, to the best of CES' knowledge, no non-American materials, supplies or services were used.

\section{Lobbying and Other Non-allowable Expenses}

No money obtained through the federal funding of this project was used at any time to pay expenses of lobbying or for any other non-allowable activity, as non-allowability is defined in the Federal Acquisition Regulations.

\section{CONCLUSION}

1. CES technology supports the nation's strategy for addressing greenhouse gases and global climate change by:

a. using technological innovation to cost-effectively produce power without pollution, including use of coal,

b. increasing national energy security by increasing domestic oil and gas production through enhanced hydrocarbon recovery with carbon dioxide,

c. promoting carbon sequestration and removing environmental and cost barriers to greater coal usage, and

d. enabling sequestration demonstration projects within the next 12-24 months.

2. CES was an initial recipient of DOE Vision 21 Program funding, and successfully showed that modified rocket technology can be used in land-based power systems. The project demonstrated cost-effective technology for producing power without pollution.

3. CES technology has industry support. America Air Liquide and Mirant Corporation are both participants, along with the California Energy Commission, in a $\$ 5$ million demonstration project under development in Antioch, California. Other government agencies, utilities, and equipment suppliers are also supportive of CES technology.

4. Environmental Benefits Perceived. Environmental groups have been briefed on CES technology, including NRDC, Sierra Club, Center for Resource Solutions, World 
Wildlife Fund, and Environmental Resources Trust. Despite CES concerns that some groups would not favor any use of hydrocarbons, there have been no major concerns voiced by these groups.

5. CES technology has congressional support. Selected members of Congress consistently follow and support CES technology.

6. Third party analysis (by Air Liquide) and work by DOE/NETL staff (Larry Sheldon and Ed Parsons) have verified the accuracy of CES efficiency calculations. Air Liquide published a paper with CES at the 2003 Clearwater Clean Coal Conference showing zero-emission cycle efficiencies with natural gas of $62 \%$, and with coal of $55 \%$, using a highly integrated, advanced CES/ASU plant. See citation at page 33, above.

7. CES technology is a FutureGen technology option - zero emission power production from coal gasification, with the capability to produce hydrogen.

8. A zero-emission plant with carbon sequestration can be developed for around $\$ 10$ million, as the "next step" toward the commercial market.

CES technology could work with today's turbines, including gas turbines, to produce power without pollution. The first commercial generation power plants using CES technology will have energy cost structures at or below those of other clean energy sources, such as wind and solar power. Since the CES process will be less efficient than conventional combined-cycle plants until the commercial availability of high-temperature, high-pressure steam turbines, the company initially will target markets where a premium is placed on clean energy. With the introduction of the advanced turbines (which have been held back historically by boiler steam temperature constraints), CES technology will operate at efficiencies above those achievable with combined cycle plants.

There are no exhaust gases to be cleaned, and no emissions of sulfur oxides, nitrogen oxides, or other pollutants. On a long-term basis, power plants based on CES technology, including all costs associated with obtaining oxygen, are expected to be cost-competitive with conventional combined-cycle technology, producing power without pollution, without reliance on economic subsidies.

\section{REFERENCES}

\section{Technical papers produced during the project period describing Program progress are:}

Anderson R., Brandt H., Doyle S., Viteri F., "A Demonstrated $20 \mathrm{MW}_{\mathrm{t}}$ Gas Generator for a Clean Steam Power Plant," a paper presented at the $28^{\text {th }}$ International Technical Conference on Coal Utilization and Fuel Systems, March 2003, Clearwater, Florida.

Anderson R., Brandt H., Pronske K., Viteri F., "Near-Term Potential for Power Generation from Coal with Zero Atmospheric Emissions," in Proceedings of the $27^{\text {th }}$ International Technical 
Conference on Coal Utilization and Fuel Systems, March 4-7, 2002, Clearwater, Florida, at page 51 .

Martinez-Frias J., Aceves S., Smith J. R., Lawrence Livermore National Laboratory, "Thermodynamic Analysis of a Zero Atmospheric Emissions Power Plant," a paper presented at the ASME International Conference in New Orleans in November 2002. The paper was accepted for publication in the Journal of Engineering for Gas Turbines and Power.

Smith J. R., and Terry Surles, Lawrence Livermore National Laboratory; Brian Marais, Bechtel National, Inc.; Harry Brandt, and F. (Vic) Viteri, Clean Energy Systems, Inc., "Power Production with Zero Atmospheric Emissions for the21st Century," a paper presented to the 5th International Conference on Greenhouse Gas Control Technologies, August 13-16, 2000, Cairns, Queensland, Australia.

Anderson R., Brandt H., Doyle S., Mueggenburg H., Taylor J., Viteri F., "A Unique Process for Production of Environmentally Clean Electric Power Using Fossil Fuels," a paper presented to the 8th International Symposium on Transport Phenomena and Dynamics of Rotating Machinery (ISROMAC-8), 28 March 2000, Honolulu, HI.

\section{Economic and technical reference sources used in this program are:}

Performance: Power plant efficiencies are based on a computer program using Engineering Equations Solver (EES), developed jointly by CES and the Lawrence Livermore National Laboratory (LLNL). This program has been checked by NETL and Air Liquide using Aspen Plus and excellent agreement was demonstrated.

Air Separation plant costs were supplied by Air Products, Inc., in a proposal titled: "Cryogenic Air Separation Unit Budgetary Estimate for Clean Energy Systems, Inc.," 4/21/99; and by A. R. Smith, et al., ASME paper 98 Gas Turbines 63.

Gas turbine and steam turbine costs were obtained from Gas Turbine World 2000 - 2001 Handbook, Volume 21, A Pequot Publication.

Heat exchangers, condenser, compressor, and pump costs were generated from vendor proposals.

Cost studies performed by Bechtel National Inc. for a 5 MW CES power plant presented at the Zero Emission Steam Technology (ZEST) Workshop, August 28 \& 29, 2001, San Francisco, California.

"Evaluation of Innovative Fossil Fuel Power Plants with $\mathrm{CO}_{2}$ Removal: Interim Report" dated December 2000, EPRI \& Cosponsors, US Department of Energy/NETL.

Chiesa, P. and Lozza, P., " $\mathrm{CO}_{2}$ Emission and Abatement in IGCC Power Plants by Semi-closed Cycles: Part B.- With Air Blown Combustion and $\mathrm{CO}_{2}$ Physical Adsorption," Journal of Engineering for Gas Turbines and Power, Oct. 1999, Vol. 121. 
Simbeck, D. (1998) “ A Portfolio Selection Approach for Power Plant $\mathrm{CO}_{2}$ Capture, Separation and R\&D Options," $4^{\text {th }}$ International Conference Greenhouse Gas Control Technology, Interlaken, Switzerland.

Gambini, M., Velleni, M. " $\mathrm{CO}_{2}$ Emission Abatement from Fossil Fuel Power Plants by Exhaust Gas Treatment," ASME Journal for Gas Turbines and Power, January 2003, Vol.125.

Ruether, J, et.al. DOE, "Prospects for Early Deployment of Power Plants Employing Carbon Capture," Electric Utilities Environment Conference, Tucson Arizona, January 22-25, 2002. 